\title{
Hepatic Differentiation of human embryonic stem cells in a 3D bioreactor environment
}

\author{
vorgelegt von \\ Diplom-Ingenieur \\ Thomas Urbaniak \\ aus Schwedt / Oder \\ Von der Fakultät III - Prozesswissenschaften \\ der Technischen Universität Berlin \\ zur Erlangung des akademischen Grades \\ Doktor der Ingenieurwissenschaften \\ Dr. Ing. \\ genehmigte Dissertation
}

Promotionsausschuss:

Vorsitzender: Prof. Dr. Juri Rappsilber

Berichter: Prof. Dr. Roland Lauster

Berichter: Dr. Katrin Zeilinger

Berichter: Prof. Dr. Jens Kurreck

Tag der wissenschaftlichen Aussprache: 07. März 2014

Berlin 2014

D83 


\section{Table of Contents}

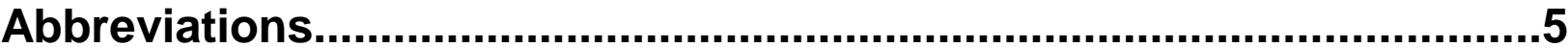

1. Introduction......................................................................................

1.1 In vitro culture of human embryonic stem cells (hESC) .............................................

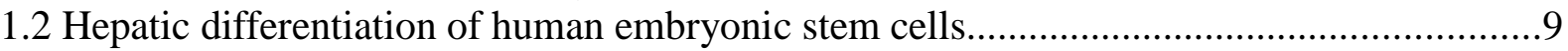

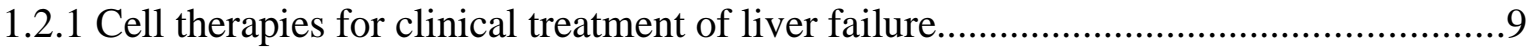

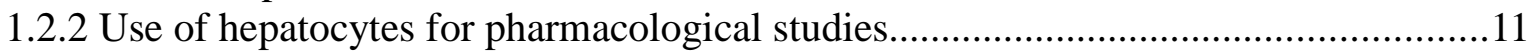

1.2.3 Bioreactor system for dynamic 3D culture of hepatic cells....................................12

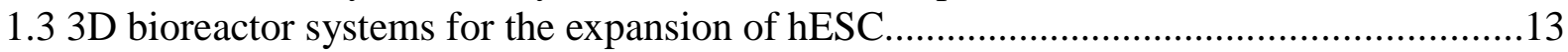

1.4 Hepatic differentiation of hESC in 3D bioreactor systems..........................................14

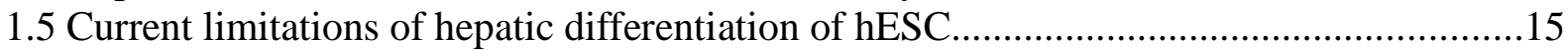

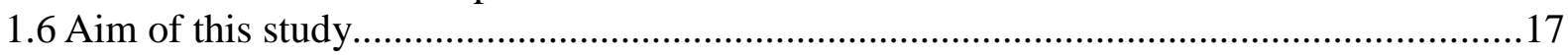

2. Material and Methods ......................................................................19

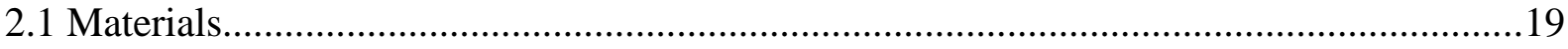

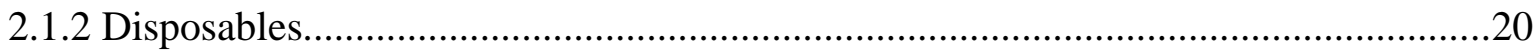

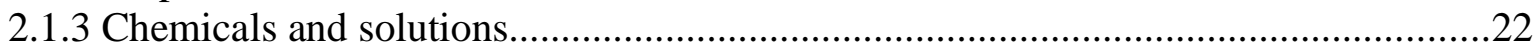

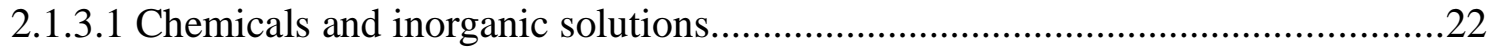

2.1.3.2 Cell culture media solutions, additives and cytokines ...................................22



2.1.3.4 Solutions for immune histochemistry and antibodies......................................25

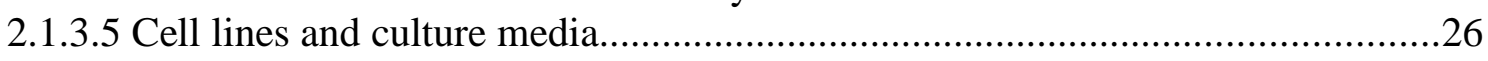

2.1.3.6 Polymerase chain reaction (PCR) primers and temperature profile.....................31

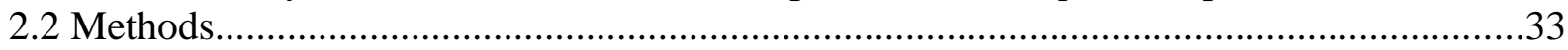

2.2.1. Preparation, culture and inactivation of mouse embryonic fibroblasts......................33

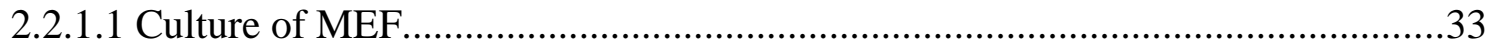

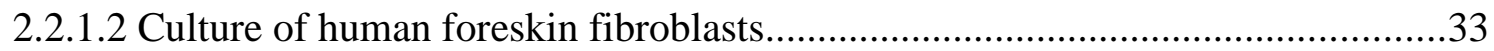

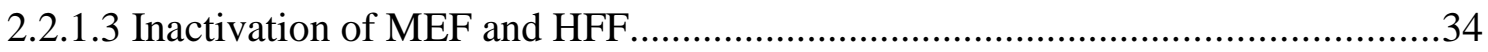

2.2.2 Culture of human embryonic stem cells in co-culture with MEF or HFF .................34

2.2.2.1 Preparation of IVF-dishes for the culture of human embryonic stem cells.........34

2.2.2.2 Culture and passage of human embryonic stem cells in co-culture with mouse

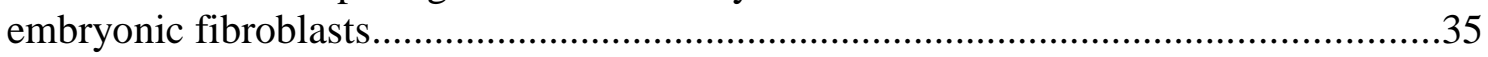

2.2.2.3 Preparation of culture flasks for single cell enzymatic dissociation (SCED)

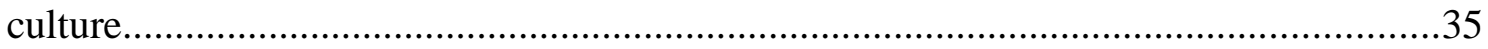

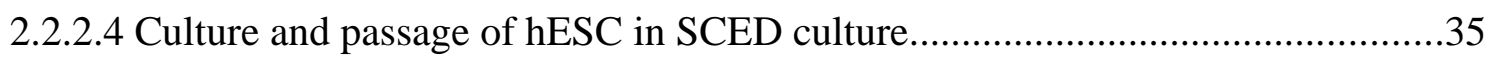

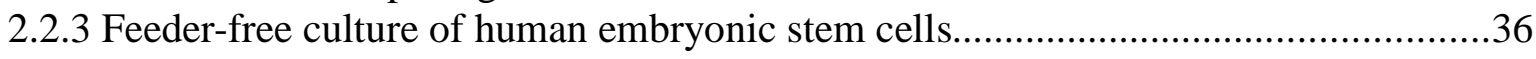

2.2.3.1 Evaluation of the undifferentiated state of human embryonic stem cells.............36

2.2.4 Evaluation of the pluripotent potential of human embryonic stem cells......................36

2.2.4.1 Evaluation of the pluripotent potential in conventional 2D culture...................36

2.2.5 Hepatic differentiation of human embryonic stem cells in conventional 2D cultures 37

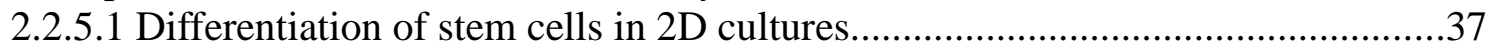

2.2.5.2 Evaluation of the stability of lineage commitment...........................................41

2.2.6 Bioreactors variants used for the hepatic differentiation of $\mathrm{hESC}$ in $3 \mathrm{D}$ culture........41

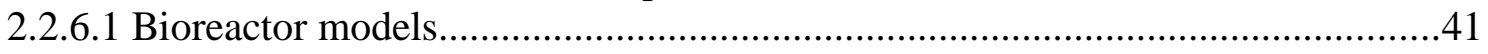

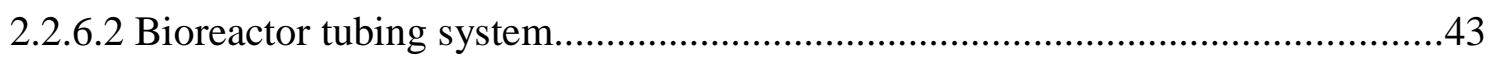




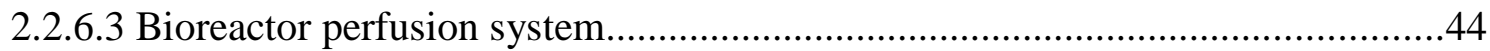

2.2.7 Evaluation of the pluripotent potential of hESC in 3D bioreactor systems...............45

2.2.8 Hepatic differentiation of human embryonic stem cells in 3D bioreactor systems.....46



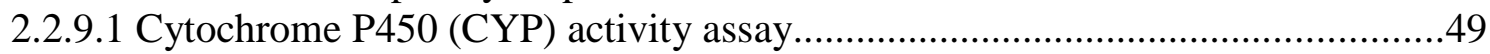

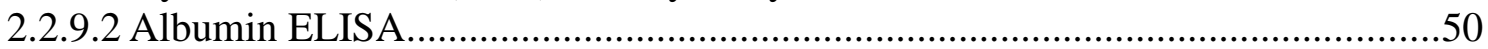

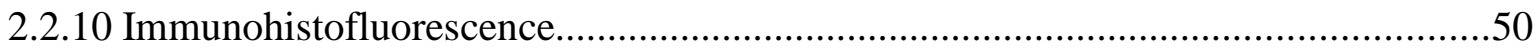

2.2.10.1 Embedding of bioreactor samples in paraffin blocks....................................50

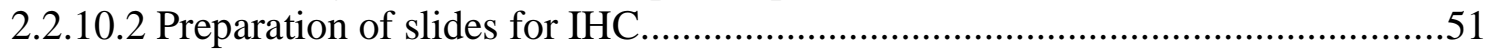





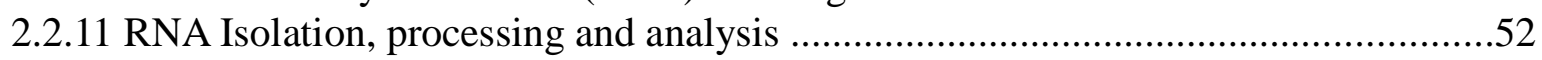

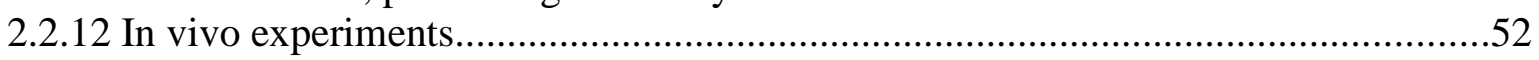

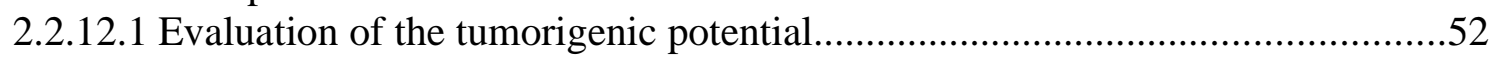

2.2 .13 Statistical evaluation



3.1 Establishment of hESC culture, reduction of components of animal origin......................54

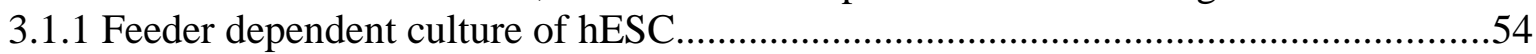

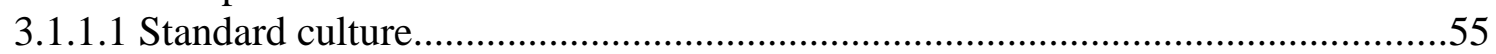

3.1.1.2 Single Cell Enzymatic Dissociation (SCED) Culture.......................................56

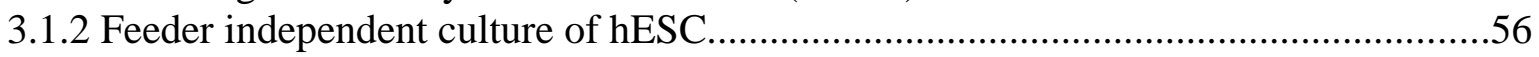

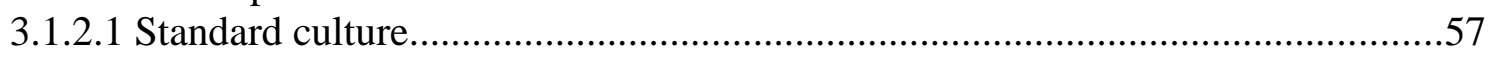

3.1.2.2 Spontaneous in vitro differentiation in conventional 2D cultures.......................58

3.1.2.3 Spontaneous in vitro differentiation in 3D bioreactors....................................62

3.1.2.4 The in vivo tumorigenic potential of feeder independent $\mathrm{hESC}(\mathrm{H} 1)$...............65

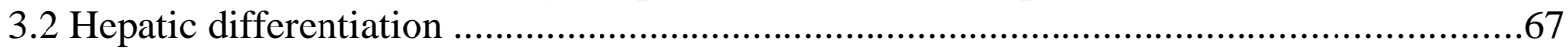

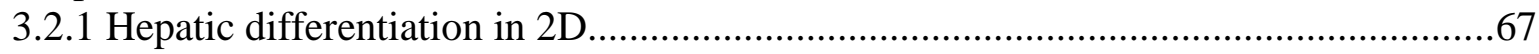

3.2.1.1 Metabolic parameters during hepatic differentiation......................................67

3.2.1.2 Cell integrity and cell numbers during hepatic differentiation.........................69

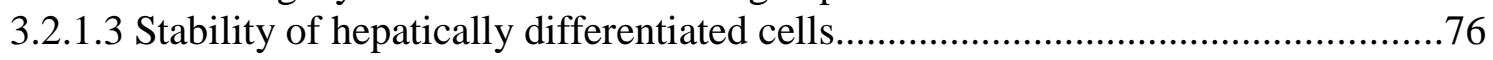

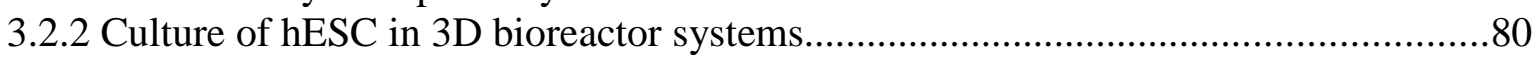

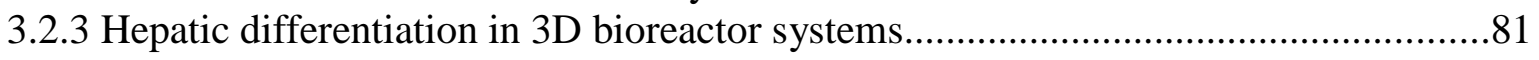

3.2.3.1 Hepatic differentiation of feeder independent hESC in 3D bioreactor systems or

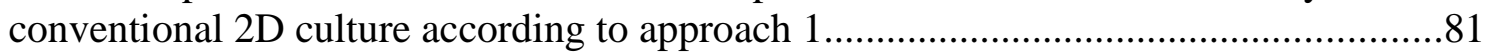

3.2.3.2 Hepatic differentiation of feeder independent hESC in 3D bioreactor systems

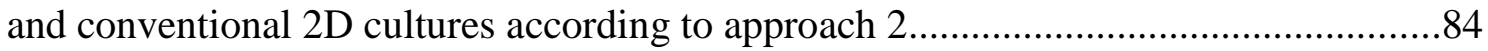

3.2.3.3 Hepatic differentiation of partial feeder dependent hESC in 3D bioreactor

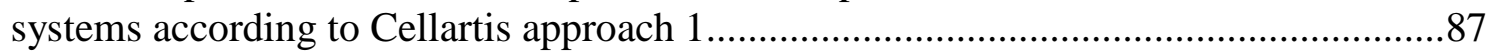

3.2.3.4 Hepatic differentiation of partial feeder dependent hESC in 3D bioreactor

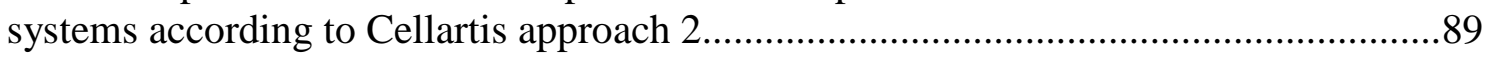

3.2.3.5 Hepatic differentiation of partial feeder dependent hESC in 3D bioreactor



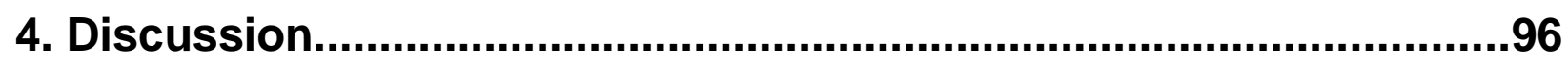

4.1 The establishment and improvement of culture conditions of hESC ...............................96 
Table of Contents

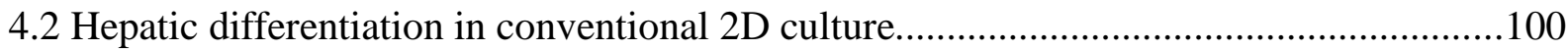



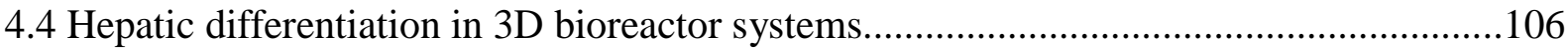

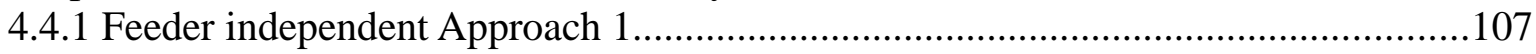

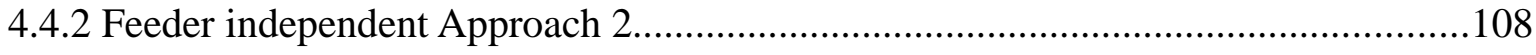

4.4.3 Partial feeder dependent Approach Cellartis 1...........................................................109

4.4.4 Partial feeder dependent Approach Cellartis 2...................................................... 110

4.4.5 Partial feeder dependent Approach Cellartis 3 ..........................................................111

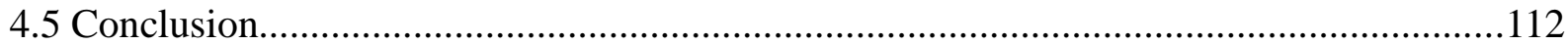

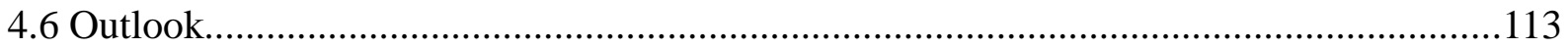

5. Abstract......................................................................................115

6. Zusammenfassung.....................................................................116

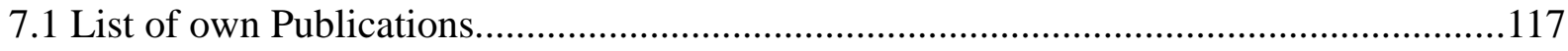

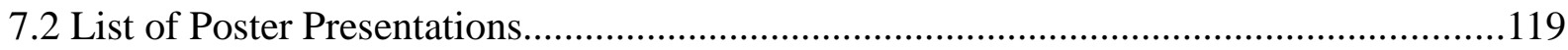

8. References...................................................................................120



10. Eigenständigkeitserklärung.....................................................131 


\section{Abbreviations}

ALF

BAL

BMP

BRY

CLF

DE

DMSO

ELAD

ELISA

ES

FGF

hESC

HGF

HRP

ICM

IHC

IMDM

IPS

i.s. Injection

IVF

$\mathrm{LDH}$

LT

MEF acute liver failure

bioartificial liver device

bone morphogenic protein

brachyury

chronic liver failure

definite endoderm

dimethyl sulfoxide

extracorporeal liver assist device

enzyme-linked immunosobent Assay

embryonic stem

fibroblast growth factor

human embryonic stem cells

hepatocyte growth factor

horseradish peroxidase

inner cell mass

immune-histochemistry

Iscove's modified Dublecco's medium

induced pluripotent stem cells

intrasplenic injection

in vitro fertilization

lactate dehydrogenase

liver transplantation

mouse embryonic fibroblasts 
NOD

NSG

Oct-4

OSM

PBS

PCR

PS

RT-PCR

s.c. Injection

SCED

SCID

SOX

VEGF

Wnt3a non-obese diabetic

NOD SCID gamma

Octamer-binding transcription factor 4

Oncostatin M

phosphate buffered saline

polymerase chain reaction

primitive streak

reverse transcription polymerase chain reaction

subcutaneous injection

single cell enzymatic dissociation

severe combined immunodeficiency

sex determining region $Y$

vascular endothelial growth factor

Wingless-type MMTV integration site family, member $3 \mathrm{~A}$ 


\section{Introduction}

In the past years great progress was made in the field of regenerative medicine research. Although cell based therapies utilizing pluripotent cells are still far away from clinical practice, it is clear that differentiated cells from IPS or hESC could play an important role in the treatment of degenerative and congenital diseases in the future. Besides the understanding of the generation of safe stem cell derivatives the reliable and cost effective supply of relatively large amounts of cells is an elemental requirement.

Embryonic stem cells owe the ability to differentiate into cell derivatives of all three germ layers. In combination with their theoretically unlimited proliferative capacity hESC could play a central role in developmental biology research as well as regenerative medicine utilizing differentiated derivatives not only for direct cell transplantation, but also in temporary supportive therapies. In first approaches undifferentiated ESC were directly transplanted into various organs and tissues. The cells did not restore organ function, but formed teratoma ${ }^{1-3}$.

Approaches investigating the supportive effect of transplanted differentiated embryonic stem cells have been conducted with promising results ${ }^{4}$. But also the formation of teratoma originating from transplanted endodermal hESC derivatives was reported ${ }^{5}$ in a mouse model. In general neural stem cells (NSC) of fetal and embryonic origin share the majority of characteristics ${ }^{6}$, and NSC of fetal origin have been demonstrated to exhibit no tendency to form tumors in an animal model ${ }^{7}$ in contrast to NSC differentiated from hESC ${ }^{8}$. But after the application of fetal neural stem cells the formation of a multi-focal donor-derived brain tumor was reported in a human patient ${ }^{9}$. Although progress on the safety of a potential medical application of differentiated stem cells has been made by the elimination of tumorigenic stem cells from differentiated hESC populations ${ }^{10}$, the application of cell derivatives in humans still remains dicey with uncertain clinical outcome. Only recently a phase I clinical trial utilizing differentiated oligodendrocyte progenitor cells (OPC) in patients suffering from spinal cord injuries was discontinued due to unimpaired function after cell application ${ }^{11}$. 
Interestingly, early results of a phase $\mathrm{I} / \mathrm{II}$ open label study treating patients suffering from dry age-related macular degeneration $(n=1)$ or Stargardt's disease $(n=1)$ with hESC derived retinal pigment epithelium cells show no adverse effects like teratoma formation, rejection or inflammation. Further on a visual improvement was seen in both patients ${ }^{12}$.

A more secure potential clinical application of differentiated hESC might be the extracorporeal organ support. Reports have been published for bioartificial liver devices utilizing porcine or human hepatocytes ${ }^{13}$. These cells could be replaced by differentiated hESC and thus avoid the risks and problems related to xenobiotic materials or scarcity of human hepatocytes. In addition the design of the bioreactor device excludes the possibility of direct cell transfer from the bioreactor device into the patient and thus eliminates the risk of tumor formation due to unintended transplantation of differentiated hESC.

\subsection{In vitro culture of human embryonic stem cells (hESC)}

The development of human embryo begins after the conjunction of the parental gametes. The zygote starts to divide and the first molecular differences in the arising cells become apparent in the 4 to 8 cell stadium ${ }^{14}$. This is followed by the formation of a morula (16 cell stadium). After further cell divisions (70 to 100 cells) and cavitation the blastocyst is formed (5 days after fertilization). It is comprised of a blastocoel cavity that is filled with fluid, the inner cell mass (ICM) and the surrounding trophoectodermal cells (trophoblast) ${ }^{15}$.

When in 1998 Thomson et al. first reported the successful isolation and cultivation of embryonic stem cells from the inner cell mass (ICM) of a human blastocyst, a useful tool for developmental biology and drug discovery as well as hope for a revolution in transplantation medicine arose.

Human embryonic stem cells possess the unique ability of self-renewal for long periods in culture and form derivatives of all three embryonic germ layers ${ }^{16}$. The differentiation of hESC has been extensively studied in the past and protocols for the 
differentiation in neuronal ${ }^{17}$, $\operatorname{cardiac}^{18}$, cartilage $^{19}$, pancreatic ${ }^{20}$, hepatic ${ }^{21,22}$ and other cell types were established. In parallel the understanding of molecular mechanisms responsible for the unique characteristics of hESC grew over time, and the culture conditions for the proliferation of undifferentiated hESC were successively more standardized and further developed from animal or human feeder-dependent coculture ${ }^{23,24}$ over xeno-culture conditions ${ }^{25}$ to defined xeno-free conditions ${ }^{26}$.

\subsection{Hepatic differentiation of human embryonic stem cells}

The endodermal and subsequent hepatic differentiation has extensively been studied in developmental models such as zebra-fish, worm and mouse. In these studies the existence of a progenitor cell population (mesendodermal cells) capable of further differentiating into cells of the mesodermal and endodermal germ layer ${ }^{27}$ was described. Interestingly several signals involved in the differentiation into the primitive streak, mesendoderm and further into mesoderm and endoderm seem to be conserved ${ }^{28}$.

Due to this, approaches for the endodermal differentiation of human embryonic stem cells were adapted from protocols for mouse ESC, in which four main pathways (Activin/Nodal, bone morphogenic proteins [BMP], FGF and Wnt) had been reported to play a crucial role in lineage commitment.

\subsubsection{Cell therapies for clinical treatment of liver failure}

Every year about 2 million people die of liver disease while waiting for a suitable organ. Acute and chronic liver failure (ALF) \& (CLF), which can be due to a plurality of physical, chemical, or infectious reasons is a devastating disease and associated with significant morbidity and a relatively high mortality $(60-90 \%){ }^{29}$. Currently the only effective therapy for ALF is liver transplantation (LT). It was first performed in 1983 and its clinical outcome improved with growing experience and enhanced operative management. Today LT is a surgical procedure performed in large centers 
with a 1 year survival rate of more than $90 \%{ }^{30}$. Due to the scarcity of donor organs the LT is not an option for all patients. In fact less than $30 \%$ of the patients on the waiting list receive a transplant ${ }^{31}$.

However, since the liver is capable of extensive self-regeneration, for example after partial hepatectomy ${ }^{32}$, or other kinds of injury, there is an alternative for a certain amount of patients waiting for a transplant. Liver assist devices have been developed and tested since the 1950s. In general two different approaches are used for liver support. The first kind of devices is based on the idea that patients with ALF or CLF are mostly affected by small dialyzable molecules such as ammonia and phenols that accumulate to toxic concentrations. However, evidence has been provided that the substances, which cause hepatic encephalopathy, multi-organ failure and further insults in case of ALF or CLF, are not just these small toxins but also mediators of systemic inflammation like various cytokines, chemokines, anaphylatoxins, etc ${ }^{33}$. On the other side also anti-inflammatory mediators can be found at elevated levels which have been shown to inhibit the proliferation of hepatocytes and mediate pro-fibrotic and pro-cancerogenic signals ${ }^{34}$. This led to the development of a second kind of devices for the support of ALF and end-stage CLF patients.

These bioartificial liver (BAL) devices use mammalian hepatic cells as central element to metabolize not only toxic components but also the mediators (also in combination with detoxification devices). It has been shown that bioartificial liver support can help to bridge patients with ALF by detoxification ${ }^{35}$ until a suitable organ is available or the regeneration of the patient's liver is advanced to a point where no liver transplantation is needed. The insufficient availability of human liver cells for hepatocyte based bioartificial liver devices led to the use of porcine hepatocytes ${ }^{36}$ or human hepatic cell lines ${ }^{37}$.

However, the concerns of potential immunological problems in case of using xenogeneic cells and the risk of tumor cell transfer into patients in case of using tumor-derived cell lines ${ }^{38}$ avert clinical application. Furthermore it has been shown that the C3A cell line, a derivate of the hepatic tumor cell line HepG2, which is used in the Extracorporeal Liver Assist Device (ELAD), caused no significant beneficial effect on the survival rate of patients in a pilot-controlled clinical trial ${ }^{39}$. These problems could be overcome by the use of differentiated hESC, capable of unlimited 
proliferation and differentiation into hepatocytes. Mature or premature hepatic cells derived from hESC could also be used for cell transplantation therapy in patients suffering from ALF or CLF, if the presence of remaining undifferentiated hESC with the risk of tumor formation can be excluded in the preparation ${ }^{40}$. Until now no clinical application of hESC in liver therapies has been reported, based on ethical issues and safety risks due to the high oncogenic potential of the cells.

\subsubsection{Use of hepatocytes for pharmacological studies}

Pharmacological companies invest enormous amounts of money into the development of new drugs. Before the application in human phase I studies any new drugs are tested in animal trials to reduce the possibility of human side-effects. However, the metabolism of various animal species used for pharmacological studies features significant differences compared to the metabolism in humans ${ }^{41,42}$. To overcome the most obvious inter-species differences, efforts have been taken to generate trans-gene animals with a more human like metabolism ${ }^{43}$. However, several differences still remain in such models and thus limit the informative value of animal experiments. It has recently been reported that hepatocytes cultured in a miniaturized bioreactor model can be cultured under maintenance of cytochrome P450 activity even under serum free conditions ${ }^{44}$. But although relatively small cell numbers are needed for one bioreactor run, the general shortage in human primary hepatocytes remains a challenge in large-scale pharmaceutical studies.

Differentiated hESC could replace primary hepatocytes and thus enable large-scale pharmaceutical studies with cells exhibiting a set of hepatocyte specific enzymes closer to physiological conditions compared to the use of cells of non-human origin. 


\subsubsection{Bioreactor system for dynamic 3D culture of hepatic cells}

An elegant alternative to animal experimental studies of drug biotransformation kinetics and in addition a valuable additional tool for the prediction of adverse events in humans might be the use of 3D bioreactor systems inoculated with hepatic cells. In addition to the gain of informative value by the use of bioreactors inoculated with human cells, the culture system switch from conventional 2D culture in static plastic dishes to 3D bioreactor systems offers a number of advantages. Bioreactor systems provide a more homogeneous environment with the possibility to constantly monitor and adjust culture parameters. Limitations of conventional 2D culture in the control of culture environment parameters like the accumulation of metabolites, the fluctuation in nutrient concentration, the adjustment of oxygen partial pressure as well as $\mathrm{pH}$ can be addressed in 3D bioreactor systems.

The bioreactor system used in this study was designed and used for extracorporeal liver support ${ }^{45,46,13}$. The bioreactor consists of interwoven hollow fiber membranes that form four independent compartments. Two of these components are utilized for the media perfusion of the cell compartment. The fourth compartment is used for the oxygenation. The combination of interwoven fiber membranes for media and gas supply in repetitive units enables a decentralized mass exchange, a reduction of distance dependent concentration gradients and a scalability of the bioreactor system itself. The cell compartment is nerved by these interwoven capillaries that allow for formation of tissue like structures in between.

The use of different 3D bioreactor systems has already been addressed in various studies with human hepatocellular carcinoma cell lines ${ }^{47}$ as well as with primary human and animal hepatocytes ${ }^{48-50}$. Although the use of human hepatocytes, isolated from tumor free tissue after partial hepatectomy, in such 3D bioreactor systems is at the moment the most promising approach, the use of human primary cell is associated naturally with a number of disadvantages. It is known that primary hepatic cells have a high inter-individual variation in cytochrome P450 expression induced not only through different genetic background and sex, but also by age, smoking habits, abuse of drugs and many more factors ${ }^{51}$. In addition the amount of primary cells needed for pre-clinical trials would exceed the amount of available 
healthy tissue suitable for cell isolation and bioreactor inoculation. Alternative approaches using hepatic carcinoma cell lines were disappointing due to the limited expression of hepatic enzymes in these transformed cells compared to primary hepatocytes ${ }^{52}$. Interestingly, it was shown that the culture of the human hepatoma cell line HepaRG in bioreactors results in a higher hepatocyte specific cytochrome P450 activity compared to the cells cultured in conventional 2D cultures ${ }^{53}$. A positive effect on hepatocyte specific functions in 3D bioreactor systems has also been reported for primary hepatocytes ${ }^{54}$. Therefore a promising alternative to the use of primary hepatocytes might be the use of differentiated human embryonic stem cells in a 3D bioreactor system.

\subsection{D bioreactor systems for the expansion of hESC}

Today stem cells are cultured mainly in conventional 2D cultures. This method bears several advantages like relatively easy morphological evaluation of the cells and the possibility to manipulate colonies directly, but it is also very labour intensive, and makes large scale expansion in an extend needed for regenerative medicine therapies practically impossible. Recently an approach for the automation of cell expansion and labour reduction has been published ${ }^{55}$. However, other disadvantages of conventional 2D cultures, especially the discontinuous medium supply, leading to an accumulation of metabolic products and the scarcity of nutritive substances, and also the rather unphysiological 2D configuration of the cell layer still remains.

The culture and expansion of stem cells in bioreactors could provide an attractive alternative. The advantage of these culture systems lies not only in the reduction of effort, it also offers the possibility of continuous monitoring and adjustment of nutrient supply, waste elimination, $\mathrm{pH}$ - and oxygen concentration. It has been reported that the growth kinetics of hESC in a stirred-tank bioreactor in combination with microcarriers were superior in comparison to conventional 2D cultures under maintenance of the undifferentiated state ${ }^{56}$. 


\subsection{Hepatic differentiation of hESC in 3D bioreactor systems}

Not only the undifferentiated expansion, but also the differentiation of stem cells in 3D bioreactor systems bears numerous advantages compared to 2D approaches. It has been reported that the formation of embryoid bodies in a stirring bioreactor with porous alginate scaffolds resulted in a superior vascularization compared to embryoid bodies gained after conventional approaches in 2D ${ }^{57}$. A higher proliferation rate, probably as a result of the more constant and optimized culture conditions, could also be reported within the same publication.

The directed differentiation of hESC in 3D bioreactors still holds a number of unanswered questions. The scientific progress made in the field of developmental biology gives us more and more insight into the molecular pathways that are involved in proliferation and differentiation of hESC into various lineages. The experiments made on the direction of differentiation into defined cell derivatives were mostly made in conventional 2D cultures. One of the essential findings from the diverse differentiation approaches was that not only the precise sequence of signal molecules, but also its concentration, the cell density, cell-cell contacts, the extracellular matrix, the nutrient supply, oxygen partial pressure and many other factors play a central role in signal conduction and thus cell differentiation. The culture environment that can be provided in a 3D bioreactor is fundamentally different from that in a culture dish. The potential of that culture system was demonstrated in a study investigating the teratoma formation from hESC in a 3D bioreactor in comparison with in vivo mouse teratoma formation ${ }^{58}$. Therefore the established protocols for the differentiation have to be adapted when applied to another environment. Initial studies on hepatic differentiation in the bioreactor system have been conducted ${ }^{59}$ and showed a hepatic commitment of the cells. 


\subsection{Current limitations of hepatic differentiation of hESC}

The directed hepatic differentiation of stem cells in conventional 2D culture has been reported to rely on the precise sequence of signal molecules. In contrast the nature of $2 \mathrm{D}$ culture systems brings fluctuation of nutrients, metabolic products, $\mathrm{pH}$ and signal molecules by the medium exchange.

The culture in a bioreactor system with continuous feed offers a fundamentally different environment. Culture parameters like nutrient content, metabolic waste concentration, and $\mathrm{pH}$ can be monitored and can be influenced by adjustment of the feed rate and gas mixture.

Two different applications are imaginable for bioreactors containing hepatic differentiated cells. The use in pharmaceutical research, in which a robust expression of the hepatic enzyme machinery is desired, and the use in acute or chronic liver failure as a therapeutic tool to support the liver function of patients. For the application in a clinical environment as extracorporeal liver assist device the use of materials of animal origin should be avoided.

When addressing the use of hepatic cells in pharmaceutical research the expression of enzymes of the cytochrome P450 family is of central interest. In a recent study cryopreserved human primary hepatocytes were cultured for 4 hours in conventional 2D culture and compared with commercially available hepatic differentiated hESC regarding their drug metabolizing capacity ${ }^{60}$. The hESC-derived differentiated cells showed only a fractional amount of activity of the investigated cytochrome P450 isoforms. Interestingly, it was shown that when the primary hepatocytes were cultured for 48 hours in conventional 2D culture instead, the drug metabolizing capacity decreases dramatically to a level comparable to hepatic differentiated hESC. It has been shown that the 3D bioreactor culture of primary human hepatocytes has a positive effect on the long-term maintenance of cytochrome P450 isoform activity ${ }^{54}$ in comparison to conventional 2D culture. It therefore appears reasonable to culture hepatic differentiated hESC under 3D bioreactor conditions to support the drug metabolism enzyme expression in pharmaceutical research.

When addressing the potential clinical use of differentiated hESC three major 
problems arise, the realization of the production of sufficient cell numbers, the functionality of the cells and the safety of medical application. In a phase I clinical study with a bioartificial liver assist device utilizing primary porcine liver cells in medical treatment of eight patients suffering from acute liver failure about $1.8 \mathrm{E} 10$ to 4.4E10 cells were used per application / patient ${ }^{35}$. Reports describing the cell numbers recovered after hepatic differentiation are rare, but it is known that the definitive endodermal commitment of hESC is a highly selective step associated with a high number of cell loss due to apoptosis.

Reports about the efficiency of differentiation of hESC into hepatocyte like cells vary from about $70 \%{ }^{61}$ of the cells expressing human Albumin to about $94 \%{ }^{62}$. Although the purity of cell preparations obtained by these approaches is remarkably high, the identity of the non-hepatic cells still remains of large clinical interest since teratoma formation has been reported after transplantation of hESC committed to the endodermal lineage ${ }^{5}$.

Until today the transplantation of mature hepatocytes is an attractive option in the treatment of metabolic disorders such as urea cycle defects or Crigler-Najjar disease. Although the transplanted cells only work transiently, hepatocyte transplantation can stabilize the medical condition and bridge the patient until classical liver transplantation ${ }^{63}$.

A more promising alternative for cell-based therapies in regenerative medicine is the transplantation of fetal hepatic stem cells. The supportive effect of these cells can last for several years instead of several months as reported for the transplantation of mature hepatocytes ${ }^{64,65}$. But ethical concerns make the use of fetal tissue difficult. But whatever hepatic cell source is used, relatively high cell numbers are needed to treat a patient. In case of immature (fetal) cells reports range from 15 million fetal stem cells for a 2 year old patient to about 100 to 150 million cells in adults ${ }^{64,65}$. Even more cells are needed if using adult hepatocytes since the cell engraftment generally accounts to not more than $3 \%$ of the host organ cells in a normal liver environment ${ }^{66}$.

Taken into consideration that differentiated hESC feature only partly the metabolic activity of primary hepatocytes ${ }^{60}$ the therapeutic value of differentiated cells is at the moment limited.

Thus, further development of differentiation methods is needed to improve the 
functional performance of hESC-derived (progenitor) cells, to ensure the clinical safety of cell preparations and to optimize the practicability of cultivation processes for clinical use.

\subsection{Aim of this study}

The aim of this study was to investigate the effects of a 3D bioreactor environment on the hepatic differentiation of human embryonic stem cells.

Two different strategies were investigated for the differentiation of hESC along the hepatic lineage in a 3D bioreactor environment.

The first strategy aims the reduction of xenobiotic material by establishing feeder free culture conditions for hESC. Further on published protocols for the hepatic differentiation were evaluated in regard to the degree of hepatic differentiation via real-time PCR as well as cell yield. In the following suitable protocols were adapted for hESC differentiation in 3D bioreactor culture systems and the cell differentiation was monitored by the determination of the metabolic activity (glucose and lactate concentrations), the measurement of factors indicating processes of differentiation (beta HCG) and endodermal commitment (AFP) as well as the expression of hepatic and non-hepatic transcripts via real-time PCR.

In the second strategy the hepatic differentiation in a 3D bioreactor system was conducted in cooperation with Cellartis according to a protocol for the hepatic differentiation in conventional 2D culture published by Brolén et al., $2010^{67}$. Cells were cultured using the Single Cell Enzymatic Dissociation (SCED) technique. The $3 \mathrm{D}$ bioreactor experiments were conducted with or without proteins and cells of animal origin. In a two-step differentiation approach cells were first committed to definitive endodermal lineage and then further proliferated and maturated into hepatic cells. The differentiation was monitored by determination of the metabolic activity, the measurement of factors indicating ongoing differentiation (beta-hCG) and definitive endodermal commitment (AFP) as well as immune histochemistry to study the formation of hepatic structures at the end of differentiation. 
An overview of the strategies followed within this study in given in figure 1.

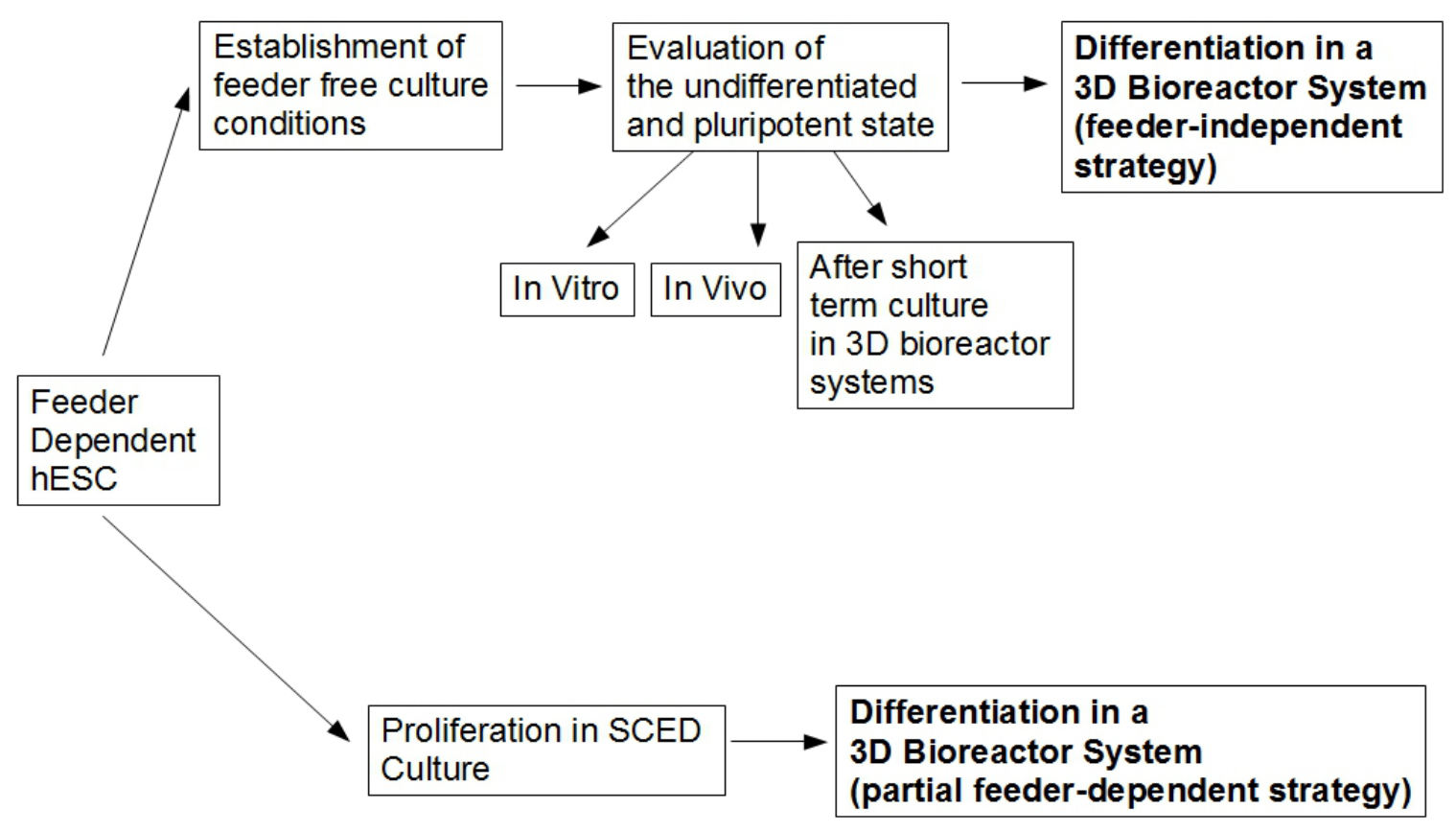

Figure 1: Strategies for the hepatic differentiation of hESC in 3D bioreactor systems. SCED = Single Cell Enzymatic Dissociation 


\section{Material and Methods}

\subsection{Materials}

\subsubsection{Equipment and Software}

Table 1: Equipment

\begin{tabular}{|c|c|}
\hline Equipment & Manufacturer \\
\hline Bench drill; OPTI B23 Pro & Optimum-Maschinen Germany GmbH, Hallstadt \\
\hline Bioreactor perfusion device & Stem Cell Systems, Berlin \\
\hline Blood gas analyzer; $A B L 700$ Series & Radiometer, Brønshøj, Denmark \\
\hline Centrifuge; Varifuge 3.OR & Heraeus Instruments $\mathrm{GmbH}$, Hanau \\
\hline Clinical analyzer; modular PPP analyzer & Roche Diagnostics, Heidelberg \\
\hline Device for gas valves & Vögtlin Instruments, Aesch, Switzerland \\
\hline Dako pen wax crayon & Dako, Hamburg \\
\hline Fluorescence microscope; Axiovert 200M & Carl Zeiss, Göttingen \\
\hline $\begin{array}{l}\text { Fluorescence microscope camera; Retiga } \\
2000 \mathrm{R}\end{array}$ & QImaging, Surrey, BC, Canada \\
\hline $\begin{array}{l}\text { Fluorescence microscope lamp; AttoArc, HBO } \\
100 \mathrm{~W}\end{array}$ & Carl Zeiss, Göttingen \\
\hline Horizontal air flow & Telstar, Terrassa, Spain \\
\hline Light microscope; Axiovert 40 CFL & Carl Zeiss, Jena \\
\hline $\begin{array}{l}\text { Light microscope camera; MicroPublisher } 3.3 \\
\text { RTV }\end{array}$ & QImaging, Surrey, BC, Canada \\
\hline Incubators; Cytoperm $\mathrm{CO}_{2} / \mathrm{O}_{2}$ & Heraeus Instruments $\mathrm{GmbH}$, Hanau \\
\hline Laminar air flow; HB2472 & Heraeus Instruments $\mathrm{GmbH}$, Hanau \\
\hline Microcentrifuge; 5417R & Eppendorf, Hamburg \\
\hline Microtome; Microm HM355s & Microm-International-GmbH, Walldorf \\
\hline Paraffin embedding center AP 250 & Microm-International-GmbH, Walldorf \\
\hline Perfusor; Secura FT & B.Braun, Melsungen \\
\hline
\end{tabular}




\begin{tabular}{|l|l|}
\hline Plate-reading fluorometer; FumostarOptima & BMG Labtech GmbH, Ortenberg \\
\hline Radiator; OB29/4 $\left({ }^{137}\right.$ Cs y source) & STS, Braunschweig \\
\hline Realtime cycler; Mastercycler ep Realplex 2 & Eppendorf, Hamburg \\
\hline Stereo microscope; Nikon SMZ1000 & $\begin{array}{l}\text { Nikon Instruments Europe BV, Amsterdam, } \\
\text { Netherlands }\end{array}$ \\
\hline Spectrophotometer; Nanodrop & Thermo Fisher Scientific, Waltham, MA, USA \\
\hline Thermal-Cycler; Veriti 96 Well & Applied Biosystems, Foster City, USA \\
\hline
\end{tabular}

Table 2: Software

\begin{tabular}{|l|l|}
\hline \multicolumn{1}{|c|}{ Software } & \multicolumn{1}{c|}{ Manufacturer } \\
\hline Get red-y 5 & Vögtlin Instruments, Aesch, Switzerland \\
\hline GraphPad Prism 5.0 & GraphPad Software, San Diego, CA, USA \\
\hline Image Pro Plus & Media Cybernetics, Silver Spring, USA \\
\hline QCapture Pro 5.1 & QImaging, Surrey, BC, Canada \\
\hline OpenOffice & $\begin{array}{l}\text { Apache OpenOffice Foundation, Los Angeles, } \\
\text { CA, USA }\end{array}$ \\
\hline Mendeley Desktop & Mendeley Ltd., New York, USA \\
\hline
\end{tabular}

\subsubsection{Disposables}

Table 3: Cell culture disposals

\begin{tabular}{|l|l|}
\hline \multicolumn{1}{|c|}{ Component } & \multicolumn{1}{c|}{ Manufacturer } \\
\hline 6-, 12- and 24-well plates & Falcon, BD Biosciences, San Jose, CA, USA \\
\hline 6-well plates, Nunclon ${ }^{\mathrm{TM}}$ surface & Nunc, Roskilde, Denmark \\
\hline 24-well plates, lumox® & Sarstedt, Nümbrecht-Rommelsdorf \\
\hline 96-well plate; Fluoronunc ${ }^{\mathrm{TM}}$ & Nunc, Roskilde, Denmark \\
\hline "In Vitro Fertilization" (IVF) dishes & Falcon, BD Biosciences, San Jose, CA, USA \\
\hline Cell culture flasks $\left(25 \mathrm{~cm}^{2}-175 \mathrm{~cm}^{2}\right)$ & Falcon, BD Biosciences, San Jose, CA, USA \\
\hline
\end{tabular}




\begin{tabular}{|c|c|}
\hline Stem Cell Cutting Tool ${ }^{\mathrm{TM}}$ & Vitrolife AB, Göteborg, Sweden \\
\hline Falcon tubes $(15 \mathrm{~mL} / 50 \mathrm{~mL})$ & BD Biosciences, San Jose, CA, USA \\
\hline Glass slides; super frost plus & R. Langenbrinck, Emmendingen \\
\hline Whatman ${ }^{\mathrm{TM}}$ paper & Schleicher \& Schuell GmbH, Dassel \\
\hline Cover slides & Carl Roth, Karlsruhe \\
\hline Thermo-Fast 96-Well-PCR-Platten & Thermo Fisher Scientific, Waltham, MA, USA \\
\hline
\end{tabular}

Table 4: Bioreactor systems and tube system components

\begin{tabular}{|l|l|}
\hline \multicolumn{1}{|c|}{ Component } & \multicolumn{1}{c|}{ Company } \\
\hline Lab Scale Bioreactor $(8 \mathrm{ml} \mathrm{BR})$ & Stem Cell Systems, Berlin \\
\hline Analytical Scale Bioreactor $(2 \mathrm{ml} \mathrm{BR})$ & Stem Cell Systems, Berlin \\
\hline Miniaturized Bioreactor $(0,2 \mathrm{ml} \mathrm{BR})$ & Stem Cell Systems, Berlin \\
\hline Miniaturized Bioreactor $(0,4 \mathrm{ml} \mathrm{BR})$ & Stem Cell Systems, Berlin \\
\hline Tubing System for bioreactor perfusion & Stem Cell Systems, Berlin \\
\hline Combi-stopper luer lock & Fresenius Kabi, Bad Homburg vor der Höhe \\
\hline Combidyn® adapter & B.Braun, Melsungen \\
\hline Disposable cannula & B.Braun, Melsungen \\
\hline Gas filter & Sartorius, Göttingen \\
\hline Glas vessel (250 $\mathrm{mL} / 500 \mathrm{~mL})$ & Schott, Mainz \\
\hline Heidelberger extension tubing & B.Braun, Melsungen \\
\hline Perfusion line & B.Braun, Melsungen \\
\hline Syringes (1-50 $\mathrm{mL})$ & B.Braun, Melsungen \\
\hline Three-way valves & B.Braun, Melsungen \\
\hline Vessel lid with integrated luer lock & Stem Cell Systems, Berlin \\
\hline
\end{tabular}




\subsubsection{Chemicals and solutions}

\subsubsection{Chemicals and inorganic solutions}

Table 5: Chemicals and inorganic solutions

\begin{tabular}{|l|l|}
\hline \multicolumn{1}{|c|}{ Component } & \multicolumn{1}{c|}{ Company } \\
\hline $\begin{array}{l}\text { 4',6-diamidino-2-phenylindole dihydrochloride } \\
\text { (DAPI) }\end{array}$ & Molecular Probes, Eugene, USA \\
\hline 4\% paraformaldehyde solution & Herbeta Arzneimittel, Berlin \\
\hline Aqua Polymount & Polysciences Inc., Warrington, PA, USA \\
\hline Eosin a & Carl Roth, Karlsruhe \\
\hline Ethanol & Herbeta Arztneimittel, Berlin \\
\hline Harris' hematoxylin solution & Sigma-Aldrich, St. Louis, MO, USA \\
\hline Methanol & J.T. Baker, Deventer, Netherlands \\
\hline ParaClear Intermedium; ProTaqs Clear & Quartett Immundiagnostika Biotechnologie GmbH, \\
\hline Paraffin & Berlin \\
\hline RNase ZAP ${ }^{\circledR}$ & Merck, Darmstadt \\
\hline TRIZOL ${ }^{\circledR}$ reagent & Life Technologies, Carlsbad, CA, USA \\
\hline Trypan blue, 0.5\% w/v & Life Technologies, Carlsbad, CA, USA \\
\hline UltraPure ${ }^{\text {TM }}$ Dnase/RNase-free Distilled Water & Biochrom, Berlin \\
\hline Vitro-Clud & Life Technologies, Carlsbad, CA, USA \\
\hline Teleosteangelatin & R. Langenbrinck, Emmendingen \\
\hline & Sigma-Aldrich, St. Louis, MO, USA \\
\hline
\end{tabular}

\subsubsection{Cell culture media solutions, additives and cytokines}

All solutions and additives were stored according to the manufacturer's instructions.

Table 6: Cell culture media solutions and additives

\begin{tabular}{|l|l|}
\hline \multicolumn{1}{|c|}{ Solution / Additive } & \multicolumn{1}{c|}{ Company } \\
\hline Bovine Serum Albumin (BSA) & Sigma-Aldrich, St. Louis, MO, USA \\
\hline Fetal Calf Serum (FCS) & PAA, Dartmouth, MA, USA \\
\hline $\begin{array}{l}\text { 1x Phosphate buffered saline (PBS) w/o } \\
\mathrm{Ca}^{2+} \text { Mg }^{2+}\end{array}$ & PAA, Dartmouth, MA, USA \\
\hline Dulbecco's Modified Eagle's Medium & Biochrom, Berlin \\
\hline
\end{tabular}




\begin{tabular}{|c|c|}
\hline (DMEM) & \\
\hline DMEM / F12 medium & Life Technologies, Carlsbad, CA, USA \\
\hline L-alanyl-L-glutamine "stable glutamine" & Biochrom, Berlin \\
\hline Gentamycin & Biochrom, Berlin \\
\hline Beta-mercaptoethanol & Sigma-Aldrich, St. Louis, MO, USA \\
\hline Sodium-butyrate & Sigma-Aldrich, St. Louis, MO, USA \\
\hline Very Low Endotoxin (VLE)-RPMI 1640 & Biochrom, Berlin \\
\hline Knockout Serum Replacement & Life Technologies, Carlsbad, CA, USA \\
\hline $\begin{array}{l}0.05 \% / 0.02 \%(w / v) \text { Trypsin/EDTA } \\
\text { solution }\end{array}$ & Biochrom, Berlin \\
\hline Dispase & Life Technologies, Carlsbad, CA, USA \\
\hline Knockout DMEM & Life Technologies, Carlsbad, CA, USA \\
\hline B-27® Supplement Minus Insulin & Life Technologies, Carlsbad, CA, USA \\
\hline VitroCol ${ }^{\circledR}$ Human Collagen Product & Inamed, Fremont, CA, USA \\
\hline Iscove's MEM & Biochrom, Berlin \\
\hline Retinoic acid & Sigma-Aldrich, St. Louis, MO, USA \\
\hline Insulin & Roche Diagnostics, Heidelberg \\
\hline Transferrin & Sigma-Aldrich, St. Louis, MO, USA \\
\hline Ly294002 & Merck, Darmstadt \\
\hline Monothioglycerol & Sigma-Aldrich, St. Louis, MO, USA \\
\hline $\mathrm{mTeSR}^{\mathrm{TM}_{1} \text { medium }}$ & Stemcell Technologies, Vancouver, BC, USA \\
\hline Dimethyl sulfoxide (DMSO) & Sigma-Aldrich, St. Louis, MO, USA \\
\hline Non essential amino acids (NEAA) & Biochrom, Berlin \\
\hline Glutamax $^{\circledR}, 200 \mathrm{mM}$ & Life Technologies, Carlsbad, CA, USA \\
\hline Hepatocyte basal medium (HBM) & Lonza, Walkersville, USA \\
\hline HCM Single Quot Kit & Lonza, Walkersville, USA \\
\hline MatrigelTM (growth factor reduced) & BD Biosciences, San Jose, CA, USA \\
\hline $0.1 \%$ gelantin solution & Sigma-Aldrich, St. Louis, MO, USA \\
\hline SB431542 & Merck, Darmstadt \\
\hline $\begin{array}{l}\text { Iscove's Modified Dulbecco's Medium } \\
\text { (IMDM) }\end{array}$ & Life Technologies, Carlsbad, CA, USA \\
\hline TrypLE $^{\circledR}$ & Life Technologies, Carlsbad, CA, USA \\
\hline mFreSR ${ }^{\mathrm{TM}}$ & StemCell Technologies \\
\hline
\end{tabular}

Cytokines were resuspended according to the manufacturer's instructions and aliquots were prepared for long-term storage. 
Table 7: Cytokines

\begin{tabular}{|l|l|}
\hline \multicolumn{1}{|c|}{ Cytokines } & \multicolumn{1}{c|}{ Company } \\
\hline Hepatocyte Growth Factor (HGF) & PeproTech, London, UK \\
\hline Oncostatin M (OSM) & PeproTech, London, UK \\
\hline Basic Fibroblast Growth factor (bFGF) & PeproTech, London, UK \\
\hline Activin A & PeproTech, London, UK \\
\hline $\begin{array}{l}\text { Wingless-type MMTV integration site } \\
\text { family, member 3a (Wnt3a) }\end{array}$ & R\&D Systems, Minneapolis, USA \\
\hline Bone morphogenic protein4 (BMP4) & PeproTech, London, UK \\
\hline FGF4 & PeproTech, London, UK \\
\hline FGF10 & PeproTech, London, UK \\
\hline
\end{tabular}

\subsubsection{Kits and assays}

Table 8: Kits and assays

\begin{tabular}{|c|c|}
\hline Component & Company \\
\hline $\begin{array}{l}\text { High Capacity RNA-to-cDNA Kit with Rnase- } \\
\text { Inhibitor }\end{array}$ & Applied Biosystems, Foster City, USA \\
\hline PureLink $^{\circledR}$ RNA Mini Kit & Life Technologies, Carlsbad, CA, USA \\
\hline RNase-free DNase Set & Quiagen, Hilden \\
\hline $\operatorname{TaqMan}^{\circledR}$ Fast Universal Master Mix & Applied Biosystems, Foster City, USA \\
\hline TaqMan Gene Expression Assays & Applied Biosystems, Foster City, USA \\
\hline AFP, HS00173490_m1, Assay & Applied Biosystems, Foster City, USA \\
\hline GAPDH, Hs03929097_g1, Assay & Applied Biosystems, Foster City, USA \\
\hline Nanog, Hs02387400_g1, Assay & Applied Biosystems, Foster City, USA \\
\hline POU5F1 (Oct 3/4), Hs00999632_g1, Assay & Applied Biosystems, Foster City, USA \\
\hline Neurofilament, Hs00196245_m1, Assay & Applied Biosystems, Foster City, USA \\
\hline GATA II, Hs00231119_m1, Assay & Applied Biosystems, Foster City, USA \\
\hline Сyp3A4, Hs00604506_m1, Assay & Applied Biosystems, Foster City, USA \\
\hline Albumin, Hs00910225_m1, Assay & Applied Biosystems, Foster City, USA \\
\hline SOX7, Hs00846731_s1, Assay & Applied Biosystems, Foster City, USA \\
\hline SOX17, Hs00751752_s1, Assay & Applied Biosystems, Foster City, USA \\
\hline Cyp2D6, Hs02576168_g1, Assay & Applied Biosystems, Foster City, USA \\
\hline Сур2B6, Hs03044634_m1, Assay & Applied Biosystems, Foster City, USA \\
\hline Сур2C9, Hs00426397_m1, Assay & Applied Biosystems, Foster City, USA \\
\hline Сyp1A2, Hs00167927_m1, Assay & Applied Biosystems, Foster City, USA \\
\hline CXCR4, Hs00607978_s1, Assay & Applied Biosystems, Foster City, USA \\
\hline Human Albumin ELISA Quantitation Set & Bethyl Laboratories, Montgomery, TX, USA \\
\hline
\end{tabular}




\subsubsection{Solutions for immune histochemistry and antibodies}

Table 9: Blocking solution

\begin{tabular}{|c|c|}
\hline Component & Concentration \\
\hline BSA & $2.5 \%(\mathrm{w} / \mathrm{v})$ \\
\hline FCS & $2.00 \%(\mathrm{v} / \mathrm{v})$ \\
\hline Teleosteangelatin & $0.20 \%(\mathrm{v} / \mathrm{v})$ \\
\hline PBS & $95.3 \%(\mathrm{v} / \mathrm{v})$ \\
\hline
\end{tabular}

Table 10: Citrate buffer

\begin{tabular}{|c|c|c|}
\hline Component & Concentration & Company \\
\hline Citric acid & $1.8 \mathrm{mM}$ & Sigma-Aldrich, St. Louis, MO, USA \\
\hline Sodium citrate & $8.2 \mathrm{mM}$ & Merck, Darmstadt \\
\hline
\end{tabular}

Antibodies were diluted in blocking buffer at defined concentrations (see table 11).

Table 11: Antibodies

\begin{tabular}{|c|c|c|c|c|c|}
\hline Antigen & $\begin{array}{c}\text { Host } \\
\text { species }\end{array}$ & Isotype & $\begin{array}{c}\text { Immuno } \\
\text { gen }\end{array}$ & Manufacturer & Dilution \\
\hline SSEA-4 & mouse & $\begin{array}{c}\text { monoclonal } \\
\text { IgG }\end{array}$ & human & $\begin{array}{c}\text { R\&D-Systems, } \\
\text { Minneapolis, USA }\end{array}$ & $1: 30$ \\
\hline Oct-4 & rabbit & $\begin{array}{c}\text { polyclonal } \\
\operatorname{lgG}\end{array}$ & human & $\begin{array}{c}\text { Santa Cruz, } \\
\text { Dallas, USA }\end{array}$ & $1: 100$ \\
\hline AFP & mouse & $\begin{array}{c}\text { monoclonal } \\
\text { IgG1 }\end{array}$ & human & $\begin{array}{c}\text { Santa Cruz, } \\
\text { Dallas, USA }\end{array}$ & $1: 100$ \\
\hline CK 18 & mouse & $\begin{array}{c}\text { monoclonal } \\
\text { IgG1 }\end{array}$ & human & $\begin{array}{c}\text { Santa Cruz, } \\
\text { Dallas, USA }\end{array}$ & $1: 100$ \\
\hline CK 19 & mouse & $\begin{array}{c}\text { monoclonal } \\
\text { IgG1 }\end{array}$ & human & $\begin{array}{c}\text { Santa Cruz, } \\
\text { Dallas, USA }\end{array}$ & $1: 100$ \\
\hline SOX 17 & mouse & $\begin{array}{c}\text { monoclonal } \\
\text { IgG3 }\end{array}$ & human & $\begin{array}{c}\text { R\&D-Systems, } \\
\text { Minneapolis, USA }\end{array}$ & $1: 100$ \\
\hline Nestin & rabbit & $\begin{array}{c}\text { polyclonal } \\
\text { IgG }\end{array}$ & human & $\begin{array}{c}\text { Santa Cruz, } \\
\text { Dallas, USA }\end{array}$ & $1: 100$ \\
\hline Desmin & mouse & monoclonal & human & $\begin{array}{c}\text { Sigma-Aldrich, } \\
\text { IgG1 }\end{array}$ & $1: 100$ \\
& & & St. Louis, USA & \\
\hline
\end{tabular}




\begin{tabular}{|c|c|c|c|c|c|}
\hline Vimentin & mouse & $\begin{array}{c}\text { monoclonal } \\
\lg \mathrm{G} 1\end{array}$ & human & $\begin{array}{l}\text { Sigma-Aldrich, } \\
\text { St. Louis, USA }\end{array}$ & $1: 40$ \\
\hline SOX 7 & rabbit & $\begin{array}{c}\text { polyclonal } \\
\lg G\end{array}$ & human & $\begin{array}{l}\text { Santa Cruz, } \\
\text { Dallas, USA }\end{array}$ & $1: 50$ \\
\hline Albumin & mouse & $\begin{array}{c}\text { monoclonal } \\
\lg G 2 a\end{array}$ & human & $\begin{array}{c}\text { Abcam, } \\
\text { Cambridge, UK }\end{array}$ & $1: 100$ \\
\hline Сур 1 A2 & rabbit & polyclonal & human & $\begin{array}{c}\text { Novus Biologicals, } \\
\text { Littleton, USA }\end{array}$ & 1:100 \\
\hline Сур 3A4 & rabbit & polyclonal & human & $\begin{array}{l}\text { Novus Biologicals, } \\
\text { Littleton, USA }\end{array}$ & $1: 100$ \\
\hline Сyp 2C9 & rabbit & polyclonal & human & $\begin{array}{l}\text { Novus Biologicals, } \\
\text { Littleton, USA }\end{array}$ & $1: 100$ \\
\hline Сyp 7A1 & rabbit & polyclonal & human & $\begin{array}{l}\text { Santa Cruz, } \\
\text { Dallas, USA }\end{array}$ & $1: 100$ \\
\hline Сур 2B6 & rabbit & polyclonal & human & $\begin{array}{l}\text { Santa Cruz, } \\
\text { Dallas, USA }\end{array}$ & $1: 100$ \\
\hline Cyp 2D6 & rabbit & polyclonal & human & $\begin{array}{c}\text { Bioss, Boston, } \\
\text { USA }\end{array}$ & $1: 100$ \\
\hline \multicolumn{6}{|c|}{ Secondary Antibodies } \\
\hline $\begin{array}{c}\text { Alexa Fluor } \\
488\end{array}$ & goat & & mouse & $\begin{array}{l}\text { Life technologies, } \\
\text { Carlsbad, USA }\end{array}$ & $1: 1000$ \\
\hline $\begin{array}{c}\text { Alexa Fluor } \\
594\end{array}$ & goat & & rabbit & $\begin{array}{c}\text { Life technologies, } \\
\text { Carlsbad, USA }\end{array}$ & $1: 1000$ \\
\hline
\end{tabular}

\subsubsection{Cell lines and culture media}

The research on human embryonic stem cells was performed with the approval by the Robert Koch Institute, Berlin, Germany, according to the German stem cell law.

Table 12: Cell lines

\begin{tabular}{|l|l|}
\hline \multicolumn{1}{|c|}{ Cell Line } & \multicolumn{1}{c|}{ Provider } \\
\hline Mouse embryonal fibroblasts (MEF) & provided by Dr. I. Fichtner, MDC, Berlin-Buch \\
\hline hESC line H1 feeder-dependent & WiCell Research Institute, Madison, WI, USA \\
\hline hESC line H1 feeder-independent & WiCell Research Institute, Madison, WI, USA \\
\hline hESC line SA002 & Cellartis, Göteborg, Sweden \\
\hline hESC line SA121 & Cellartis, Göteborg, Sweden \\
\hline Human foreskin fibroblasts & $\begin{array}{l}\text { American Type Culture Collection, Manassas, VA, } \\
\text { USA }\end{array}$ \\
\hline
\end{tabular}


Culture media were used within two weeks after supplementation with additives and were stored at $4^{\circ} \mathrm{C}$.

Table 13: Composition of MEF Medium

\begin{tabular}{|l|r|}
\hline \multicolumn{1}{|c|}{ Component } & \multicolumn{1}{|c|}{ Final Concentration } \\
\hline DMEM & $87 \%(\mathrm{v} / \mathrm{v})$ \\
\hline FCS & $10 \%(\mathrm{v} / \mathrm{v})$ \\
\hline L-Glutamine $(\mathrm{c}=200 \mathrm{mM}), 100 \mathrm{x}$ & $1 \%(\mathrm{v} / \mathrm{v})(\mathrm{c}=2 \mathrm{mM})$ \\
\hline NEAA $(\mathrm{c}=20 \mathrm{mM}), 100 \mathrm{x}$ & $1 \%(\mathrm{v})(\mathrm{c}=0.2 \mathrm{mM})$ \\
\hline $\begin{array}{l}\text { Penicillin/Streptomycin } \\
(\mathrm{c}=10000 \mathrm{U} / \mathrm{ml} / 10000 \mu \mathrm{g} / \mathrm{ml}), 100 \mathrm{x}\end{array}$ \\
\hline
\end{tabular}

Table 14: Composition of HFF Medium

\begin{tabular}{|l|r|}
\hline \multicolumn{1}{|c|}{ Component } & \multicolumn{2}{|c|}{ Final Concentration } \\
\hline IMDM & $89 \%(\mathrm{v} / \mathrm{v})$ \\
\hline FCS & $10 \%(\mathrm{v} / \mathrm{v})$ \\
\hline $\begin{array}{l}\text { Penicillin/Streptomycin } \\
\text { (c=10000 U/ml/10000 } \mu \mathrm{g} / \mathrm{ml}), 100 \mathrm{x}\end{array}$ \\
\hline
\end{tabular}

Table 15: Composition of mouse-feeder-dependent hESC Medium

\begin{tabular}{|l|r|}
\hline \multicolumn{1}{|c|}{ Component } & \multicolumn{1}{|c|}{ Final Concentration } \\
\hline DMEM & $77.5 \%(\mathrm{v} / \mathrm{v})$ \\
\hline Knockout Serum Replacement & $20 \%(\mathrm{v} / \mathrm{v})$ \\
\hline NEAA $(\mathrm{c}=20 \mathrm{mM}), 100 \mathrm{x}$ & $1 \%(\mathrm{v} / \mathrm{v})(\mathrm{c}=0.1 \mathrm{mM})$ \\
\hline Glutamax $(\mathrm{c}=200 \mathrm{mM}), 100 \mathrm{x}$ & $1 \%(\mathrm{v} / \mathrm{v})(\mathrm{c}=2 \mathrm{mM})$ \\
\hline Beta-Mercaptoethanol & $1 \%(\mathrm{v} / \mathrm{v})(\mathrm{c}=0.1 \mathrm{mM})$ \\
\hline bFGF & $4 \mathrm{ng} / \mathrm{ml}$ \\
\hline Gentamycin $(\mathrm{c}=10 \mathrm{mg} / \mathrm{ml}), 200 \mathrm{x}$ & $0.5 \%(\mathrm{v} / \mathrm{v})(\mathrm{c}=50 \mu \mathrm{g} / \mathrm{ml})$ \\
\hline
\end{tabular}


Table 16: Composition of medium for SCED culture

\begin{tabular}{|l|r|}
\hline \multicolumn{1}{|c|}{ Component } & \multicolumn{1}{|c|}{ Final Concentration } \\
\hline DMEM & $77.5 \%(\mathrm{v} / \mathrm{v})$ \\
\hline Knockout Serum Replacement & $20 \%(\mathrm{v} / \mathrm{v})$ \\
\hline NEAA $(\mathrm{c}=20 \mathrm{mM}), 100 \mathrm{x}$ & $1 \%(\mathrm{v} / \mathrm{v})(\mathrm{c}=0.1 \mathrm{mM})$ \\
\hline Glutamax $(\mathrm{c}=200 \mathrm{mM}), 100 \mathrm{x}$ & $1 \%(\mathrm{v} / \mathrm{v})(\mathrm{c}=2 \mathrm{mM})$ \\
\hline Beta-Mercaptoethanol & $0.1 \mathrm{mM}$ \\
\hline bFGF & $10 \mathrm{ng} / \mathrm{ml}$ \\
\hline Gentamycin $(\mathrm{c}=10 \mathrm{mg} / \mathrm{ml}), 200 \mathrm{x}$ & $0.5 \%(\mathrm{v} / \mathrm{v})(\mathrm{c}=50 \mu \mathrm{g} / \mathrm{ml})$ \\
\hline
\end{tabular}

Table 17: Composition of feeder-independent hESC Medium

\begin{tabular}{|l|r|}
\hline \multicolumn{1}{|c|}{ Component } & \multicolumn{1}{c|}{ Final Concentration } \\
\hline mTeSR $^{\mathrm{TM}} 1$ Basal Medium & $79.5 \%(\mathrm{v} / \mathrm{v})$ \\
\hline mTeSR $^{\mathrm{TM}} 15 \mathrm{x}$ Supplement & $20 \%$ \\
\hline Gentamycin $(\mathrm{c}=10 \mathrm{mg} / \mathrm{ml}), 200 \mathrm{x}$ & $0.5 \%(\mathrm{v} / \mathrm{v})(\mathrm{c}=50 \mu \mathrm{g} / \mathrm{ml})$ \\
\hline
\end{tabular}

The following media were used for hepatic differentiation of hESC:

Table 18: Medium one of Differentiation Approach one (M1.1)

\begin{tabular}{|l|r|}
\hline \multicolumn{1}{|c|}{ Component } & \multicolumn{1}{c|}{ Final Concentration } \\
\hline Knockout DMEM & $77.5 \%(\mathrm{v} / \mathrm{v})$ \\
\hline Serum Replacement & $20 \%(\mathrm{v} / \mathrm{v})$ \\
\hline L-Glutamine $(\mathrm{c}=200 \mathrm{mM}), 100 \mathrm{x}$ & $1 \%(\mathrm{v} / \mathrm{v})(\mathrm{c}=2 \mathrm{mM})$ \\
\hline Beta-Mercaptoethanol & $0.1 \mathrm{mM}$ \\
\hline NEAA (c = 20 mM), 100x & $1 \%(\mathrm{v} / \mathrm{v})(\mathrm{c}=0.2 \mathrm{mM})$ \\
\hline BFGF & $4 \mathrm{ng} / \mathrm{ml}$ \\
\hline DMSO & $1 \%(\mathrm{v} / \mathrm{v})$ \\
\hline Gentamycin $(\mathrm{c}=10 \mathrm{mg} / \mathrm{ml}), 200 \mathrm{x}$ & $0.5 \%(\mathrm{v} / \mathrm{v})(\mathrm{c}=50 \mu \mathrm{g} / \mathrm{ml})$ \\
\hline
\end{tabular}

Table 19: Medium two of Approach one (M1.2)

\begin{tabular}{|l|r|}
\hline \multicolumn{1}{|c|}{ Component } & \multicolumn{2}{c|}{ Final Concentration } \\
\hline HBM & $97 \%(\mathrm{v} / \mathrm{v})$ \\
\hline HCM SingleQuot Kit & $2.5 \%(\mathrm{v} / \mathrm{v})$ \\
\hline HGF & $10 \mathrm{ng} / \mathrm{ml}$ \\
\hline Gentamycin $(\mathrm{c}=10 \mathrm{mg} / \mathrm{ml}), 200 \mathrm{x}$ & $0.5 \%(\mathrm{v} / \mathrm{v})(\mathrm{c}=50 \mu \mathrm{g} / \mathrm{ml})$ \\
\hline
\end{tabular}


Table 20: Medium three of Approach one (M1.3)

\begin{tabular}{|l|r|}
\hline \multicolumn{1}{|c|}{ Component } & \multicolumn{1}{|c|}{ Final Concentration } \\
\hline HBM & $97 \%(\mathrm{v} / \mathrm{v})$ \\
\hline HCM SingleQuot Kit & $2.5 \%(\mathrm{v} / \mathrm{v})$ \\
\hline HGF & $10 \mathrm{ng} / \mathrm{ml}$ \\
\hline Oncostatin M & $10 \mathrm{ng} / \mathrm{ml}$ \\
\hline Gentamycin $(\mathrm{c}=10 \mathrm{mg} / \mathrm{ml}), 200 \mathrm{x}$ & $0.5 \%(\mathrm{v} / \mathrm{v})(\mathrm{c}=50 \mu \mathrm{g} / \mathrm{ml})$ \\
\hline
\end{tabular}

Table 21: Medium one of Approach two (M2.1)

\begin{tabular}{|l|r|}
\hline \multicolumn{1}{|c|}{ Component } & \multicolumn{2}{c|}{ Final Concentration } \\
\hline RPMI 1640 & $96.5 \%(\mathrm{v} / \mathrm{v})$ \\
\hline Glutamax $(\mathrm{c}=200 \mathrm{mM})$ & $1 \%(\mathrm{v} / \mathrm{v})(\mathrm{c}=2 \mathrm{mM})$ \\
\hline B27 & $2 \%(\mathrm{v} / \mathrm{v})$ \\
\hline Sodium Butyrate & $1 \mu \mathrm{M}$ \\
\hline Activin A & $100 \mathrm{ng} / \mathrm{ml}$ \\
\hline Wnt3a & $50 \mathrm{ng} / \mathrm{ml}$ \\
\hline Gentamycin $(\mathrm{C}=10 \mathrm{mg} / \mathrm{ml}), 200 \mathrm{x}$ & \\
\hline
\end{tabular}

Table 22: Medium two of Approach two (M2.2)

\begin{tabular}{|l|r|}
\hline \multicolumn{1}{|c|}{ Component } & \multicolumn{2}{c|}{ Final Concentration } \\
\hline HBM & $97 \%(\mathrm{v} / \mathrm{v})$ \\
\hline HCM SingleQuot Kit & $2.5 \%(\mathrm{v} / \mathrm{v})$ \\
\hline HGF & $10 \mathrm{ng} / \mathrm{ml}$ \\
\hline Gentamycin $(\mathrm{C}=10 \mathrm{mg} / \mathrm{ml}), 200 \mathrm{x}$ & $0.5 \%(\mathrm{v} / \mathrm{v})(\mathrm{c}=50 \mu \mathrm{g} / \mathrm{ml})$ \\
\hline
\end{tabular}

Table 23: Medium three of Approach two (M2.3)

\begin{tabular}{|l|r|}
\hline \multicolumn{1}{|c|}{ Component } & \multicolumn{1}{|c|}{ Final Concentration } \\
\hline HBM & $97 \%(\mathrm{v} / \mathrm{v})$ \\
\hline HCM SingleQuot Kit & $2.5 \%(\mathrm{v} / \mathrm{v})$ \\
\hline HGF & $10 \mathrm{ng} / \mathrm{ml}$ \\
\hline Oncostatin M & $10 \mathrm{ng} / \mathrm{ml}$ \\
\hline Gentamycin $(\mathrm{c}=10 \mathrm{mg} / \mathrm{ml}), 200 \mathrm{x}$ & $0.5 \%(\mathrm{v} / \mathrm{v})(\mathrm{c}=50 \mu \mathrm{gg} / \mathrm{ml})$ \\
\hline
\end{tabular}


Table 24: Medium one of Approach three (M3.1)

\begin{tabular}{|l|r|}
\hline \multicolumn{1}{|c|}{ Component } & \multicolumn{1}{|c|}{ Final Concentration } \\
\hline RPMI 1640 & $97.5 \%(\mathrm{v} / \mathrm{v})$ \\
\hline FBS & $0.5 \%(\mathrm{v} / \mathrm{v})$ \\
\hline Activin A & $100 \mathrm{ng} / \mathrm{ml}$ \\
\hline Glutamax $(\mathrm{c}=200 \mathrm{mM})$ & $1 \%(\mathrm{v} / \mathrm{v})(\mathrm{c}=2 \mathrm{mM})$ \\
\hline Gentamycin $(\mathrm{c}=10 \mathrm{mg} / \mathrm{ml}), 200 \mathrm{x}$ & $0.5 \%(\mathrm{v} / \mathrm{v})(\mathrm{c}=50 \mu \mathrm{g} / \mathrm{ml})$ \\
\hline
\end{tabular}

Table 25: Medium one of Approach four (M4.1)

\begin{tabular}{|l|r|}
\hline \multicolumn{1}{|c|}{ Component } & \multicolumn{1}{|c|}{ Final Concentration } \\
\hline RPMI 1640 & $97.5 \%(\mathrm{v} / \mathrm{v})$ \\
\hline B27 & $2 \%(\mathrm{v} / \mathrm{v})$ \\
\hline Activin A & $100 \mathrm{ng} / \mathrm{ml}$ \\
\hline Glutamax $(\mathrm{c}=200 \mathrm{mM})$ & $1 \%(\mathrm{v} / \mathrm{v})(\mathrm{c}=2 \mathrm{mM})$ \\
\hline Gentamycin $(\mathrm{c}=10 \mathrm{mg} / \mathrm{ml}), 200 \mathrm{x}$ & $0.5 \%(\mathrm{v} / \mathrm{v})(\mathrm{c}=50 \mu \mathrm{g} / \mathrm{ml})$ \\
\hline
\end{tabular}

Table 26: Medium one of Approach four (M4.1)

\begin{tabular}{|l|r|}
\hline \multicolumn{1}{|c|}{ Component } & \multicolumn{1}{c|}{ Final Concentration } \\
\hline RPMI 1640 & $97.5 \%(\mathrm{v} / \mathrm{v})$ \\
\hline B27 & $2 \%(\mathrm{v} / \mathrm{v})$ \\
\hline BMP4 & $20 \mathrm{ng} / \mathrm{ml}$ \\
\hline bFGF & $10 \mathrm{ng} / \mathrm{ml}$ \\
\hline Glutamax $(\mathrm{c}=200 \mathrm{mM})$ & $1 \%(\mathrm{v} / \mathrm{v})(\mathrm{c}=2 \mathrm{mM})$ \\
\hline Gentamycin $(\mathrm{c}=10 \mathrm{mg} / \mathrm{ml}), 200 \mathrm{x}$ & $0.5 \%(\mathrm{v} / \mathrm{v})(\mathrm{c}=50 \mu \mathrm{g} / \mathrm{ml})$ \\
\hline
\end{tabular}

Table 27: Medium one of Approach five (M5.1)

\begin{tabular}{|l|r|}
\hline \multicolumn{1}{|c|}{ Component } & \multicolumn{1}{c|}{ Final Concentration } \\
\hline RPMI 1640 & $97.5 \%(\mathrm{v} / \mathrm{v})$ \\
\hline B27 & $2 \%(\mathrm{v} / \mathrm{v})$ \\
\hline bFGF & $20 \mathrm{ng} / \mathrm{ml}$ \\
\hline BMP4 & $10 \mathrm{ng} / \mathrm{ml}$ \\
\hline Ly294002 & $1 \mu \mathrm{M}$ \\
\hline Activin A & $100 \mathrm{ng} / \mathrm{ml}$ \\
\hline Glutamax $(c=200 \mathrm{mM})$ & $1 \%(\mathrm{v} / \mathrm{v})(\mathrm{c}=2 \mathrm{mM})$ \\
\hline Gentamycin $(c=10 \mathrm{mg} / \mathrm{ml}), 200 \mathrm{x}$ & $0.5 \%(\mathrm{v} / \mathrm{v})(\mathrm{c}=50 \mu \mathrm{g} / \mathrm{ml})$ \\
\hline
\end{tabular}


Table 28: Medium for embryoid body formation (EB-Medium)

\begin{tabular}{|l|r|}
\hline \multicolumn{1}{|c|}{ Component } & \multicolumn{1}{|c|}{ Final Concentration } \\
\hline DMEM/F12 & $78.5 \%(\mathrm{v} / \mathrm{v})$ \\
\hline Serum Replacement & $20 \%(\mathrm{v} / \mathrm{v})$ \\
\hline L-Glutamine $(\mathrm{c}=200 \mathrm{mM})$ & $1 \%(\mathrm{v} / \mathrm{v})(\mathrm{c}=2 \mathrm{mM})$ \\
\hline Beta-Mercaptoethanol & $0,1 \mathrm{mM}$ \\
\hline Gentamycin $(\mathrm{c}=10 \mathrm{mg} / \mathrm{ml}), 200 \mathrm{x}$ & $0.5 \%(\mathrm{v} / \mathrm{v})(\mathrm{c}=50 \mu \mathrm{g} / \mathrm{ml})$ \\
\hline
\end{tabular}

\subsubsection{Polymerase chain reaction (PCR) primers and temperature profile}

Table 29: PCR Primers

\begin{tabular}{|c|c|c|c|c|c|}
\hline $\begin{array}{c}\text { Germinal } \\
\text { sheet }\end{array}$ & Primer & $\begin{array}{c}\text { Orientat } \\
\text { ion }\end{array}$ & Sequence & $\begin{array}{l}\mathrm{TM} \\
{\left[{ }^{\circ} \mathrm{C}\right]}\end{array}$ & $\begin{array}{c}\text { Product Size } \\
\text { [bp] }\end{array}$ \\
\hline \multirow[t]{4}{*}{ Pluripotent } & \multirow[t]{2}{*}{ Oct-4 } & forward & $\begin{array}{l}\text { CCCTGGTGCCGT } \\
\text { GAAGCTGG }\end{array}$ & 65.85 & \multirow[t]{2}{*}{180} \\
\hline & & reverse & $\begin{array}{l}\text { ACCTTCCCAAATA } \\
\text { GAACCCCCAGGG }\end{array}$ & 65.90 & \\
\hline & \multirow[t]{2}{*}{ Nanog } & forward & $\begin{array}{l}\text { AGGAAGACAAGG } \\
\text { TCCCGGTCAA }\end{array}$ & 63.29 & \multirow[t]{2}{*}{256} \\
\hline & & reverse & $\begin{array}{l}\text { GGTGCTGAGGCC } \\
\text { TTCTGCGT }\end{array}$ & 65,20 & \\
\hline \multirow[t]{4}{*}{ Ectoderm } & \multirow[t]{2}{*}{ Neurofilament } & forward & $\begin{array}{l}\text { ACGAGGTGTCCG } \\
\text { AGAGCCGT }\end{array}$ & 65.49 & \multirow[t]{2}{*}{282} \\
\hline & & reverse & $\begin{array}{l}\text { CCTCGCCTTCCA } \\
\text { AGAGTTTCCTGT }\end{array}$ & 64.65 & \\
\hline & \multirow[t]{2}{*}{ Beta-III Tubulin } & forward & $\begin{array}{l}\text { GCGGGGCCGCG } \\
\text { GCTATAA }\end{array}$ & 65.31 & \multirow[t]{2}{*}{172} \\
\hline & & reverse & $\begin{array}{l}\text { GACTTCCCAGAA } \\
\text { CTTGGCCCCGA }\end{array}$ & 66.48 & \\
\hline \multirow[t]{2}{*}{ Mesoderm } & \multirow[t]{2}{*}{ GATA2 } & forward & $\begin{array}{l}\text { ACGCCCATCCAC } \\
\text { СССТССТC }\end{array}$ & 66.01 & \multirow[t]{2}{*}{285} \\
\hline & & reverse & $\begin{array}{l}\text { CCTGGGCAGCAG } \\
\text { TCAGGTGC }\end{array}$ & 65.83 & \\
\hline
\end{tabular}




\begin{tabular}{|l|l|l|l|l|l|}
\hline Endoderm & AFP & forward & $\begin{array}{l}\text { GCCCACTCCAGC } \\
\text { ATCGATCCC }\end{array}$ & 65.21 & 235 \\
\cline { 3 - 5 } & & reverse & $\begin{array}{l}\text { TGTTGCTGCCTT } \\
\text { TGTTTGGAAGCA }\end{array}$ & 64.46 & \\
\cline { 3 - 5 } & & & & \\
\hline
\end{tabular}

Table 30: Temperature Profile $\left[{ }^{\circ} \mathrm{C}\right]$

\begin{tabular}{|c|c|c|}
\hline Temperature $\left[{ }^{\circ} \mathbf{C}\right]$ & $\begin{array}{c}\text { Time } \\
\text { [seconds] }\end{array}$ & Number of cycles \\
\hline 94 & 180 & 1 \\
\hline 94 & 30 & 35 \\
\hline 58 & 45 & \\
\hline 72 & 45 & 1 \\
\hline 72 & 600 & - \\
\hline 4 & Forever & \\
\hline
\end{tabular}




\subsection{Methods}

\subsubsection{Preparation, culture and inactivation of mouse embryonic fibroblasts}

\subsubsection{Culture of MEF}

Mouse embryonic fibroblasts (MEF) from CF-1 mice at day 13 to 14 of pregnancy were provided by the group of Dr. Fichtner / Dr. Eckert, MDC, Berlin-Buch. The MEF were cultured in an incubator at $37^{\circ} \mathrm{C}$ in a $5 \% \mathrm{CO}_{2}$ atmosphere. MEF - Medium was changed every two to three days. Once cultures reached about 90 to $95 \%$ confluence, the medium was aspirated, the cells were washed once with PBS and then incubated for 5 minutes with a pre-warmed trypsin-EDTA solution at $37^{\circ} \mathrm{C}$. Then the digestion was stopped by addition of MEF - medium and the non-adherent cells were spun down for 5 minutes at $300 \mathrm{~g}$. After that the cells were resuspended in MEF Medium, counted and inoculated in T175 culture flasks at a splitting ratio of 1:4.

\subsubsection{Culture of human foreskin fibroblasts}

Human foreskin fibroblasts (HFF) were cultured in an incubator at $37^{\circ} \mathrm{C}$ in a $5 \% \mathrm{CO}_{2}$ atmosphere. The medium was changed every 48 to 72 hours. Once cultures reached about $100 \%$ confluence and the cells showed a spindle like shape, the culture was once washed with PBS and then incubated for about 5 minutes with pre-warmed trypsin-EDTA solution at $37^{\circ} \mathrm{C}$. The digestion was stopped by addition of HFF medium and the cells were spun down for 5 minutes at $300 \mathrm{~g}$. After that the cells were resuspended, counted and inoculated in culture flasks at a split ratio of $1: 4$ to $1: 6$. 


\subsubsection{Inactivation of MEF and HFF}

Mouse embryonic fibroblasts were cultured and proliferated until the $4^{\text {th }}$ passage. HFF were used until the $40^{\text {th }}$ passage. Then cells were treated with trypsin-EDTA to detach them from the culture flasks and re-suspended in MEF medium. The cells were counted using a hemocytometer and inactivated by exposure to 30 Gray by a $\mathrm{Y}$ - radiation source. After inactivation cells were either used immediately for the coculture with human embryonic stem cells, or they were cryopreserved for later use.

\subsubsection{Culture of human embryonic stem cells in co-culture with MEF or HFF}

\subsubsection{Preparation of IVF-dishes for the culture of human embryonic stem cells}

The coculture of $\mathrm{hESC}$ and MEF was carried out in in vitro fertilization (IVF) dishes. At least 24 hours prior to hESC transfer, IVF dishes were pre-coated with a $0.1 \%$ gelatine solution for 30 minutes at $37^{\circ} \mathrm{C}$. After this, the gelatine solution was aspirated and the plates were rinsed once with PBS. Then $1 \mathrm{ml}$ of MEF - medium was added to the center well and $1 \mathrm{ml}$ of the resuspended MEF cells at a concentration of $7.6 \times 10^{4}$ cells per $\mathrm{ml}$ was added per well. This resulted in a feeder cell density of $4 \times 10^{4}$ per $\mathrm{cm}^{2}$. Additionally hESC medium was added to the peripheral ring of the dish. The feeder cell containing IVF dishes could be used for the coculture with hESC for about 7 to 10 days. For hESC medium composition see table 15. 


\subsubsection{Culture and passage of human embryonic stem cells in co-culture with mouse embryonic fibroblasts}

One hour prior to manual passage of hESC, the MEF medium of the prepared IVF dishes was removed and the plates were washed once with PBS. Then $2 \mathrm{ml}$ of prewarmed hESC medium were added. The hESC cultures to be passaged were checked for visible hallmarks of differentiation and undifferentiated hESC colonies of appropriate size were marked. To passage the hESC, preselected colonies were dissected into rectangles with an edge length of about $300 \mu \mathrm{m}$ by using a Stem Cell Cutting Tool under a stereo-microscope. The microscope table was equipped with a heating unit to ensure a constant temperature environment. After colonies had been divided by cutting as described, the pieces were slightly pushed to loosen up and get into solution. After that about 10 pieces were aspirated using the cutting tool, and firmly distributed in an IVF dish.

\subsubsection{Preparation of culture flasks for single cell enzymatic dissociation (SCED) culture}

About 30 minutes prior to HFF inoculation the culture flasks were pre-coated with a $0.1 \%$ gelatine solution at $37^{\circ} \mathrm{C}$. The solution was aspirated and the plates were rinsed once with PBS. The HFF were inoculated at a density of $5 \times 10^{4}$ cells per $\mathrm{cm}^{2}$ in SCED medium.

\subsubsection{Culture and passage of hESC in SCED culture}

The hESC were washed with PBS and incubated for 5 minutes with pre-warmed TrypLE ${ }^{\circledR}$ solution. The digestion was stopped by addition of medium for SCED cultures. The cells were spun down at $300 \mathrm{~g}$, the supernatant was aspirated, the cells were resuspended in Medium for SCED culture and split at a ratio of 1:4 to 1:10. Medium was changed every 48 to 72 hours. 


\subsubsection{Feeder-free culture of human embryonic stem cells}

The hESC cell line $\mathrm{H} 1$ adapted for feeder-free culture was maintained in mTeSR1 medium and routinely passaged according to the manufacturer's recommendations. Briefly cells were cultured in Matrigel coated 6 well dishes, and passaged using dispase solution every five to six days at a split ratio of about 1:4. A complete medium exchange was performed daily.

\subsubsection{Evaluation of the undifferentiated state of human embryonic stem cells}

To evaluate the undifferentiated state of cultured hESC, standard procedures including immune histochemistry and polymerase chain reaction (PCR) for the detection of markers for undifferentiated hESC as well as differentiated cells were performed.

PCR primer sequences and annealing temperatures are given in table 29, the PCR temperature profile is given in table 30 . Additionally $\mathrm{IHC}$ stainings were performed. Antibodies, host species, manufactures and used dilutions are given in table 11.

\subsubsection{Evaluation of the pluripotent potential of human embryonic stem cells}

\subsubsection{Evaluation of the pluripotent potential in conventional 2D culture}

To evaluate the potential of cultured hESC to differentiate into cells of the three germ layers, undifferentiated cells were cultured under conditions that support spontaneous differentiation for 17 days. Medium was changed every $48 \mathrm{~h}$ to $72 \mathrm{~h}$ and RNA was isolated after 5, 10 or 17 days. The supernatant was analyzed for differentiation markers (bHCG and AFP) as well as for glucose, lactate and LDH concentration. 


\subsubsection{Hepatic differentiation of human embryonic stem cells in conventional 2D cultures}

\subsubsection{Differentiation of stem cells in $2 \mathrm{D}$ cultures}

In order to establish a suitable protocol for hepatic differentiation of human embryonic stem cells, five different approaches recently published were compared and further investigated. Strategies and references for definitive endodermal (DE) commitment and hepatic maturation of committed cells are given in table 31 .

Table 31: Approaches for the hepatic differentiation of hESC

\begin{tabular}{|c|c|c|c|}
\hline $\begin{array}{c}\text { Approach } \\
\text { number }\end{array}$ & Reference & $\begin{array}{c}\text { Strategy for definitive } \\
\text { endodermal (DE) } \\
\text { commitment }\end{array}$ & $\begin{array}{l}\text { Strategy for the proliferation / } \\
\text { maturation of DE committed } \\
\text { cells }\end{array}$ \\
\hline 1 & Hay et al. $2007^{22}$ & $\begin{array}{l}8 \text { days in medium containing } \\
\text { - } \text { DMSO } \\
\text { - } \text { bFGF }\end{array}$ & \begin{tabular}{|c|c|}
10 days in medium containing \\
$\cdot$ & Insulin, Transferrin, Epidermal \\
& Growth Factor (EGF), \\
& Ascorbic Acid, \\
& Hydrocortisone, Bovine \\
& serum Albumin $\left(=\mathbf{H C M}^{\circledR}\right)$ \\
$\cdot$ & HGF \\
4 days in medium containing \\
$\cdot \quad \mathrm{HCM}^{\circledast}$ \\
$\cdot$ HGF \\
$\cdot$ OSM
\end{tabular} \\
\hline 2 & Hay et al. $2008^{68}$ & \begin{tabular}{|l} 
days in medium containing \\
- Activin A \\
- Wnt3a \\
- Sodium Butyrate \\
- B27
\end{tabular} & 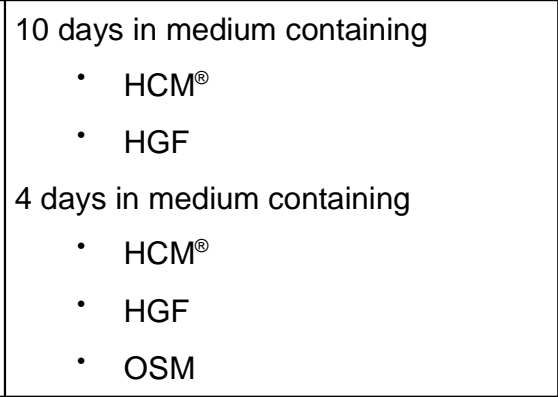 \\
\hline 3 & Agarwal et al. $2008{ }^{69}$ & \begin{tabular}{|l} 
days in medium containing \\
- Activin A \\
- FBS
\end{tabular} & \begin{tabular}{|l}
6 days in medium containing \\
- FGF 4 \\
- Knockout Serum Replacement
\end{tabular} \\
\hline
\end{tabular}




\begin{tabular}{|c|c|c|c|}
\hline & & \begin{tabular}{|l} 
days in medium containing \\
- Activin A \\
- Knockout Serum \\
Replacement
\end{tabular} & 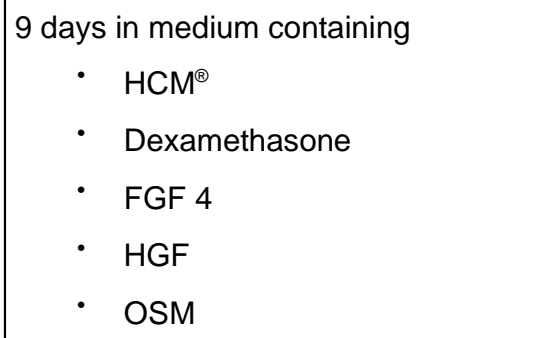 \\
\hline 4 & Si Tayeb et al. $2010^{70}$ & $\begin{array}{c}5 \text { days in medium containing } \\
\text { - } \quad \text { Activin A } \\
\text { - } \\
\text { B27 }\end{array}$ & 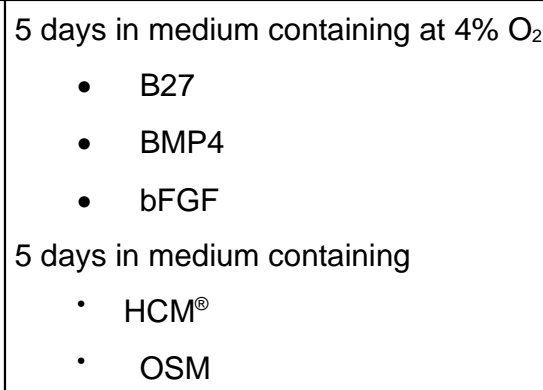 \\
\hline 5 & Touboul et al. $2010^{71}$ & \begin{tabular}{|l} 
days in medium containing \\
- bFGF \\
- BMP4 \\
- Ly294002 \\
- Activin A
\end{tabular} & \begin{tabular}{|c} 
days in medium containing \\
- FGF 10 \\
- B27 \\
2 days in medium containing \\
- FGF 10 \\
- SB431542 \\
- B27 \\
- Retinoic Acid \\
10 days in medium containing \\
- B27 \\
- Insulin \\
- Transferrin \\
- Monothioglycerol \\
- BSA \\
- FGF4 \\
- HGF \\
- EGF
\end{tabular} \\
\hline
\end{tabular}

The differentiation approaches were conducted as shown in table 32. A schematic overview of the strategies is given in table 31 . The medium compositions used in hepatic differentiation experiments are given in table 18 to table 27 . All approaches were based on a two-step procedure, including differentiation of the hESC into definitive endoderm (DE) in the first step, followed by maturation to functional hepatocytes in the second step. 
Table 32: Overview of hepatic differentiation experiments

\begin{tabular}{|c|c|c|c|c|c|}
\hline Day & Approach 1 & Approach 2 & Approach 3 & Approach 4 & Approach 5 \\
\hline-1 & $\begin{array}{l}100 \% \text { medium } \\
\text { change } \\
\left(\mathrm{MteSR}^{\mathrm{TM}} 1\right)\end{array}$ & $\begin{array}{l}100 \% \text { medium } \\
\text { change } \\
\left(\mathrm{MteSR}^{\mathrm{TM} 1}\right)\end{array}$ & $\begin{array}{l}100 \% \text { medium } \\
\text { change } \\
\left(\mathrm{MteSR}^{\mathrm{TM}} 1\right)\end{array}$ & $\begin{array}{l}100 \% \text { medium } \\
\text { change } \\
\left(\text { MteSR }^{\mathrm{TM}} 1\right)\end{array}$ & $\begin{array}{l}100 \% \text { medium } \\
\text { change } \\
\left(\mathrm{MteSR}^{\mathrm{TM}} 1\right)\end{array}$ \\
\hline 0 & $\begin{array}{l}\text { wash plates } 3 x \\
\text { with PBS, change } \\
\text { to Medium } 1.1\end{array}$ & $\begin{array}{l}\text { wash plates } 3 x \\
\text { with PBS, change } \\
\text { to Medium2.1 }\end{array}$ & $\begin{array}{l}\text { wash plates } 3 x \\
\text { with PBS, change } \\
\text { to Medium3.1 }\end{array}$ & $\begin{array}{l}\text { wash plates } 3 x \\
\text { with PBS, change } \\
\text { to Medium4.1 }\end{array}$ & $\begin{array}{l}\text { Precoated dishes } \\
\text { (FCS), add } \\
\text { medium } 5.1\end{array}$ \\
\hline 1 & $\begin{array}{l}100 \% \text { medium } \\
\text { change } \\
\text { (Medium } 1.1 \text { ) }\end{array}$ & $\begin{array}{l}100 \% \text { medium } \\
\text { change } \\
\text { (Medium2.1) }\end{array}$ & - & $\begin{array}{l}100 \% \text { medium } \\
\text { change } \\
\text { (Medium4.1) }\end{array}$ & $\begin{array}{l}100 \% \text { medium } \\
\text { change } \\
\text { (Medium5.1) }\end{array}$ \\
\hline 2 & $\begin{array}{l}100 \% \text { medium } \\
\text { change } \\
\text { (Medium } 1.1 \text { ) }\end{array}$ & $\begin{array}{l}100 \% \text { medium } \\
\text { change } \\
\text { (Medium2.1) }\end{array}$ & $\begin{array}{l}100 \% \text { medium } \\
\text { change } \\
(\text { Medium3.1) }\end{array}$ & $\begin{array}{l}100 \% \text { medium } \\
\text { change } \\
(\text { Medium4.1) }\end{array}$ & $\begin{array}{l}100 \% \text { medium } \\
\text { change } \\
\text { (Medium5.1) }\end{array}$ \\
\hline 3 & $\begin{array}{l}100 \% \text { medium } \\
\text { change } \\
\text { (Medium } 1.1 \text { ) }\end{array}$ & $\begin{array}{l}100 \% \text { medium } \\
\text { change (HCM2.1) }\end{array}$ & $\begin{array}{l}100 \% \text { medium } \\
\text { change } \\
\text { (Medium3.2) }\end{array}$ & $\begin{array}{l}100 \% \text { medium } \\
\text { change } \\
\text { (Medium4.1) }\end{array}$ & $\begin{array}{l}100 \% \text { medium } \\
\text { change } \\
\text { (Medium5.2) }\end{array}$ \\
\hline 4 & $\begin{array}{l}100 \% \text { medium } \\
\text { change } \\
\text { (Medium1.1) }\end{array}$ & $\begin{array}{l}100 \% \text { medium } \\
\text { change (HCM2.1) }\end{array}$ & - & $\begin{array}{l}100 \% \text { medium } \\
\text { change } \\
\text { (Medium4.1) }\end{array}$ & $\begin{array}{l}100 \% \text { medium } \\
\text { change } \\
\text { (Medium5.2) }\end{array}$ \\
\hline 5 & $\begin{array}{l}100 \% \text { medium } \\
\text { change } \\
\text { (Medium1.1) }\end{array}$ & $\begin{array}{l}100 \% \text { medium } \\
\text { change (HCM2.1) }\end{array}$ & $\begin{array}{l}\text { Remove } \\
\text { Medium3.2, } \\
\text { passage cells with } \\
\text { Trypsin, inoculate } \\
\text { cells on collagen } \\
1 \text { coated dishes, } \\
\text { culture in medium } \\
3.3\end{array}$ & $\begin{array}{l}\text { Remove Medium } \\
4.1, \text { add } \\
\text { medium4.2; } \\
\text { incubate at } 4 \% \\
\text { O2 }\end{array}$ & $\begin{array}{l}100 \% \text { medium } \\
\text { change } \\
\text { (Medium5.2) }\end{array}$ \\
\hline 6 & $\begin{array}{l}100 \% \text { medium } \\
\text { change } \\
\text { (Medium1.1) }\end{array}$ & $\begin{array}{l}100 \% \text { medium } \\
\text { change (HCM2.1) }\end{array}$ & - & - & $\begin{array}{l}100 \% \text { medium } \\
\text { change } \\
\text { (Medium5.3) }\end{array}$ \\
\hline 7 & $\begin{array}{l}100 \% \text { medium } \\
\text { change (HCM1.1) }\end{array}$ & - & $\begin{array}{l}100 \% \text { medium } \\
\text { change } \\
\text { (Medium3.3) }\end{array}$ & $\begin{array}{l}100 \% \text { medium } \\
\text { change } \\
\text { (Medium4.2) }\end{array}$ & $\begin{array}{l}100 \% \text { medium } \\
\text { change } \\
\text { (Medium5.3) }\end{array}$ \\
\hline 8 & $\begin{array}{l}100 \% \text { medium } \\
\text { change (HCM1.1) }\end{array}$ & $\begin{array}{l}100 \% \text { medium } \\
\text { change (HCM2.1) }\end{array}$ & - & - & $\begin{array}{l}100 \% \text { medium } \\
\text { change } \\
\text { (Medium5.4) }\end{array}$ \\
\hline 9 & $\begin{array}{l}100 \% \text { medium } \\
\text { change (HCM1.1) }\end{array}$ & - & $\begin{array}{l}100 \% \text { medium } \\
\text { change } \\
\text { (Medium3.3) }\end{array}$ & $\begin{array}{l}100 \% \text { medium } \\
\text { change } \\
\text { (Medium4.2) }\end{array}$ & - \\
\hline 10 & $\begin{array}{l}100 \% \text { medium } \\
\text { change (HCM1.1) }\end{array}$ & $\begin{array}{l}100 \% \text { medium } \\
\text { change (HCM2.1) }\end{array}$ & - & $\begin{array}{l}100 \% \text { medium } \\
\text { change (HCM4.1) }\end{array}$ & $\begin{array}{l}100 \% \text { medium } \\
\text { change }\end{array}$ \\
\hline
\end{tabular}




\begin{tabular}{|c|c|c|c|c|c|}
\hline & & & & & (Medium5.4) \\
\hline 11 & $\begin{array}{l}100 \% \text { medium } \\
\text { change (HCM1.1) }\end{array}$ & - & $\begin{array}{l}100 \% \text { medium } \\
\text { change (HCM3.1) }\end{array}$ & - & - \\
\hline 12 & - & $\begin{array}{l}100 \% \text { medium } \\
\text { change (HCM2.2) }\end{array}$ & - & $\begin{array}{l}100 \% \text { medium } \\
\text { change (HCM4.1) }\end{array}$ & $\begin{array}{l}100 \% \text { medium } \\
\text { change } \\
\text { (Medium5.4) }\end{array}$ \\
\hline 13 & $\begin{array}{l}100 \% \text { medium } \\
\text { change (HCM1.1) }\end{array}$ & - & $\begin{array}{l}100 \% \text { medium } \\
\text { change (HCM3.1) }\end{array}$ & - & - \\
\hline 14 & - & $\begin{array}{l}100 \% \text { medium } \\
\text { change (HCM2.2) }\end{array}$ & - & $\begin{array}{l}100 \% \text { medium } \\
\text { change (HCM4.1) }\end{array}$ & $\begin{array}{l}100 \% \text { medium } \\
\text { change } \\
\text { (Medium5.4) }\end{array}$ \\
\hline 15 & $\begin{array}{l}100 \% \text { medium } \\
\text { change (HCM1.1) }\end{array}$ & - & $\begin{array}{l}100 \% \text { medium } \\
\text { change (HCM3.1) }\end{array}$ & $\begin{array}{l}\text { End of } \\
\text { experiment }\end{array}$ & - \\
\hline 16 & - & $\begin{array}{l}\text { End of } \\
\text { experiment }\end{array}$ & - & & $\begin{array}{l}100 \% \text { medium } \\
\text { change } \\
\text { (Medium5.4) }\end{array}$ \\
\hline 17 & $\begin{array}{l}100 \% \text { medium } \\
\text { change (HCM1.2) }\end{array}$ & & $\begin{array}{l}100 \% \text { medium } \\
\text { change (HCM3.1) }\end{array}$ & & - \\
\hline 18 & - & & - & & $\begin{array}{l}\text { End of } \\
\text { experiment }\end{array}$ \\
\hline 19 & $\begin{array}{l}100 \% \text { medium } \\
\text { change (HCM1.2) }\end{array}$ & & $\begin{array}{l}100 \% \text { medium } \\
\text { change (HCM3.1) }\end{array}$ & & \\
\hline 20 & - & & $\begin{array}{l}\text { End of } \\
\text { experiment }\end{array}$ & & \\
\hline 21 & $\begin{array}{l}\text { End of } \\
\text { experiment }\end{array}$ & & & & \\
\hline
\end{tabular}

\section{End of DE differentiation}

End of experiment

Glucose and lactate measurements in samples from the supernatant were performed with a blood gas analyser. Lactate dehydrogenase (LDH), Alpha fetoprotein (AFP) and Human Chorionic Gonadotropin (beta HCG) were determined with an automated clinical chemistry analyzer. At the end of both differentiation steps, RNA was isolated for analysis of the differentiation outcome. Immune histochemistry was performed on cells after DE commitment and at the end of differentiation. Additionally cell counts using a Neubauer hematocytometer were performed. 


\subsubsection{Evaluation of the stability of lineage commitment}

To evaluate the stability of the lineage commitment after differentiation, cells were cultured under conditions that support either the maintenance of hepatic functions or spontaneous differentiation. RNA samples were collected after 0, 3, 7 and 14 days. The supernatants were analyzed for differentiation markers (bHCG and AFP), glucose, lactate and LDH concentrations.

\subsubsection{Bioreactors variants used for the hepatic differentiation of hESC in 3D culture}

\subsubsection{Bioreactor models}

For hepatic differentiation of hESC under 3D culture conditions a multi-compartment hollow-fiber bioreactor technology for high-density perfusion culture of cells ${ }^{72,73}$ was used. The bioreactor is composed of three independent hollow-fiber capillary membrane systems, which are interwoven thus offering decentralized gas and medium exchange. The cells are cultured within the cell compartment, which is nerved by oxygen and medium capillaries. Two of the capillary systems are made of hydrophilic microporous polyethersulfone (mPES, Membrana, Wuppertal) with a molecular weight cut-off of approximately MW 500,000. They serve for countercurrent medium perfusion. The third capillary system is made of hydrophobic multilaminate hollow fiber membrane oxygenation capillaries (MHF, Mitsubishi, Tokyo, Japan). By this way the supply with nutrients and oxygen of the cells within the cell compartment, as well as the removal of potentially toxic metabolites and carbon dioxide are ensured. The mass transfer into the cell compartment can by carried out via diffusion or laminar flow depending on the perfusion mode selected. In counter-current medium perfusion mode the in- and outlet of each medium capillary system are open. Thus medium exchange is carried out via diffusion. During crossflow perfusion mode the capillary outlet of the one, and the medium inlet of the other 
capillary system are mechanically blocked, thus mass exchange is mainly carried out via laminar flow.

This complex interwoven membrane system is potted in a two-component polyurethane housing. Direct access to the cell compartment (for cell inoculation, cell sample collection or direct substance administration) is enabled by open ending silicon capillaries.

Three differently sized variants of the bioreactor technology were used in this study.

The capillary system of the Analytical Scale bioreactor ( $4 \mathrm{ml}$ cell compartment volume) and the Lab Scale bioreactor (17.2 $\mathrm{ml}$ cell compartment volume) are made of multiple capillary layers each consisting of one type of capillaries (either medium or oxygenation capillaries). Medium and gas capillary layers are arranged in an alternating order.

The miniaturized bioreactor disposes of only four (miniaturized bioreactor with $0.4 \mathrm{ml}$ cell compartment volume) respectively two layers (miniaturized bioreactor with $0.2 \mathrm{ml}$ cell compartment volume).

An overview of the bioreactor models used for the hepatic differentiation of hESC is given in table 33 and figure 2.

Table 33: Bioreactor variants used in differentiation experiments

\begin{tabular}{|c|c|c|c|}
\hline & $\begin{array}{c}\text { Miniaturized } \\
\text { Bioreactor }\end{array}$ & $\begin{array}{c}\text { Analytical Scale } \\
\text { Bioreactor }\end{array}$ & $\begin{array}{c}\text { Lab Scale } \\
\text { Bioreactor }\end{array}$ \\
\hline $\begin{array}{c}\text { Volume cell } \\
\text { compartment [ml] }\end{array}$ & $0.2-0.4$ & 4.0 & 17.2 \\
\hline $\begin{array}{c}\text { capillary surface area } \\
{\left[\mathrm{cm}^{2} \text { ] }\right.}\end{array}$ & $28-56$ & 293 & 986 \\
\hline $\begin{array}{c}\text { Volume bioreactor } \\
\text { system [ml] }\end{array}$ & 12 & 20 & 40 \\
\hline
\end{tabular}



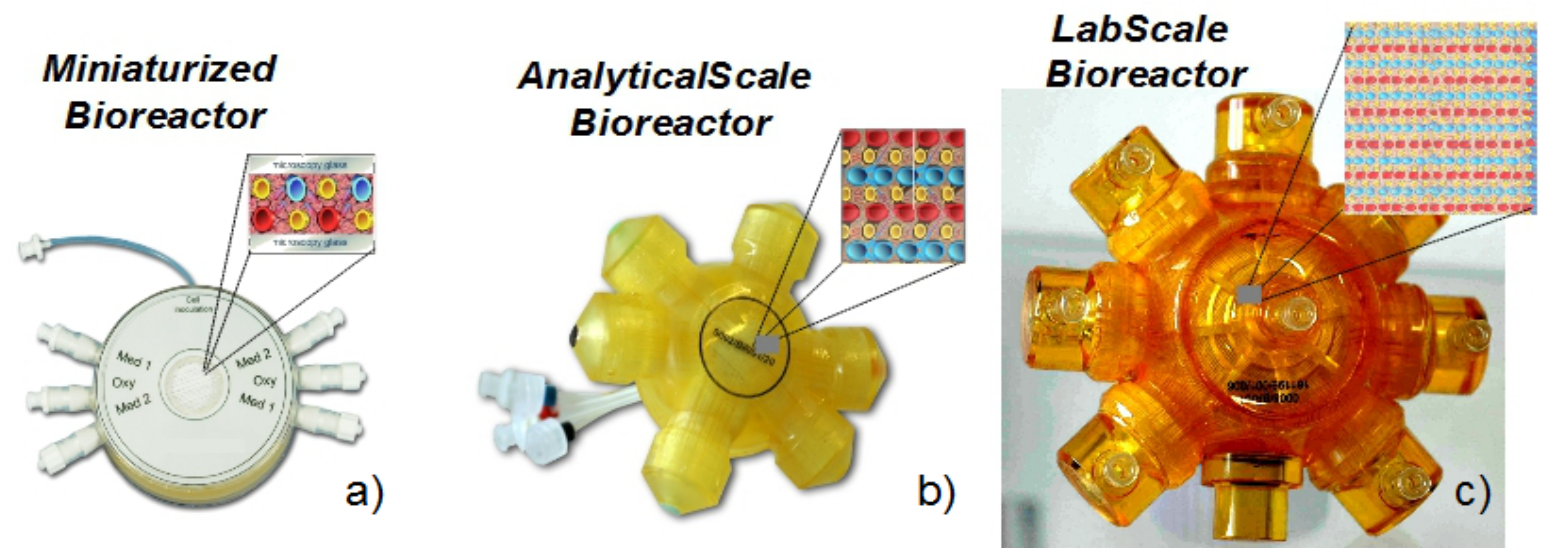

Figure 2: Bioreactor variants used in this study. a) Miniaturized bioreactor, the medium capillaries (red and blue) are arranged in an alternating way with the oxygenation capillaries (yellow). The capillary layers in Analytical Scale bioreactors (b) and Lab Scale bioreactors are either dedicated for medium supply (red and blue) or for oxygenation (yellow) as illustrated in the inserts.

\subsubsection{Bioreactor tubing system}

The bioreactor tubing system (Stem Cell Systems, Berlin) includes a bubble trap to avoid air insertion and a connection for sample removal as well as substance addition. A schematic overview of the bioreactor tubing system is given in figure 3 . The bioreactor and the tubing system were sterilized by formaldehyde treatment at least 7 days before use. 
Figure 3: Tubing System. Schematic illustration of the tubing system for bioreactor systems.



In addition gas supply, gas outlet tubes and sampling / injection ports are shown.

\subsubsection{Bioreactor perfusion system}

The bioreactors connected to their tubing system were operated in perfusion systems (Stem Cell Systems, Berlin) designed and built for the long term maintenance of bioreactor cultures. The device includes a processor controlled heating unit, a gas mixing unit and pressure controlled pumps for medium recirculation and feed (figure 3). During the experiment perfusion devices were connected via an integrated USB port to a PC and the perfusion parameters (pressure, temperature, pump speeds) were continuously recorded and graphically monitored using a stand-alone measurement program created with LabVIEW (National Instruments, Munich, Germany). The program also provides the opportunity for remote monitoring via the Internet. 


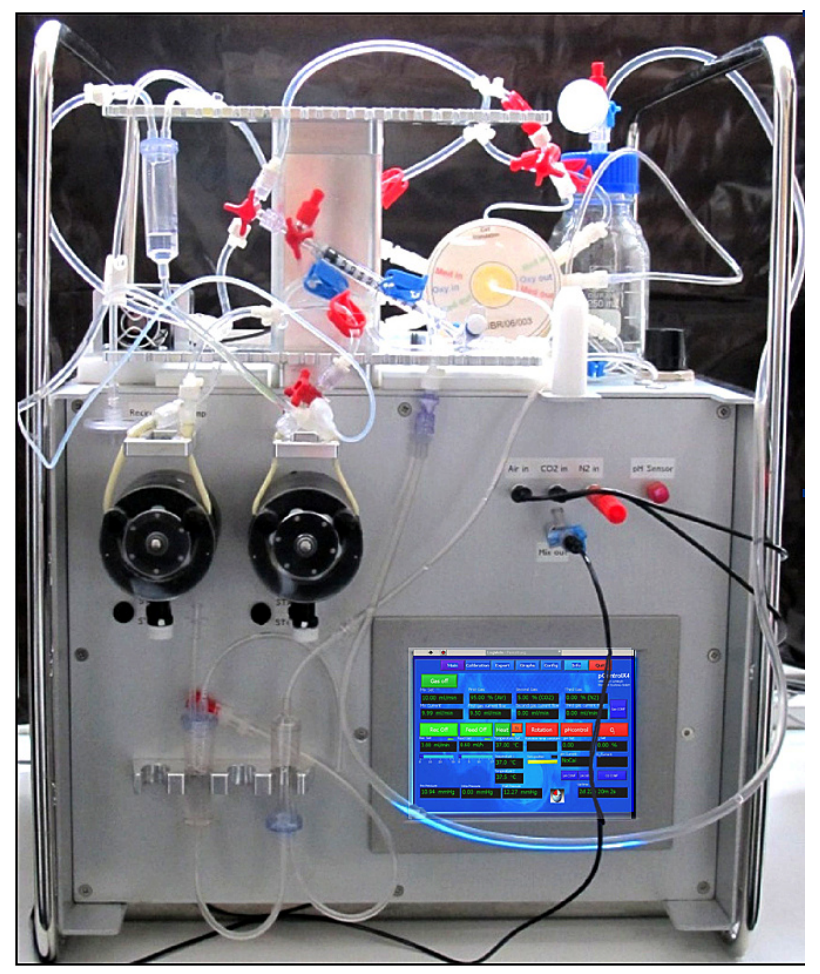

Figure 4: Perfusion device, equipped with a recirculation and fresh medium feed pump, a gas mixing unit, and a heating device. A bioreactor (in this picture a miniaturized bioreactor) is placed on top of the perfusion device. After attachment of the cover temperature, gas mixture supply, recirculation and feed pump rates are controlled by an integrated personal computer with touchscreen interface.

\subsubsection{Evaluation of the pluripotent potential of hESC in 3D bioreactor systems}

To evaluate the pluripotent potential of hESC under 3D culture conditions, undifferentiated feeder independent cells were cultured under conditions that support spontaneous differentiation for 17 days. Differentiation markers (bHCG and AFP) as well as glucose, lactate and LDH were measured. After bioreactor shutdown RNA samples were isolated and further processed for Real-Time PCR analysis. 


\subsubsection{Hepatic differentiation of human embryonic stem cells in 3D bioreactor systems}

Feeder independent and feeder dependent human embryonic stem cells were differentiated according to protocols established for the differentiation of hESC in conventional 2D culture. The protocols were adapted regarding the inoculated cell number and medium exchange to the requirements of different bioreactor models. An overview of the conducted bioreactor experiments is given in table 34 .

Table 34: Hepatic differentiation of hESC in bioreactors

\begin{tabular}{|c|c|c|c|c|c|}
\hline & \multicolumn{2}{|c|}{$\begin{array}{l}\text { Approaches with feeder } \\
\text { independent cells }\end{array}$} & \multicolumn{3}{|c|}{$\begin{array}{l}\text { Approaches with partial feeder } \\
\text { dependent cells }\end{array}$} \\
\hline & Approach 1 & Approach 2 & $\begin{array}{c}\text { Cellartis } \\
\text { Approach } 1\end{array}$ & $\begin{array}{c}\text { Cellartis } \\
\text { Approach } 2\end{array}$ & $\begin{array}{c}\text { Cellartis } \\
\text { Approach } 3\end{array}$ \\
\hline Reference & $\begin{array}{l}\text { Hay et al., } 2007 \\
22\end{array}$ & Hay et al., $2008{ }^{68}$ & $\begin{array}{l}\text { Brolén et al., } \\
2010^{67}\end{array}$ & $\begin{array}{l}\text { Brolén et al., } \\
2010^{67}\end{array}$ & $\begin{array}{l}\text { Brolén et al., } \\
201067\end{array}$ \\
\hline $\begin{array}{l}\text { hESC Cell } \\
\text { line }\end{array}$ & $\mathrm{H} 1$ & $\mathrm{H} 1$ & SA121 & SA121 & SA002 \\
\hline $\begin{array}{l}\text { Bioreactor } \\
\text { variants }\end{array}$ & $\begin{array}{c}\text { Miniaturized } \\
\text { Bioreactor } \\
(0.4 \mathrm{ml})\end{array}$ & $\begin{array}{c}\text { Miniaturized } \\
\text { Bioreactor }(0.4 \mathrm{ml})\end{array}$ & $\begin{array}{c}\text { Miniaturized } \\
\text { Bioreactor (0.2 } \\
\mathrm{ml})\end{array}$ & $\begin{array}{l}\text { Analytical } \\
\text { Scale } \\
\text { Bioreactor }\end{array}$ & $\begin{array}{l}\text { Lab Scale } \\
\text { Bioreactor }\end{array}$ \\
\hline $\begin{array}{l}\text { Number of } \\
\text { bioreactor } \\
\text { runs }\end{array}$ & 2 & 2 & 2 & 1 & 2 \\
\hline $\begin{array}{l}\text { Number } \\
\text { (vital) of } \\
\text { inoculated } \\
\text { cells } \\
\text { (passage) }\end{array}$ & 25E6 & $25 \mathrm{E} 6$ & 10E6 (p53) & 50E6 (p34) & $\begin{array}{c}\text { 8.5E7 (p74) - } \\
\text { hESC } \\
\text { 4.75E7 (p4) - } \\
\text { MEF }\end{array}$ \\
\hline $\begin{array}{l}\text { Experiment } \\
\text { duration }\end{array}$ & $21+3$ days & $17+3$ days & $\begin{array}{c}25 \text { days }+7 \\
\text { days }+5 \text { days }\end{array}$ & $30+3$ days & $46+3$ days \\
\hline
\end{tabular}

In all five approaches the cells were first committed to the definitive endodermal lineage, then proliferated and finally maturated. 
An overview of the factors used in each step is given in table 35 .

Table 35: Overview of factors used in various differentiation approaches

\begin{tabular}{|c|c|c|c|c|}
\hline & $\begin{array}{l}\text { Medium for } \\
\text { proliferation } \\
\text { of } \\
\text { undifferenti- } \\
\text { ated hESC }\end{array}$ & $\begin{array}{l}\text { Factors for DE } \\
\text { commitment }\end{array}$ & $\begin{array}{c}\text { Factors for } \\
\text { proliferation of DE } \\
\text { committed cells }\end{array}$ & $\begin{array}{l}\text { Factors for the } \\
\text { maturation of } \\
\text { differentiated } \\
\text { cells }\end{array}$ \\
\hline $\begin{array}{l}\text { Approach } 1 \\
\text { (feeder } \\
\text { independent) }\end{array}$ & $\begin{array}{l}\mathrm{mTeSR}^{\mathrm{TM}} 1 \\
\text { Medium }\end{array}$ & $\begin{array}{l}\text { - DMSO 1\% (v/v) } \\
\text { - bFGF } 4 \mathrm{ng} / \mathrm{ml} \\
\text { for } 8 \text { days }\end{array}$ & $\begin{array}{l}\text { Insulin, Transferrin, } \\
\text { Epidermal Growth } \\
\text { Factor (EGF), } \\
\text { Ascorbic Acid, } \\
\text { Hydrocortisone, } \\
\text { Bovine serum } \\
\text { Albumin } \\
\text { - HGF } 10 \mathrm{ng} / \mathrm{ml} \\
\text { for } 10 \text { days }\end{array}$ & $\begin{array}{l}\text { - Insulin, } \\
\text { Transferrin, } \\
\text { Epidermal Growth } \\
\text { Factor (EGF), } \\
\text { Ascorbic Acid, } \\
\text { Hydrocortisone, } \\
\text { Bovine serum } \\
\text { Albumin } \\
\text { - } \quad \text { HGF } 10 \mathrm{ng} / \mathrm{ml} \\
\text { - } \quad \text { Oncostatin M } \\
10 \mathrm{ng} / \mathrm{ml} \\
\text { for } 4 \text { days }\end{array}$ \\
\hline $\begin{array}{c}\text { Approach } 2 \\
\text { (feeder } \\
\text { independent) }\end{array}$ & $\begin{array}{l}\mathrm{mTeSR}^{\mathrm{TM}} 1 \\
\text { Medium }\end{array}$ & $\begin{array}{l}\text { - } \text { Activin A } \\
100 \mathrm{ng} / \mathrm{ml} \\
\text { - Wnt3a } 50 \mathrm{ng} / \mathrm{ml} \\
\text { - } \text { Sodium Butyrate } \\
1 \mu \mathrm{M} \\
\text { - } \mathrm{B} 27 \\
\text { for } 3 \text { days }\end{array}$ & $\begin{array}{l}\text { Insulin, Transferrin, } \\
\text { Epidermal Growth } \\
\text { Factor (EGF), } \\
\text { Ascorbic Acid, } \\
\text { Hydrocortisone, } \\
\text { Bovine serum } \\
\text { Albumin } \\
\text { - HGF } 10 \mathrm{ng} / \mathrm{ml} \\
\text { for } 10 \text { days }\end{array}$ & $\begin{array}{l}\text { - Insulin, } \\
\text { Transferrin, } \\
\text { Epidermal Growth } \\
\text { Factor (EGF), } \\
\text { Ascorbic Acid, } \\
\text { Hydrocortisone, } \\
\text { Bovine serum } \\
\text { Albumin } \\
\text { - } \text { HGF } 10 \mathrm{ng} / \mathrm{ml} \\
\text { - Oncostatin M } \\
10 \mathrm{ng} / \mathrm{ml} \\
\text { for } 4 \text { days }\end{array}$ \\
\hline $\begin{array}{c}\text { Cellartis } \\
\text { Approach } 1 \\
\text { (partial feeder } \\
\text { dependent) }\end{array}$ & $\begin{array}{l}\text { Standard } \\
\text { Medium }\end{array}$ & $\begin{array}{l}\text { - Activin A } \\
100 \mathrm{ng} / \mathrm{ml} \\
\text { - Sodium Butyrate } \\
1 \mu \mathrm{M} \\
\text { for } 24 \text { hours } \\
\text { - Activin A }\end{array}$ & $\begin{array}{l}\text { - } \text { aFGF } 50 \mathrm{ng} / \mathrm{ml} \\
\text { - } \text { bFGF } 5 \mathrm{ng} / \mathrm{ml} \\
\text { - } \text { BMP2 } 25 \mathrm{ng} / \mathrm{ml} \\
\text { - } \text { BMP4 } 100 \mathrm{ng} / \mathrm{ml} \\
\text { for } 7 \text { days } \\
\text { - } \\
\end{array}$ & $\begin{array}{l}\text { Insulin, } \\
\text { Transferrin, EGF, } \\
\text { Ascorbic Acid, } \\
\text { Hydrocortisone, } \\
\text { Bovin serum } \\
\text { Albumin } \\
\text { - Dexametasone }\end{array}$ \\
\hline
\end{tabular}




\begin{tabular}{|c|c|c|c|c|}
\hline & & $\begin{array}{l}100 \mathrm{ng} / \mathrm{ml} \\
\text { - } \quad \text { Sodium Butyrate } \\
0,5 \mu \mathrm{M} \\
\text { for } 6 \text { days }\end{array}$ & for 48 hours & 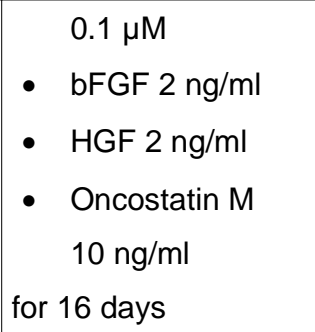 \\
\hline $\begin{array}{c}\text { Cellartis } \\
\text { Approach } 2 \\
\text { (partial feeder } \\
\text { dependent) }\end{array}$ & $\begin{array}{l}\text { Standard } \\
\text { Medium }\end{array}$ & 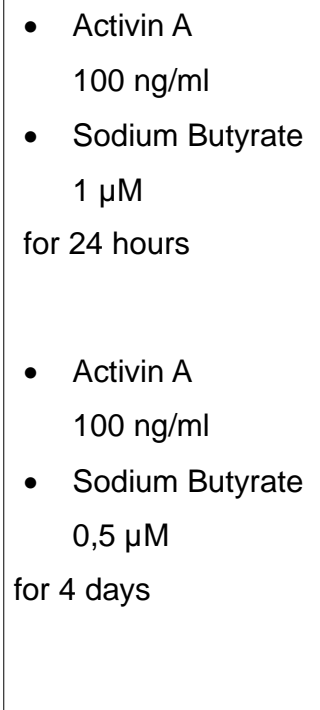 & $\begin{array}{l}\text { - } \text { aFGF } 50 \mathrm{ng} / \mathrm{ml} \\
\text { - } \text { bFGF } 5 \mathrm{ng} / \mathrm{ml} \\
\text { - } \text { BMP2 } 25 \mathrm{ng} / \mathrm{ml} \\
\text { - } \text { BMP4 } 100 \mathrm{ng} / \mathrm{ml} \\
\text { for } 8 \text { days } \\
\text { - } \quad \text { Insulin, Transferrin, } \\
\text { EGF, Ascorbic Acid, } \\
\text { Hydrocortisone, Bovine } \\
\text { serum Albumin } \\
\text { - } \quad \text { bFGF } 2 \text { ng/ml } \\
\text { - HGF } 20 \mathrm{ng} / \mathrm{ml} \\
\text { for } 9 \text { days }\end{array}$ & $\begin{array}{l}\text { - Insulin, } \\
\text { Transferrin, EGF, } \\
\text { Ascorbic Acid, } \\
\text { Hydrocortisone, } \\
\text { Bovin serum } \\
\text { Albumin } \\
\text { - } \text { Dexametasone } \\
0.1 \mu \mathrm{M} \\
\text { - } \mathrm{bFGF} 2 \mathrm{ng} / \mathrm{ml} \\
\text { - } \mathrm{HGF} 2 \mathrm{ng} / \mathrm{ml} \\
\text { - Oncostatin M } \\
10 \mathrm{ng} / \mathrm{ml} \\
\text { for } 8 \text { days }\end{array}$ \\
\hline $\begin{array}{c}\text { Cellartis } \\
\text { Approach } 3 \\
\text { (partial feeder } \\
\text { dependent) }\end{array}$ & $\begin{array}{l}\text { Standard } \\
\text { Medium }\end{array}$ & 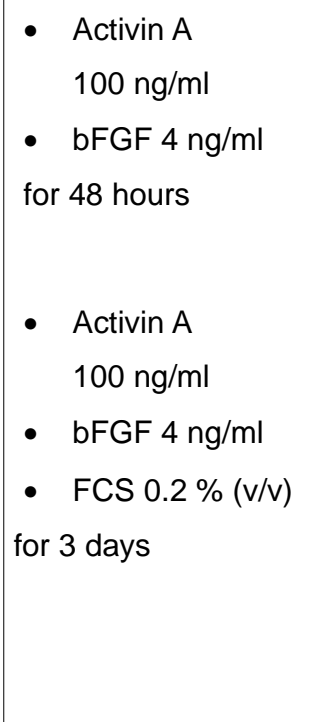 & $\begin{array}{l}\text { - } \text { aFGF } 100 \mathrm{ng} / \mathrm{ml} \\
\text { - } \text { bFGF } 5 \mathrm{ng} / \mathrm{ml} \\
\text { - } \text { BMP2 } 50 \mathrm{ng} / \mathrm{ml} \\
\text { - } \text { BMP4 } 200 \mathrm{ng} / \mathrm{ml} \\
\text { - } \text { FCS } 0.2 \%(\mathrm{v} / \mathrm{v}) \\
\text { for } 8 \text { days } \\
\text { - Insulin, Transferrin, } \\
\text { EGF, Ascorbic Acid, } \\
\text { Hydrocortisone, Bovine } \\
\text { serum Albumin } \\
\text { - } \quad \text { bFGF } 2 \mathrm{ng} / \mathrm{ml} \\
\text { - HGF } 20 \mathrm{ng} / \mathrm{ml} \\
\text { for } 9 \text { days }\end{array}$ & $\begin{array}{l}\text { - Insulin, } \\
\text { Transferrin, EGF, } \\
\text { Ascorbic Acid, } \\
\text { Hydrocortisone, } \\
\text { Bovin serum } \\
\text { Albumin } \\
\text { Dexametasone } \\
0.1 \mu \mathrm{M} \\
\text { bFGF } 2 \mathrm{ng} / \mathrm{ml} \\
\text { HGF } 2 \mathrm{ng} / \mathrm{ml} \\
\text { Oncostatin } \mathrm{M} \\
10 \mathrm{ng} / \mathrm{ml} \\
\text { for } 24 \text { days }\end{array}$ \\
\hline
\end{tabular}




\subsubsection{Determination of hepatocyte-specific functions}

\subsubsection{Cytochrome P450 (CYP) activity assay}

The determination of CYP activity was performed using a mixture of three different drugs that are transformed by different CYP450 isoenzymes. The specific isoenzyme for each drug and the final concentration in the medium are given in table 36 .

Table 36: Substrates for testing hepatocyte-specific functions

\begin{tabular}{|c|c|c|c|}
\hline Drug & $\begin{array}{c}\text { Converted by } \\
\text { isoenzyme }\end{array}$ & $\begin{array}{c}\text { Final concentration } \\
\text { in medium }\end{array}$ & Product \\
\hline Phenacetin & CYP1A1/1A2 & $26 \mu \mathrm{mol} / \mathrm{I}$ & Acetaminophen \\
\hline Midazolam & CYP3A4 & $3 \mu \mathrm{mol} / /$ & $1-\mathrm{OH}$-midazolam \\
\hline Diclofenac & CYP2C9 & $9 \mu \mathrm{mol} / \mathrm{I}$ & $4-\mathrm{OH}$-diclofenac \\
\hline
\end{tabular}

Immediately before starting a CYP experiment, the filter at the sample port was removed to avoid sticking of the lipophilic drugs to the membrane, and $1 \mathrm{ml}$ of culture medium was drawn from the circuit, which served as blank value for the analysis. During the incubation with the drugs the feed pump of the bioreactor circuit was switched off to provide a constant reaction volume. Samples $(200 \mu \mathrm{l})$ for analysis of substrates and their metabolites were taken 24 hours after drug administration. After each experiment the bioreactor circuit was rinsed with 15 to $50 \mathrm{ml}$ of culture medium (depending on the bioreactor circuit volume) and was then reset to the standard operation mode.

The analysis of substrate and metabolite concentrations was performed by LC-MS analysis by Pharmacelsus $\mathrm{GmbH}$, Saarbrücken. 


\subsubsection{Albumin ELISA}

An Albumin ELISA was performed using the Human Albumin ELISA Quantitation Set according to the manufacturer's instructions. The optimal horseradish peroxidase (HRP) detection antibody dilution for this kid was tested before and set to 1:50,000.

\subsubsection{Immunohistofluorescence}

\subsubsection{Embedding of bioreactor samples in paraffin blocks}

At the beginning of the preparation process samples from the bioreactor cell compartment were transferred into a 4\% paraformaldehyde solution for at least 10 minutes. This was followed by sequential application of differently concentrated ethanol solutions (50\%, 70\%, 85\%, 96\%, 100\%) in ascending order for 30 minutes respectively.

Afterwards the samples were incubated in Paraclear for at least 1 hour. Then the probes were transferred into preheated $\left(60^{\circ} \mathrm{C}\right)$ liquid paraffin. After 12 hours the samples were transferred into embedding forms and the liquid paraffin was cured by cooling.

The paraffin embedded bioreactor samples were cooled down in a $-20^{\circ} \mathrm{C}$ freezer for at least 12 hours to ensure proper rigidity of the paraffin.

Paraffin blocks were sliced into $2.5 \mu \mathrm{m}$ thick slides using a Microm HM355S microtome and attached to glass slides. To ensure proper adherence and dehydration glass slides were dried for at least 24 hours at room temperature or for 1 hour at $37^{\circ} \mathrm{C}$ in a dry incubator. Slides were stored at room temperature until further processing. 


\subsubsection{Preparation of slides for IHC}

To de-paraffinize the samples, the slides were transferred into Paraclear for at least 2 hours, followed by sequential application of ethanol solutions with various concentrations $(100 \%, 96 \%, 80 \%, 70 \%)$ in descending order over 5 minutes, respectively.

Afterwards, the slides were treated in a pressure cooker for 15 minutes (effective cooking time) in citrate buffer (the buffer composition is given in table 6).

After the buffer solution containing the slides had been cooled down in an ice bath, samples were transferred into a dark chamber with high humidity and blocking buffer. The blocking buffer composition is given in table 5 .

\subsubsection{Immune histochemical staining}

After 1 hour the blocking buffer was removed, and fresh blocking buffer containing primary antibodies was applied. The primary and secondary antibodies used are shown in table 7.

After 1 hour incubation the buffer was removed and the slides / wells were washed with PBS. Afterwards blocking buffer containing the secondary antibodies was added and incubated for 1 hour. This was followed by a washing step again using PBS. In the next step a DAPI solution was added and incubated for 10 minutes. After extensive washing the stained cells on the slides / wells were mounted using Aqua Polymount and covered using glass slides.

\subsubsection{Hematoxylin \& Eosin (H\&E) Staining}

Prior to the H\&E staining the slides were treated in Paraclear for about 2 hours. This was followed by sequential application of ethanol solutions with various concentrations (100\%, 96\%, 80\%, 70\%, 50\%) in descending order for 4 minutes (100\%) or 2 minutes (all other concentrations). 
After the ethanol treatment the slides were transferred into distilled water for a couple of seconds and afterwards transported into a hematoxylin solution. After 10 minutes the slides were transferred into cold tap water and incubated for 10 minutes. This was followed by a 2 minutes eosin treatment. The eosin stain was washed out by a 5 second bath in distilled water. After that the slides were again transferred into a $70 \%(\mathrm{v} / \mathrm{v})$ ethanol bath for about 5 seconds, followed by a $96 \%(\mathrm{v} / \mathrm{v})$ ethanol bath for about 30 seconds and finally a 100\% (v/v) ethanol bath for about 2 minutes. The slides were then incubated in paraclear for another 5 minutes. The tissue containing parts of the slides were then coated with Vitro-Clud and covered using glass cover slides.

\subsubsection{RNA Isolation, processing and analysis}

Cells were lysed by addition of $\mathrm{TRIZOL}^{\circledR}$ agent. The solution was either further processed or stored at $-20^{\circ} \mathrm{C}$. The isolation was performed using the PureLink ${ }^{\circledR}$ RNA Mini Kit according to manufacturer's instructions for $\mathrm{TRIZOL}^{\circledR}$ lysed samples. After accomplishment of the isolation protocol the RNA content was determined via NANODROP ${ }^{\circledR}$ spectrometry. Afterwards RNA was reverse transcribed using the High Capacity RNA-to-cDNA Kit with RNAse-Inhibitor according to the manufacturer's instructions. The cDNA was stored at $-80^{\circ} \mathrm{C}$ until it was analyzed via Real Time PCR.

\subsubsection{In vivo experiments}

\subsubsection{Evaluation of the tumorigenic potential}

The tumorigenic potential of feeder independent undifferentiated, definitive endodermal and fully hepatic differentiated hESC (differentiated according to the protocol published by Hay et al. $2008{ }^{68}$ ) was evaluated by in vivo transplantation experiments performed in cooperation with Dr. Klaus Eckert and Maria Stecklum (EPO GmbH, Berlin-Buch). The cells were gently detached and suspended in a 100 
$\mu \mathrm{l}$ mixture of Matrigel and cells in case of subcutaneous injection and a total volume of $40 \mu \mathrm{l}$ in case of intrasplenic injection. Various cell numbers were injected subcutaneously into NOD/SCID or NOD scid gamma (NSG) mice. After 120 days the tumor tissue was removed and the tumor size and weight were determined.

Subsequently samples were further processed for RNA analysis and histological analysis. Histological analysis was performed by S. Brunk (Institut für Tierpathologie, Berlin). An overview of the performed in vivo experiments is given in table 37 .

Table 37: Overview of performed in vivo experiments for the determination of the tumorigenic potential of undifferentiated, definitive endodermal committed and hepatic differentiated hESC.

\begin{tabular}{|l|c|c|c|c|c|c|}
\hline \multirow{4}{*}{} & \multicolumn{3}{|c|}{ NOD/SCID } & \multicolumn{3}{c|}{ NSG } \\
\cline { 2 - 7 } & $\begin{array}{c}\text { Number of } \\
\text { cells per } \\
\text { animal }\end{array}$ & $\begin{array}{c}\text { Number of } \\
\text { animals }\end{array}$ & $\begin{array}{c}\text { Side of } \\
\text { injection }\end{array}$ & $\begin{array}{c}\text { Number of } \\
\text { cells per } \\
\text { animal }\end{array}$ & $\begin{array}{c}\text { Number of } \\
\text { animals }\end{array}$ & $\begin{array}{c}\text { Side of } \\
\text { injection }\end{array}$ \\
\hline \multirow{2}{*}{$\begin{array}{l}\text { un- } \\
\text { differentiated } \\
\text { hESC }\end{array}$} & $1 \mathrm{E} 5$ & 9 & s.c. & $1 \mathrm{E} 5$ & 5 & s.c. \\
\cline { 2 - 7 } & $1 \mathrm{E} 6$ & 21 & s.c. & $1 \mathrm{E} 6$ & 14 & s.c. \\
\cline { 2 - 7 } & $1 \mathrm{E} 7$ & 9 & s.c. & $1 \mathrm{E} 7$ & 14 & s.c. \\
\cline { 2 - 7 } & $5 \mathrm{E} 5$ & 9 & i.s. & $5 \mathrm{E} 5$ & 5 & i.s. \\
\cline { 2 - 7 } & $1 \mathrm{E} 6$ & 3 & i.s. & $5 \mathrm{E} 6$ & 5 & i.s. \\
\cline { 2 - 7 } & $1 \mathrm{E} 7$ & 3 & i.s. & - & - & - \\
\hline \multirow{2}{*}{$\begin{array}{l}\text { Definitive } \\
\text { endodermal } \\
\text { committed } \\
\text { cells }\end{array}$} & $1 \mathrm{E} 5$ & 3 & s.c. & $1 \mathrm{E} 5$ & 5 & s.c. \\
\cline { 2 - 7 } & $1 \mathrm{E} 6$ & 3 & s.c. & $1 \mathrm{E} 6$ & 5 & s.c. \\
\hline \multirow{2}{*}{$\begin{array}{l}\text { Hepatic } \\
\text { differentiated } \\
\text { cells }\end{array}$} & - & - & - & $5 \mathrm{E} 5$ & 5 & i.s. \\
\cline { 2 - 7 } & $1 \mathrm{E} 5$ & 9 & s.c. & $1 \mathrm{E} 5$ & 2 & s.c. \\
\cline { 2 - 7 } & $5 \mathrm{E} 5$ & 9 & i.s. & $5 \mathrm{E} 5$ & 2 & s.c. \\
\hline
\end{tabular}

\subsubsection{Statistical evaluation}

The hepatic and spontaneous differentiation in conventional 2D culture has been performed three times $(n=3)$. The hepatic differentiation in 3D bioreactor cultures according to approach two and Cellartis approach one have been conducted twice $(n=2)$, the remaining bioreactor experiments were performed once $(n=1)$. The results are presented as means +/- standard deviation (SD) of data from the experiments. 
3. Results

\section{Results}

\subsection{Establishment of hESC culture, reduction of components of animal origin}

Three different human embryonic stem cells lines were used in this study. Culture conditions were continuously improved in regard of the reduction of animal components, and improvement of labor sensitivity and reproducibility.

\subsubsection{Feeder dependent culture of hESC}

The mouse embryonic fibroblast dependent human embryonic stem cell line SA002 and $\mathrm{H} 1$ were cultured according to previously established protocols. The quality of cells and their grade of differentiation were evaluated by marker expression (immunohistochemistry), gene expression (real-time PCR) and morphology. Undifferentiated hESC exhibit a typical and unique morphology. The cells grow in flat and homogenous colonies. The cells exhibit a high nucleus to cytoplasm ratio and lay tightly packed with prominent nucleoli and close cell-cell contacts (figure 5a).

Any deviation from these characteristics can be interpreted as sign of differentiation (figure 5b). 

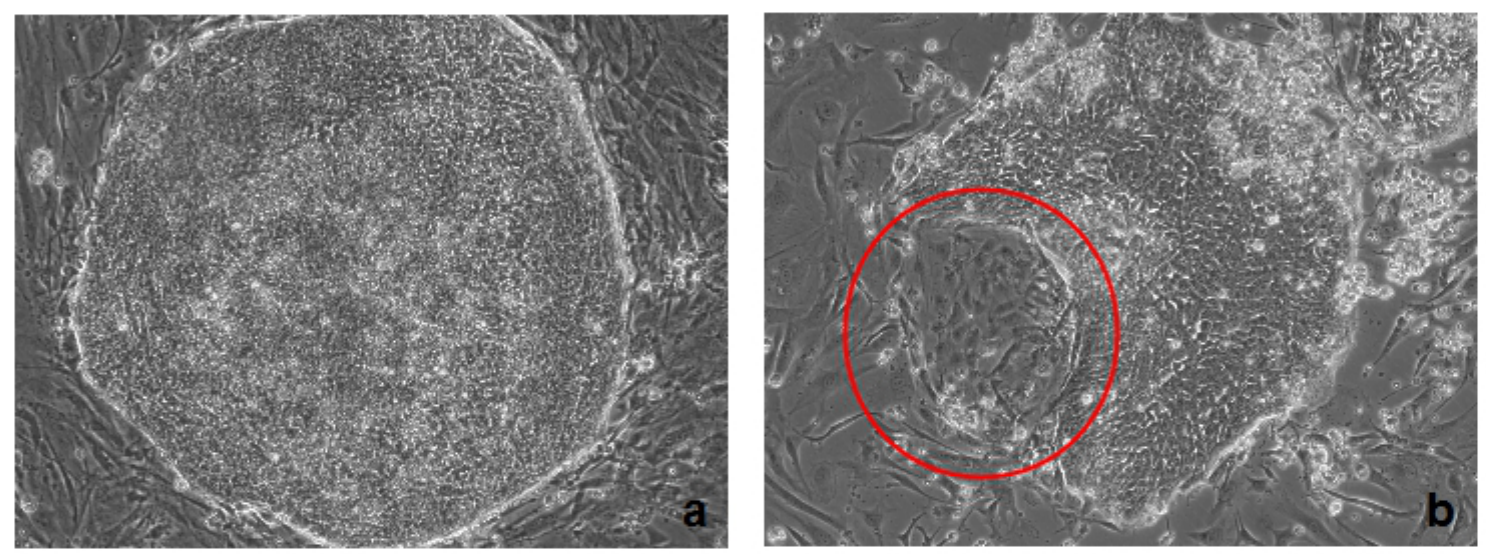

Figure 5: MEF dependent hESC; a) undifferentiated colony of hESC, b) colony of hESC with signs of differentiation (red circle), 100x total magnification

\subsubsection{Standard culture}

Half of the medium was exchanged by fresh medium every 24 hours. Feeder dependent hESC cultures that exhibited no signs of differentiation were cut into squares using a stem cell knife. The resulting pieces were gently detached from the culture dish and transferred into a new in vitro fertilization dish.

The hESC were cultured for more than 20 passages under the described culture conditions. The expression of markers indicating the pluripotent state were confirmed via immune cytochemistry and RT-PCR. The manual dissection of undifferentiated hESC colonies resulted in about 5 to 10 squares depending on size and quality of the cells. In average about 20 to 30 squares were harvested per plate. Differentiated areas were spared, resulting in a reduction of differentiated cells in the following passage. About 10 squares were transferred into a new in vitro fertilization dish. 


\subsubsection{Single Cell Enzymatic Dissociation (SCED) Culture}

In order to obtain larger cell numbers for bioreactor experiments the cells were detached enzymatically and transferred in gelatin coated standard culture flasks that had been inoculated with human foreskin fibroblasts 24 hours before. Cells were passaged every 6 to 8 days. In comparison to the co-culture with MEF, HFF induced a change in the growth patterns of hESC. The cells grew not as flat colonies on top of the (MEF) feeder layer, but within the HFF layer. Microscopic evaluation of the cell quality was therefore not possible. The SCED cultures were expanded for up to 5 passages showing no signs of differentiation as verified by immune cytochemistry and RT-PCR analysis.
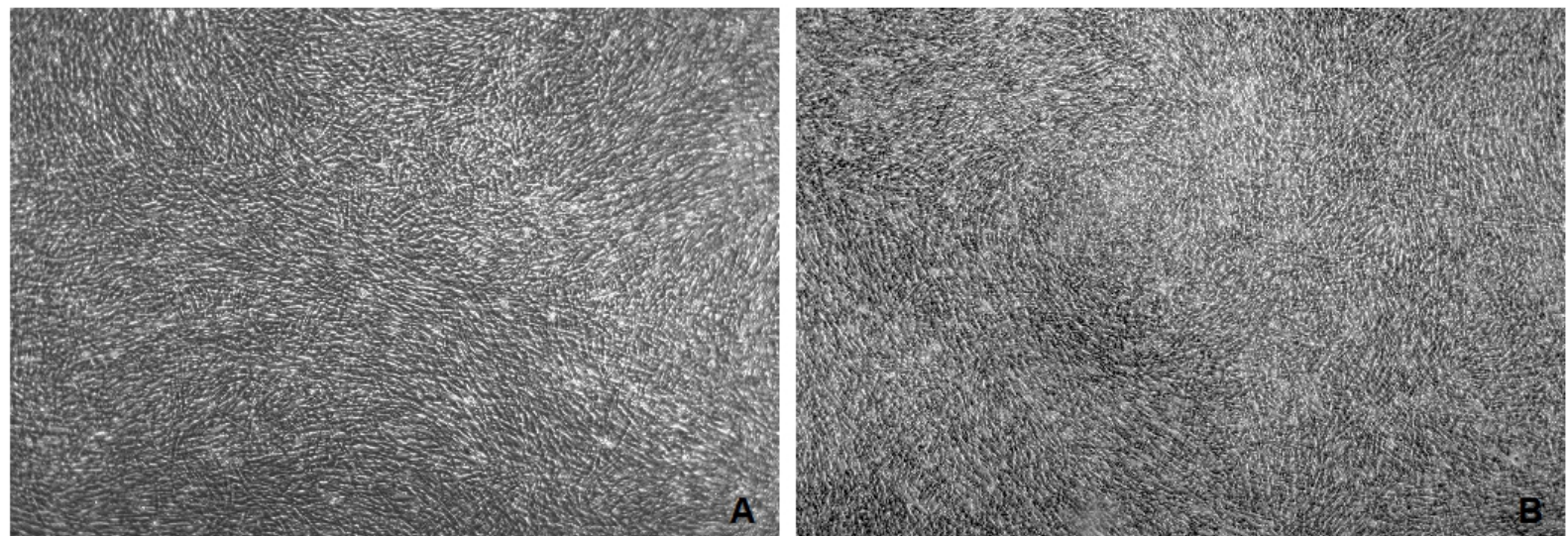

Figure 6: SCED culture, (A) culture one day after enzymatic passage, (B) SCED culture right before passage; $50 x$ total magnification

\subsubsection{Feeder independent culture of hESC}

In order to simplify the culture of hESC, to avoid (MEF) batch variation and to minimize components of animal origin in culture conditions the feeder independent culture of hESC was established. The culture of the feeder independent cell line $\mathrm{H} 1$ (WiCell Research Institute, Madison, WI, USA) was established according to the supplier's recommendations. 


\subsubsection{Standard culture}

Feeder independent hESC grown in $\mathrm{mTeSR}^{\mathrm{TM}} 1$ exhibited morphological characteristics similar to feeder dependent hESC. They possessed a prominent cell nucleus and a high nuclear to cytoplasm ratio. The cells within the colonies were tightly packed. The quality of hESC cultures was regularly evaluated by microscopic analysis of cell morphology, by real-time PCR and by immune cytochemistry. In figure 7 a representative colony stained for Oct-4 (7b), Nanog (7c) and SSEA4 (7f) is shown.
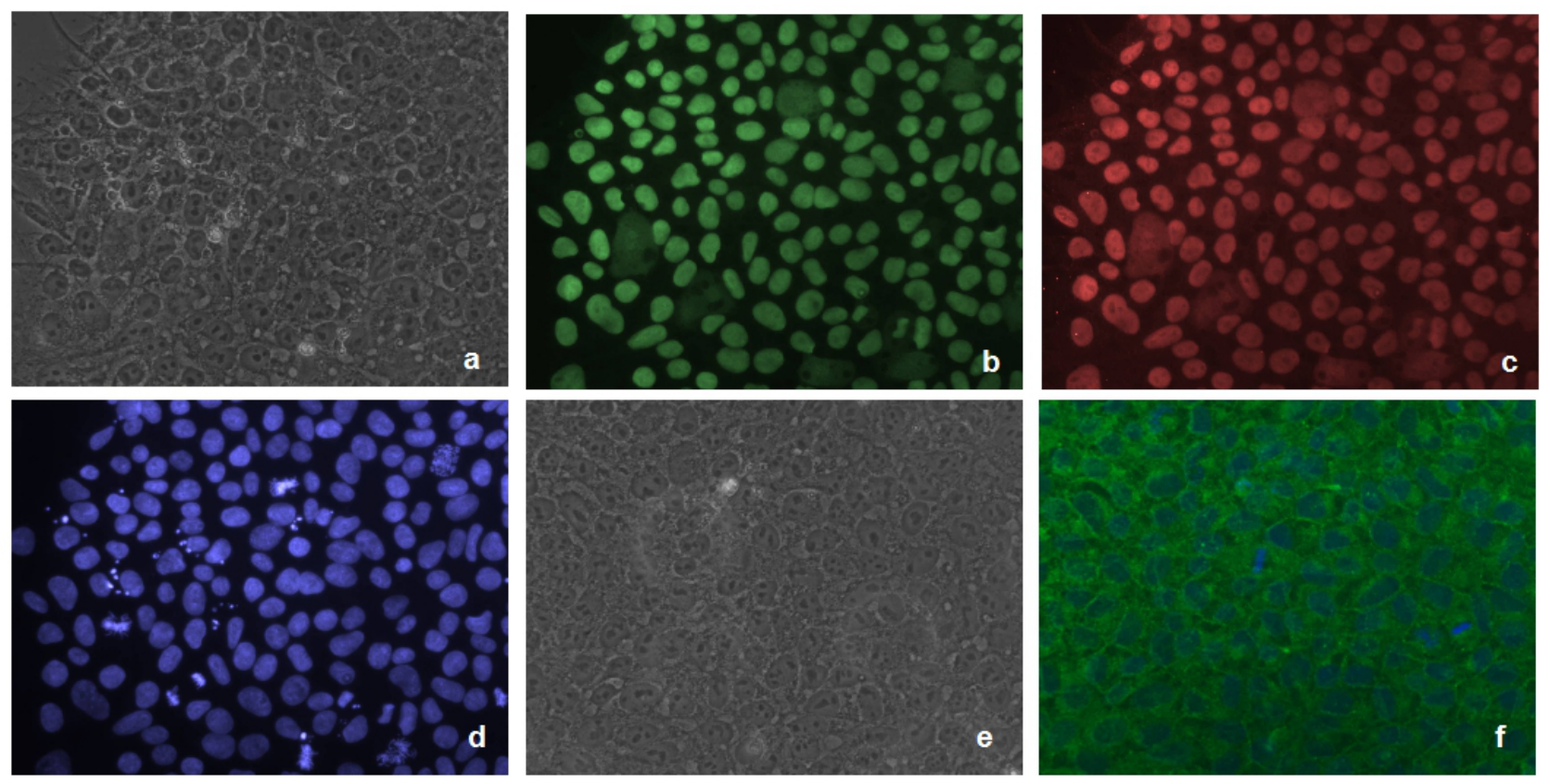

Figure 7: Immune cytochemical staining of undifferentiated hESC in conventional 2D culture; a) - d): hESC colony stained for Oct-4(b), Nanog(c), DAPI(d) and phase contrast picture (a); e) phase contrast picture of a hESC colony, f) same colony stained for SSEA4 (green) and DAPI (blue), 400x total magnification in all pictures.

A high expression of pluripotency markers Oct-4 and Nanog besides a weak expression of lineage specific markers (Neurofilament, AFP) was found in the reverse transcription (RT) PCR analysis (see table 38). No expression of GATAll was found in the samples analyzed. 
Table 38: Expression of pluripotency markers and lineage specific markers in undifferentiated feeder independent hESC (H1), “++" = strong expression, "(+)“ weak expression, "-" = absent expression

\begin{tabular}{|c|c|}
\hline PCR Product & Expression \\
\hline Oct-4 & ++ \\
\hline Nanog & ++ \\
\hline GATAll & - \\
\hline Neurofilament & $(+)$ \\
\hline AFP & $(+)$ \\
\hline
\end{tabular}

\subsubsection{Spontaneous in vitro differentiation in conventional 2D cultures}

In order to determine the potential of cultured stem cells to form cells of the three germ layers feeder independent hESC $(\mathrm{H} 1)$ were differentiated in conventional 2D cultures for 17 days using EB-Medium. Medium was changed every 48 to 72 hours and factors indicating differentiation (bHCG, AFP) were measured as well as glucose, lactate and lactate dehydrogenase (LDH). Additionally RNA samples were taken after 5, 9 and 17 days of differentiation and analyzed via real-time PCR. 

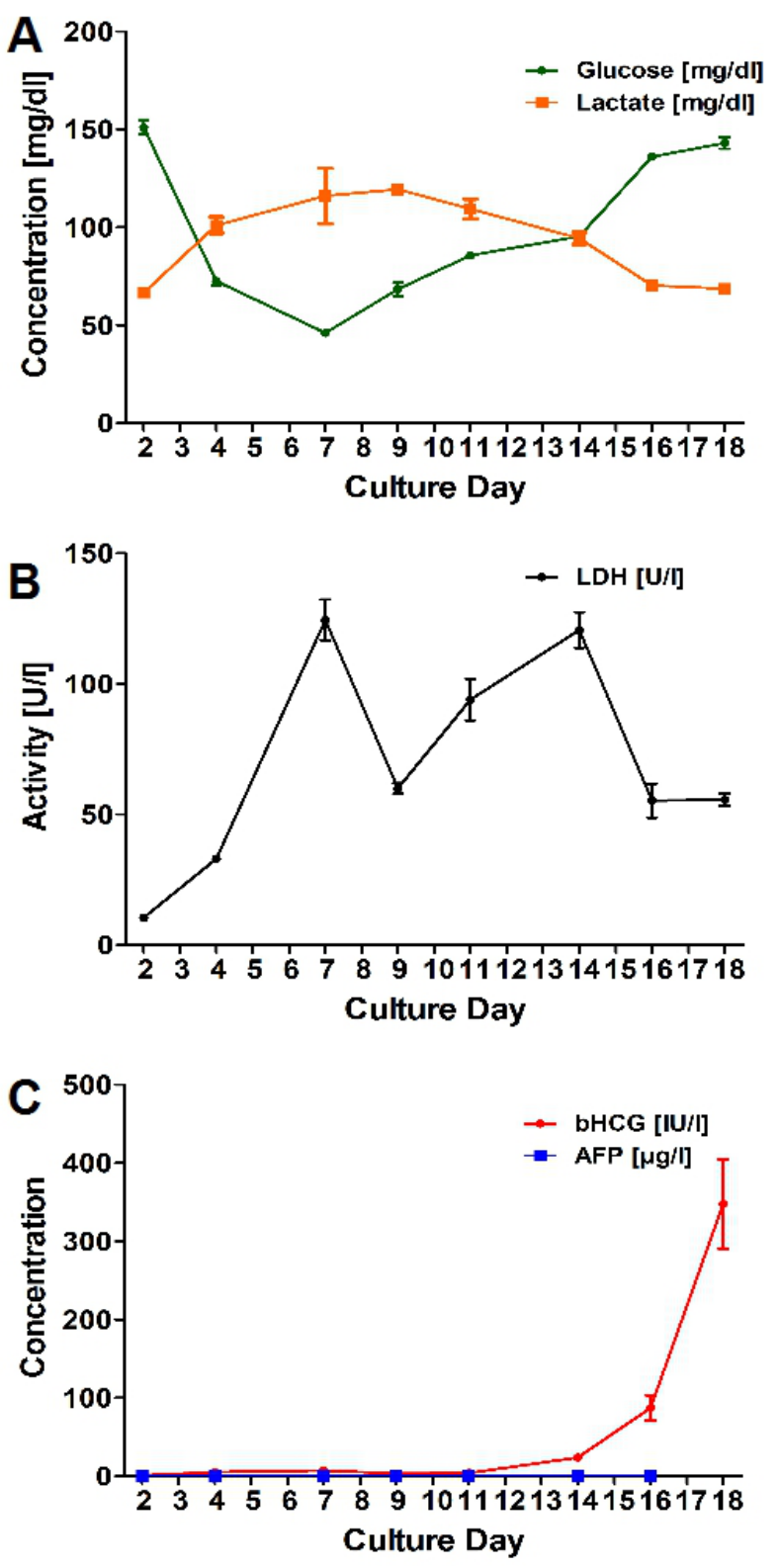

Figure 8: Time-course of glucose, lactate (A), LDH (B), bHCG and AFP (C) during spontaneous differentiation of hESC in $2 D$ culture $(n=3)$.

The time-course of metabolic activities, enzyme release and differentiation factor release are shown in figure 8 . The glucose consumption and lactate production increased until day 7 , indicating cell proliferation. This was followed by a decrease of metabolic activity to a level comparable to activities measured at day 2 .

The LDH concentration measured in the supernatant also increased until day 7 . The 
concentration remained at high levels.

The bHCG concentration remained at very low concentrations during the whole experiment. A strong increase in AFP concentration was seen from day 14 until the end of the experiment.

The RNA samples taken on day 5, 9 and 17 were reverse transcribed and the expression of genes for the three germ layers (AFP, Neurofilament and GATA II) as well as the expression of genes characterizing the undifferentiated state of hESC was analyzed. The expression was normalized to GAPDH. In figure 9 the fold expression change compared to undifferentiated hESC is shown.

The expression of markers indicating the pluripotent state of hESC (Oct-4 and Nanog) was already reduced after 5 days and remained stable over the duration of the experiment. The expression of the mesodermal marker GATA II was already strong on day 5 , increased to day 9 and slightly decreased until day 17 . The endodermal marker AFP was not induced after 5 days in spontaneous differentiation. The expression level increased continuously till day 17. A weak induction of the ectodermal marker neurofilament was found only at the end of the experiment. 


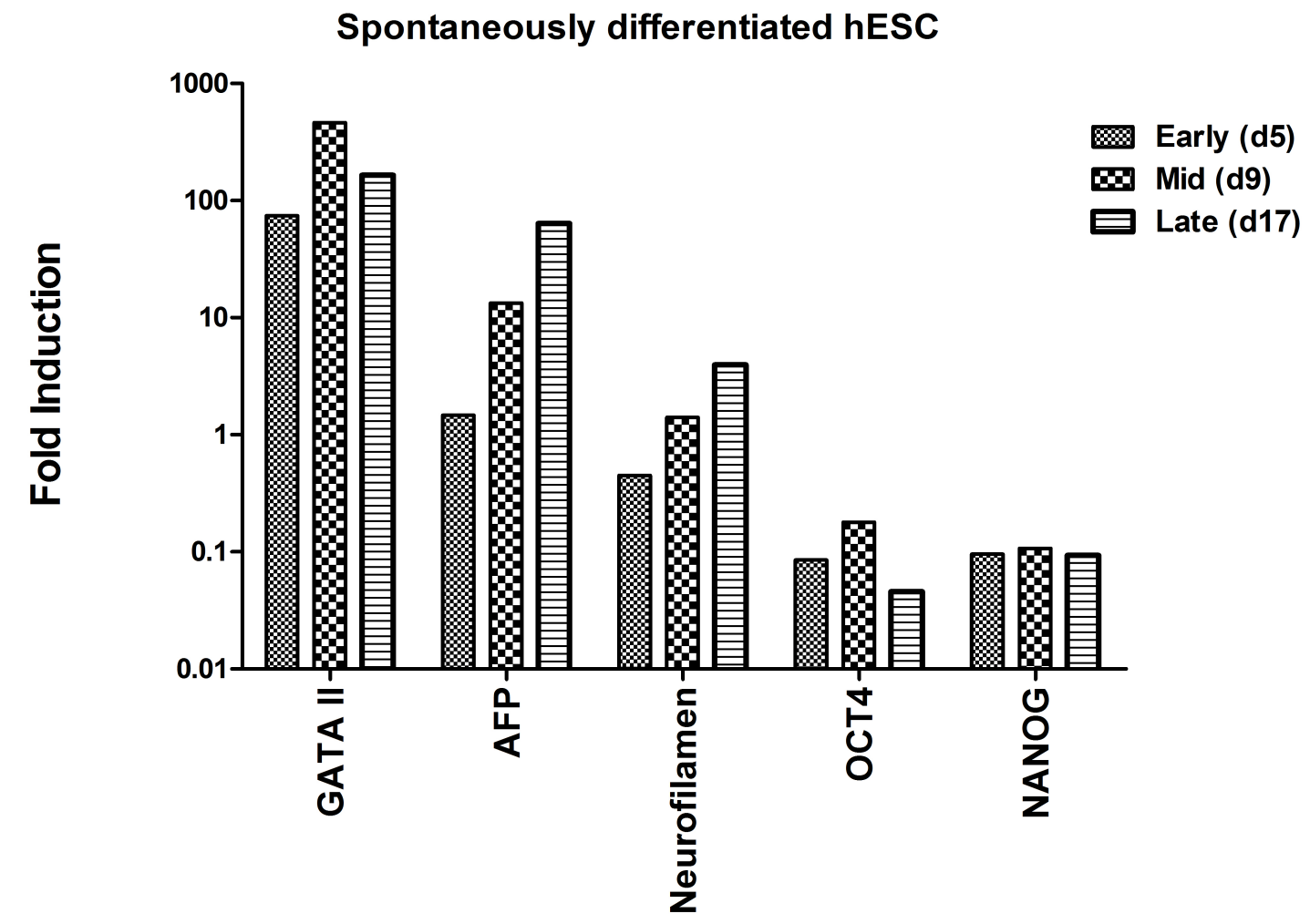

Figure 9: Fold expression of GATA II, AFP, Neurofilament, Oct-4 and Nanog in spontaneously differentiated hESC normalized to undifferentiated hESC $(=1)$ after 5 (Early), 9 (Mid) and 17 (Late) days in conventional 2D culture.

A change in morphological appearance was seen during the spontaneous differentiation (Figure 10). The experiment was started when the cultures were about $70 \%$ confluent. In the first phase of the experiment the cells formed a confluent cell layer, a dramatic change in cell morphology was not seen. Once the culture reached $100 \%$ confluence (at day 5), the cells tended to form colonies made of multiple layers of inhomogeneous cells. In addition larger cell aggregates formed that grew in size over time. Due to the high cell density morphological changes of the cells could not be detected after day 5 . 

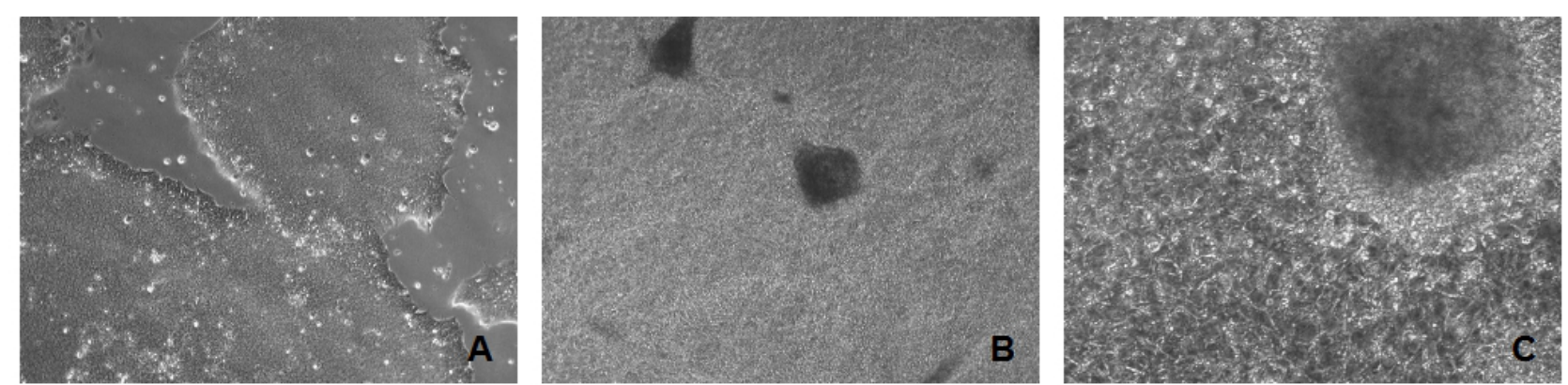

Figure 10: hESC, undifferentiated at $d 0(A)$ and after 17 days of spontaneous differentiation in conventional $2 \mathrm{D}$ culture, $\mathrm{A}$ and $\mathrm{B}: 100 \mathrm{x}$ total magnification, $\mathrm{C}: 320 \mathrm{x}$ total magnification.

\subsubsection{Spontaneous in vitro differentiation in 3D bioreactors}

In order to determine the potential of spontaneously differentiating hESC in 3D bioreactors, 25E6 undifferentiated feeder independent hESC $(\mathrm{H} 1)$ were inoculated in a miniaturized bioreactor model ( $0.4 \mathrm{ml}$ cell compartment volume). The cells were differentiated for 17 days, daily factors indicating differentiation (bHCG, AFP) as well as glucose, lactate and lactate dehydrogenase (LDH) were measured (Figure 11). The metabolic activity indicated by glucose consumption and lactate production was low during the experiment. A high concentration of LDH was seen during the first days, with a maximum concentration found on day 4 . During the whole experimental duration only low concentrations of HCG were measured, whereas the concentration of AFP was rising from day 11 on. At bioreactor shutdown RNA was isolated and further processed for Real-time PCR analysis. 

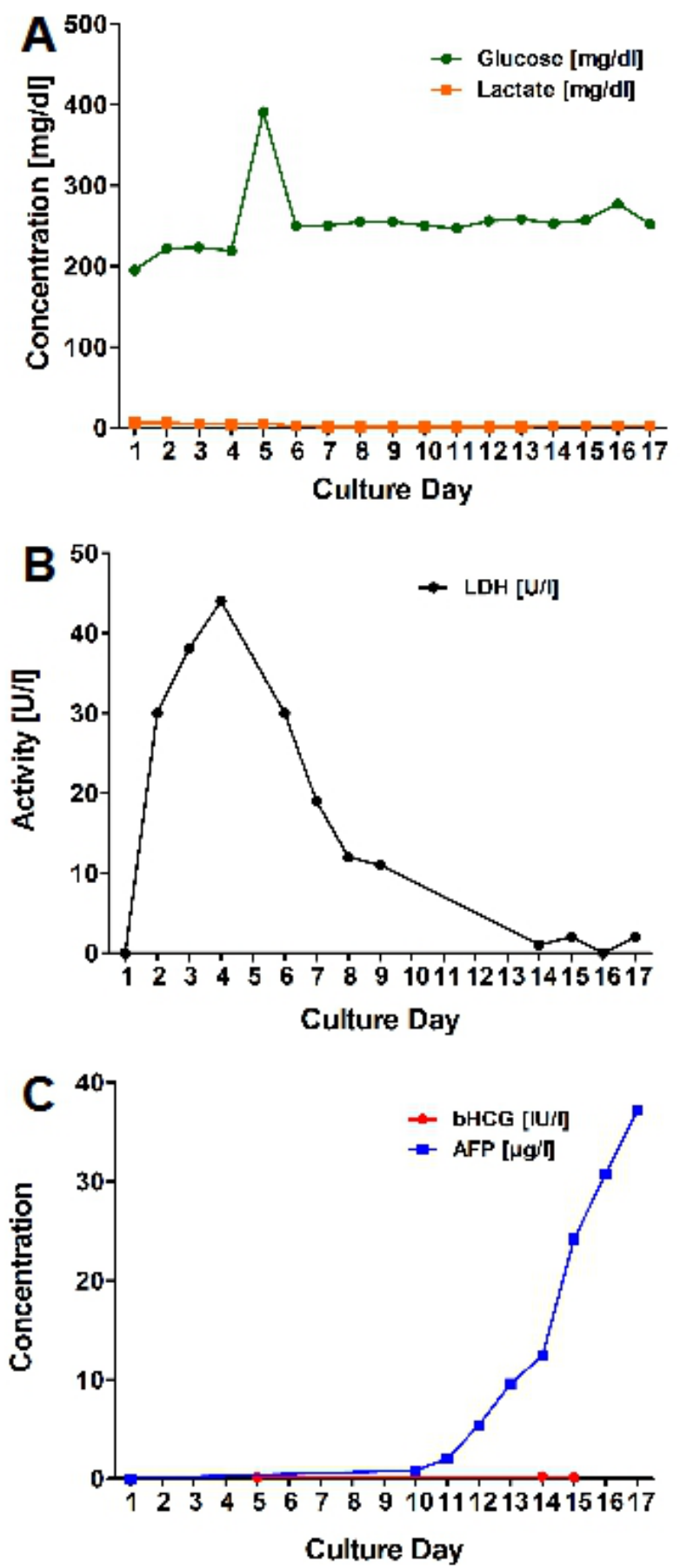

Figure 11: Time-course of glucose and lactate (A), LDH (B), bHCG and AFP (C) during spontaneous differentiation of hESC in a 3D bioreactor.

The RNA isolated after bioreactor shutdown were reverse transcribed and the expression of genes for the three germ layers (AFP, Neurofilament and GATA II), and 
of those characterizing the undifferentiated state of hESC (Oct-4, Nanog) and of endodermal / hepatocyte-specific genes (SOX7, SOX17, Albumin, Cyp 2D6, Cyp 2B6, Cyp 3A4, Cyp 2C9) was analyzed. The expression was normalized to GAPDH. In figure 12 the fold expression change compared to undifferentiated hESC is shown. A strong induction of AFP expression was found after 17 days of bioreactor culture, while only a moderate induction of GATA II, neurofilament and hepatocyte specific transcripts was found. In contrast the expression of markers indicating the undifferentiated state of hESC (Oct-4 and Nanog) was found to be down-regulated.

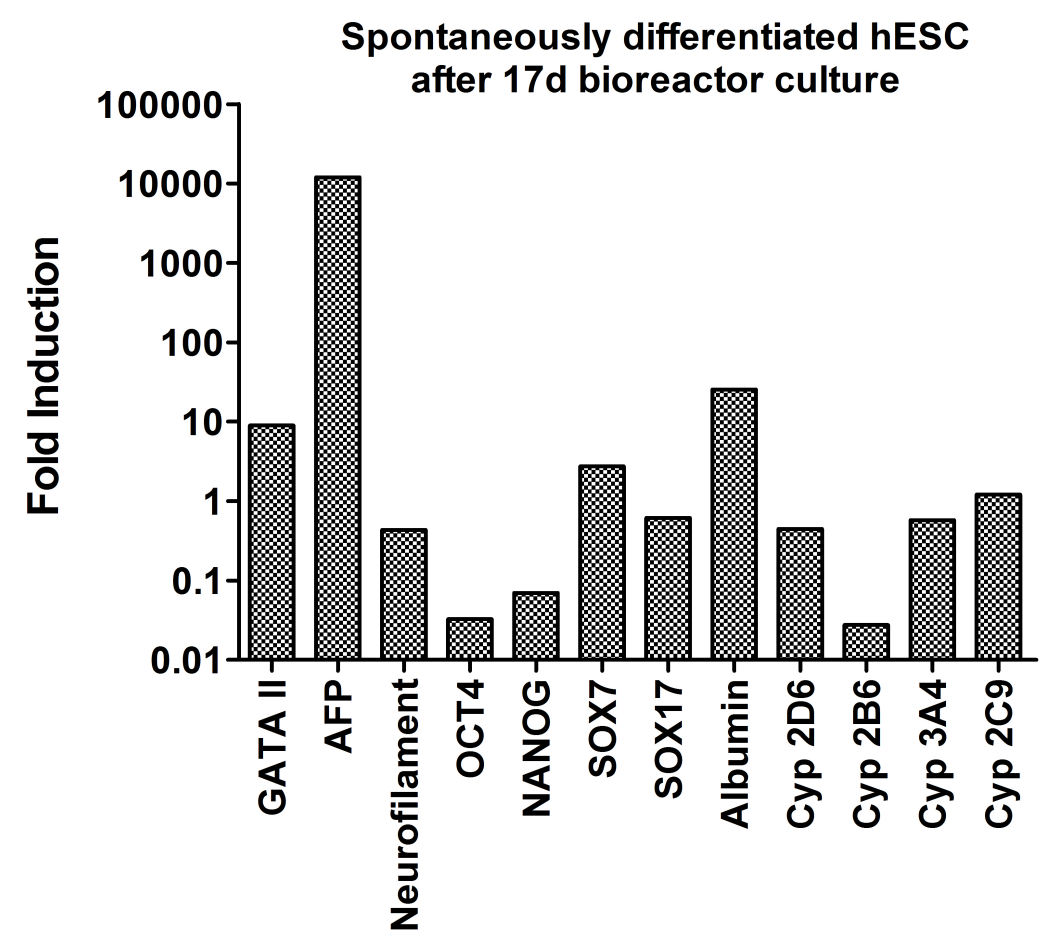

Figure 12: Fold induction of GATA II, AFP, Neurofilament, Oct-4, Nanog, SOX7, SOX17, Albumin, Cyp 2D6, Cyp 2B6, Cyp 3A4 and Cyp 2C9, normalized to undifferentiated hESC $(n=1)$. 


\subsubsection{The in vivo tumorigenic potential of feeder independent hESC (H1)}

Undifferentiated hESC $(\mathrm{H} 1)$ were injected subcutaneously into NOD/SCID mice or NSG mice as described under methods. After 120 days 3 solid tumors could be isolated out of NOD/SCID mice that received $1 \times 10^{7}$ ( 3 mice) cells each and 2 tumors out of NSG mice that received $1 \times 10^{6}$ (1 mouse) or $1 \times 10^{7}$ (1 mouse) cells each. Three of the harvested tumors were processed and HE staining was performed. In two of these tumors cell derivatives of all three germ layers were identified (Figure 13). In one tumor cells of the ectodermal germ layer were not identified clearly.

In order to determine the tumorigenic potential of differentiated cells, feeder independent hESC $(\mathrm{H} 1)$ were differentiated to the definitive endodermal and hepatocyte state according to Hay et al. 2008. No teratoma was found in NOD/SCID ( $n=33)$ or NSC $(n=21)$ mice after the subcutaneous or intrasplenic application of definitive endodermal or hepatic differentiated cells $\left(1 \times 10^{5}\right.$ to $1 \times 10^{6}$ cells per injection). 


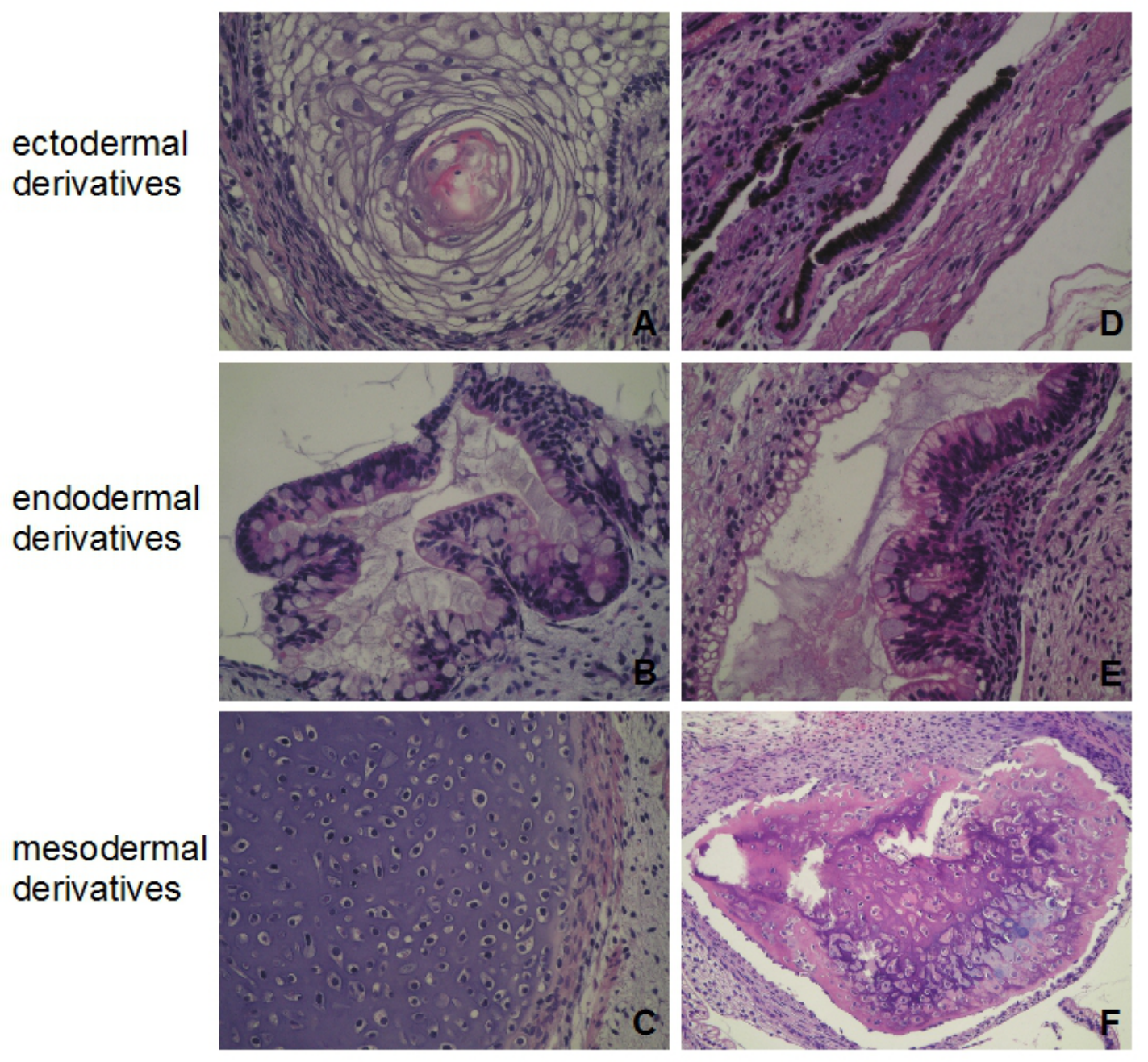

Figure 13: HE-staining of samples from teratoma: A) keratin rich epithelium; B) goblet cells and ciliated epithelium; C) cartilage; D) pigmented epithelium and neuroectodermal tubular structures; E) goblet cells and ciliated epithelium; F) cartilage and skeletal muscles, HEstainings and histological evaluation was performed by S.Brunk, Institut für Tierpathologie, Berlin. 


\subsection{Hepatic differentiation}

\subsubsection{Hepatic differentiation in 2D}

Five different protocols (Table 31) were investigated in order to establish a method for the hepatic differentiation of hESC under conventional 2D conditions. In all approaches undifferentiated cells first undergo commitment to the definitive endodermal (DE) lineage. Subsequently after completion, cells were treated with cytokines that stimulate cell proliferation. The hepatic differentiation was accomplished by a combination of cytokines that support maturation of hepatic cells (see table 31). During the differentiation process the concentration of factors that indicate metabolic activity (glucose and lactate), differentiation (AFP and bHCG) and cell integrity (LDH) were measured in the supernatant. RNA samples and cells for IHC were collected before differentiation, after accomplishment of DE-commitment and at the end of the hepatic differentiation. In addition samples from hESC that received $\mathrm{mTeSR} 1^{\mathrm{TM}}$ medium during the process of differentiation were collected as control. The cell number of vital cells was determined at the beginning, after DEcommitment and after accomplishment of hepatic differentiation.

\subsubsection{Metabolic parameters during hepatic differentiation}

The hESC that underwent hepatic differentiation according to the first approach showed the highest metabolic activity among all protocols investigated (Figure 14). A significant drop in glucose consumption a well as lactate production was seen around day 15 , which is likely a result of the altered medium change cycle beginning at day 12.

In the second approach the metabolic activity dropped significantly after the start of differentiation. The metabolic rate increased again after day 6 , which can be interpreted as result of the pro-mitotic effect of the cytokines given after day four. 
The third approach showed a metabolic rate that lied between the rates of approach one and two. No metabolic conversion of glucose could be observed after transferring the cells. The collection of samples was stopped for this approach at day nine.

The cells in approach 4 and 5 perished within the first days of DE differentiation. The course of metabolic rates in approaches four and five was characterized by a dramatic drop. After day three no activity could be observed. The collection of samples was discontinued at day five.
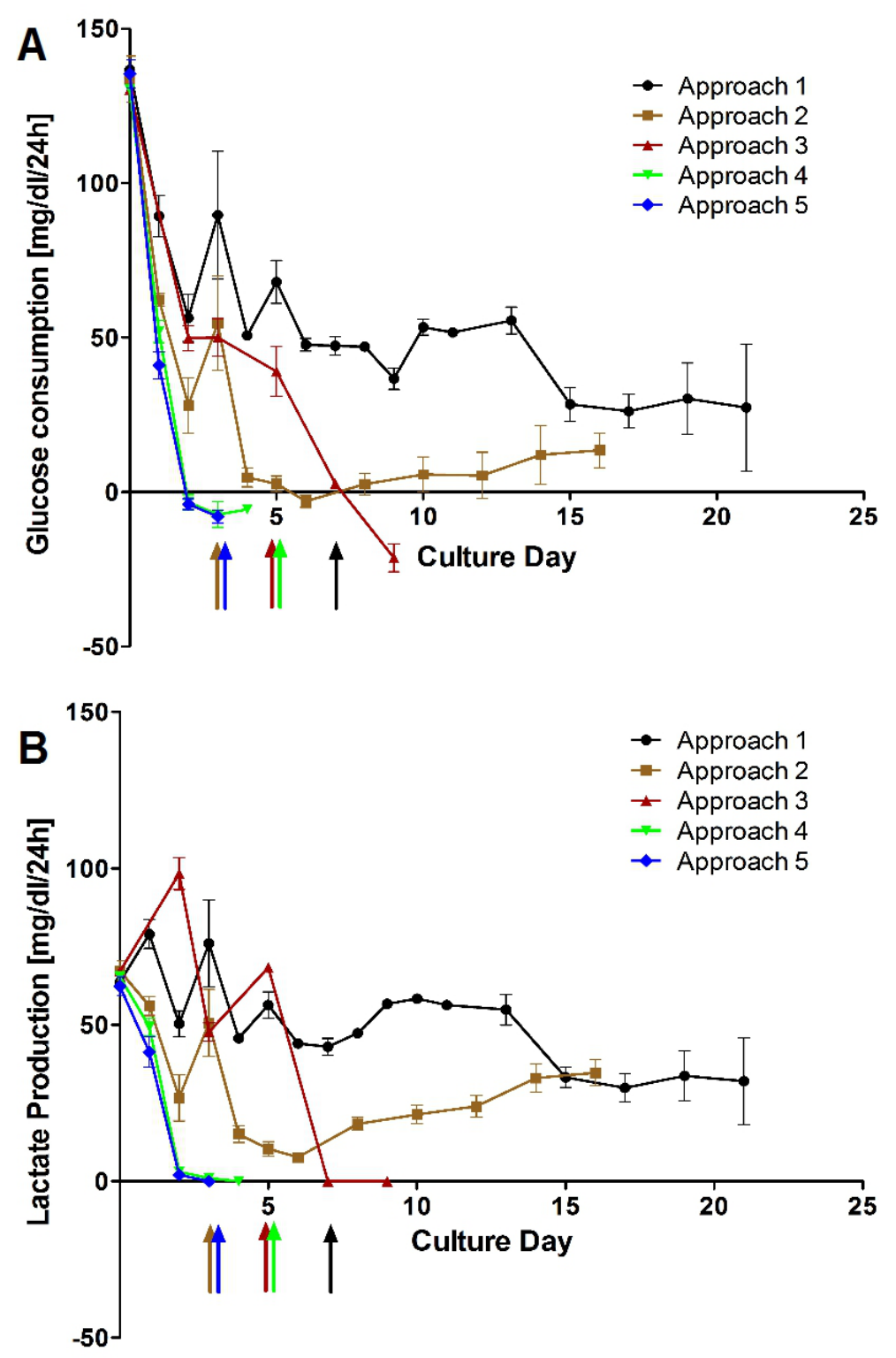

Figure 14: Time course of $(A)$ glucose consumption and (B) lactate production of the 5 different approaches investigated in conventional 2D culture. Arrows indicate the end of endodermal commitment of the cells in colors corresponding to the approaches $(n=3)$. 


\subsubsection{Cell integrity and cell numbers during hepatic differentiation}

The induction of DE commitment of the hESC seemed to have a vast impact on cell integrity. In all approaches the LDH concentration reached high levels in the supernatant (Figure 15). In Approach one the first step of differentiation had the lowest impact on cell integrity. This assumption is supported by the cell numbers counted after DE commitment (Figure 16). During the second step of the hepatic differentiation no significant increase in LDH concentrations was measured in any of the approaches.

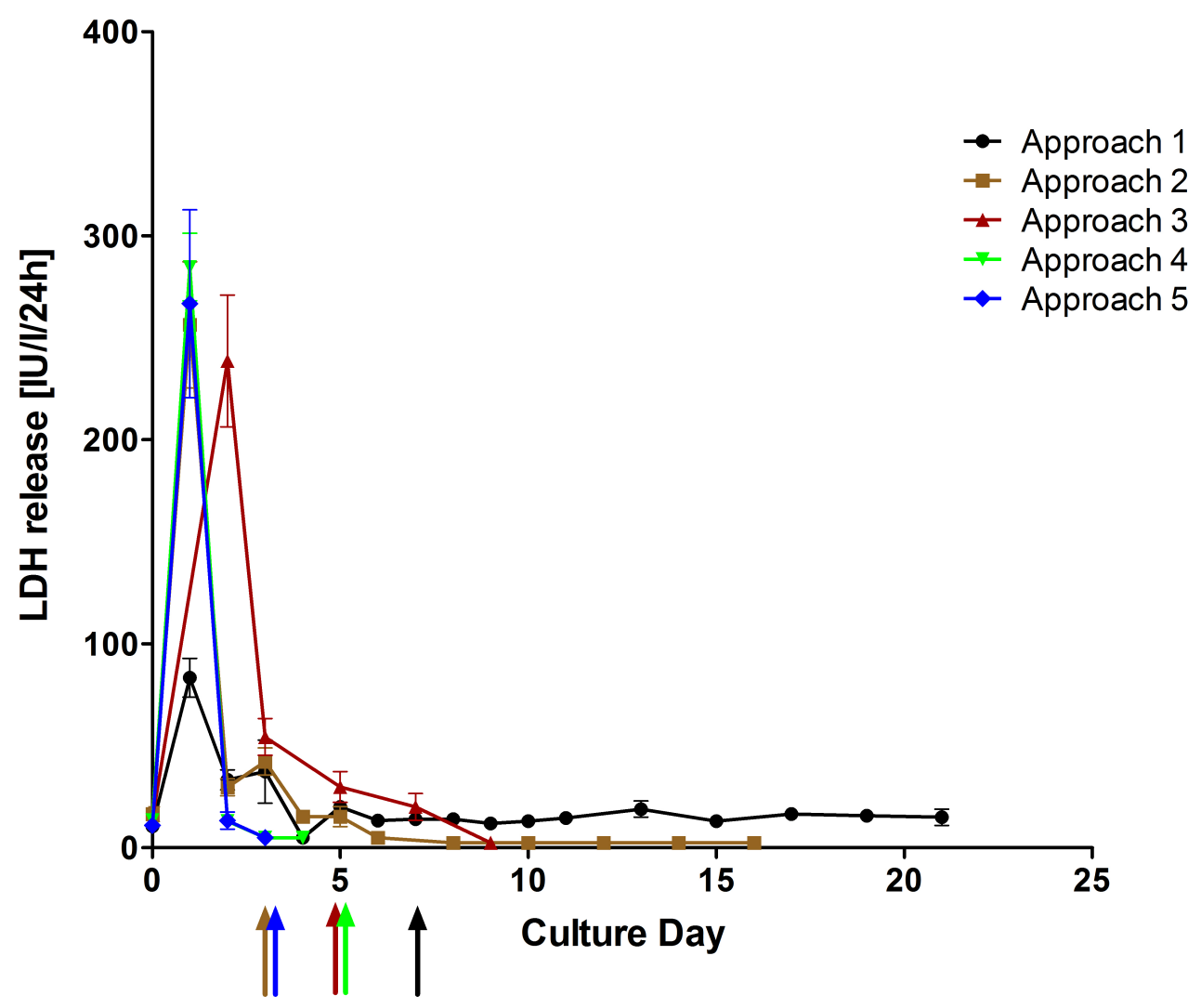

Figure 15: LDH release of the 5 different approaches measured during hepatic differentiation. Arrows indicate the end of endodermal commitment of the cells in colors corresponding to the approaches $(n=3)$.

The high LDH concentrations during definitive endodermal differentiation are consistent with the number of cells found after DE and at the end of differentiation compared to the cell number before starting the differentiation process (Figure $16 \mathrm{~A}$ 
\& B). The amount of cells was significantly higher for both time points in approach 1 compared to approach 2.
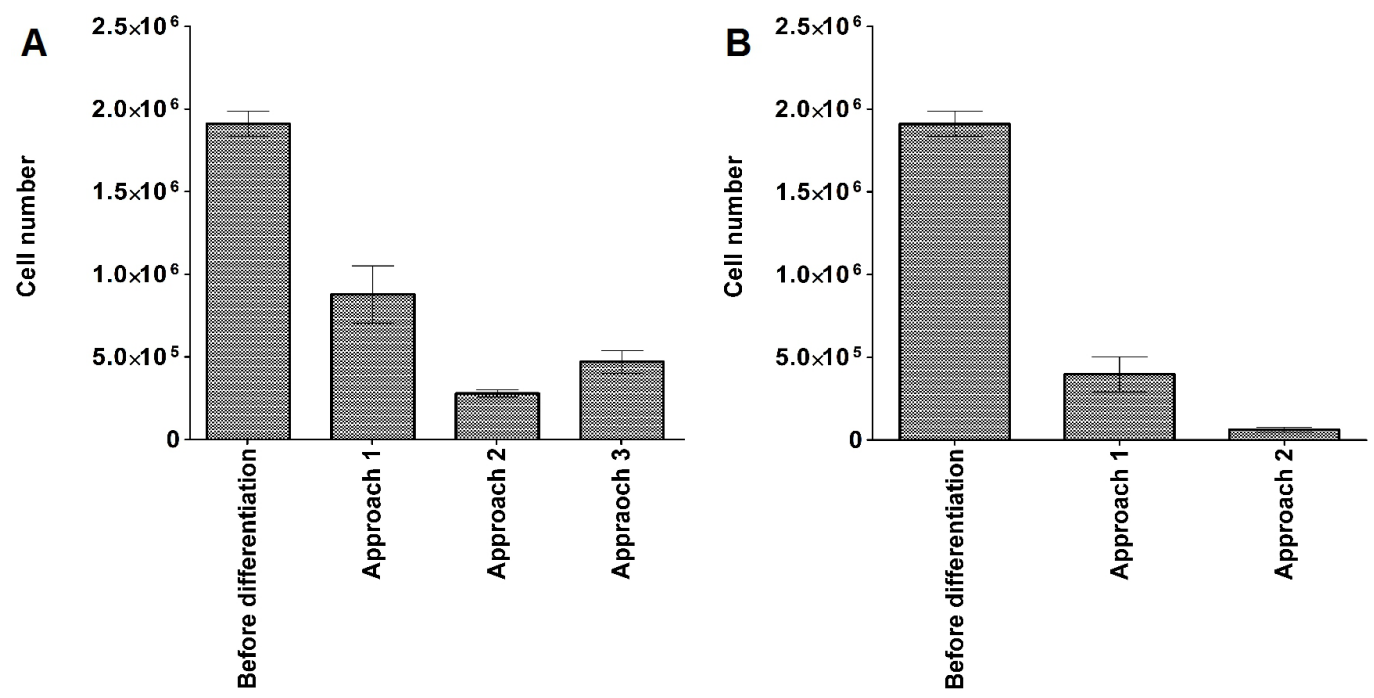

Figure 16: Cell numbers of differentiating hESC after accomplishment of DE differentiation (A) and at the end of differentiation $(B)(n=3)$.

During the experiment markers indicating differentiation first accrued in elevated levels at around day 8. The time courses of AFP and bHCG concentrations in approach 1 and 2 are given in figure 17. In approach 1 a significant increase of bHCG was seen from day 8 on. The highest concentration was measured around day 10. Afterwards the concentration decreased and reached basal levels at around day 15. The concentration of AFP in cells differentiating according to approach 1 was constantly low over the time of the experiment.

In approach 2 constantly low levels of bHCG were measured during the differentiation. The levels of AFP increased constantly from day 8 on. 

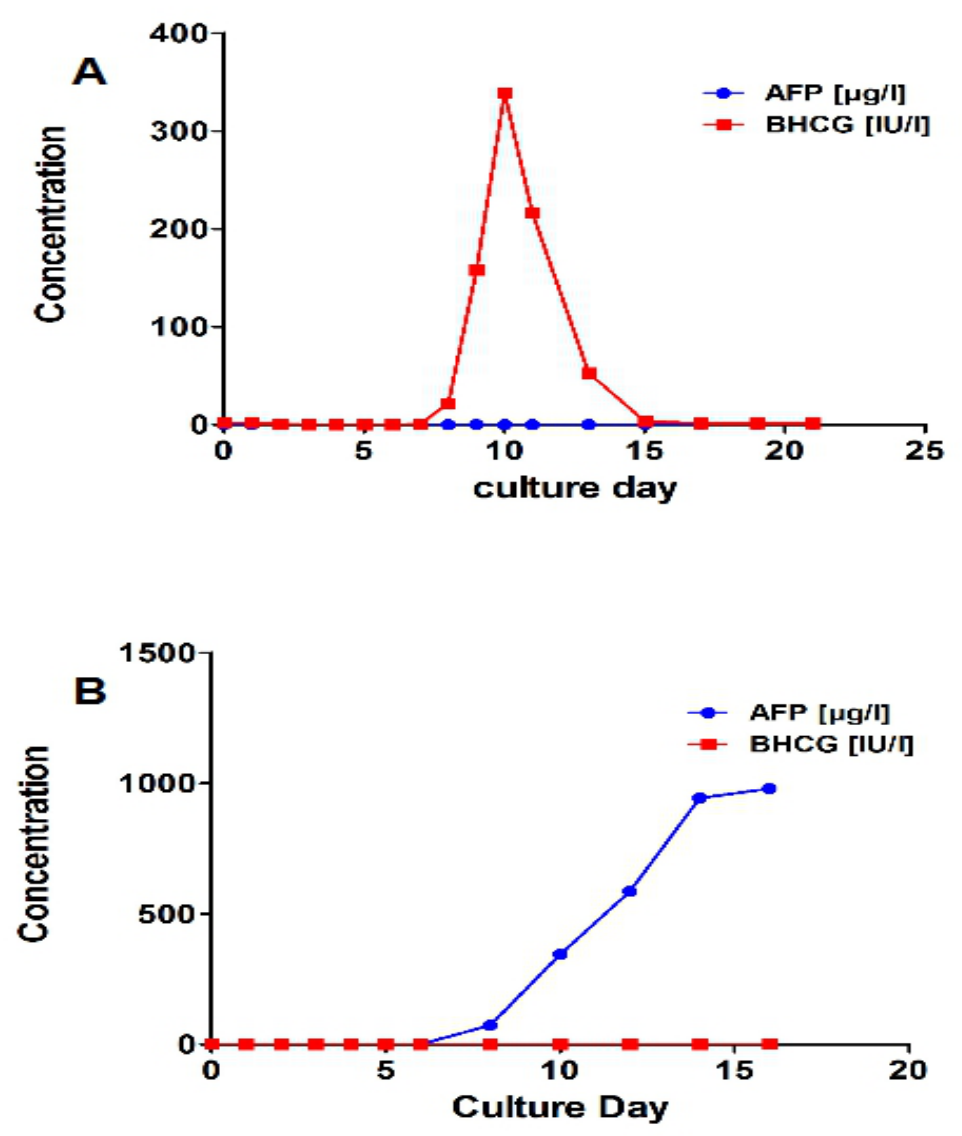

Figure 17: Concentration of bHCG and AFP during differentiation of hESC according to approach 1 (A) and approach 2 (B).

The cells underwent specific morphological changes during differentiation, as compared to undifferentiated cells (Figure 18, F).

DE differentiated cells in the first approach showed an inhomogeneous morphology (Figure 18, A and B). Round cells that were tightly packed could be seen next to spindle shaped cells. At the end of differentiation the cells were less heterogeneous. In the second approach the cells acquired a "cobblestone" like morphology (Figure $18, C$ and D). During further progress in differentiation, the cells grew in size and the cell nucleus became apparent.

In the third approach the cells appeared less "organized" compared to the second approach, but still homogenous (Figure 18, E). Subsequently after accomplishment of the DE step the cells were transferred into new culture flasks. The cells were not 
able to adhere, and perished right after passage.

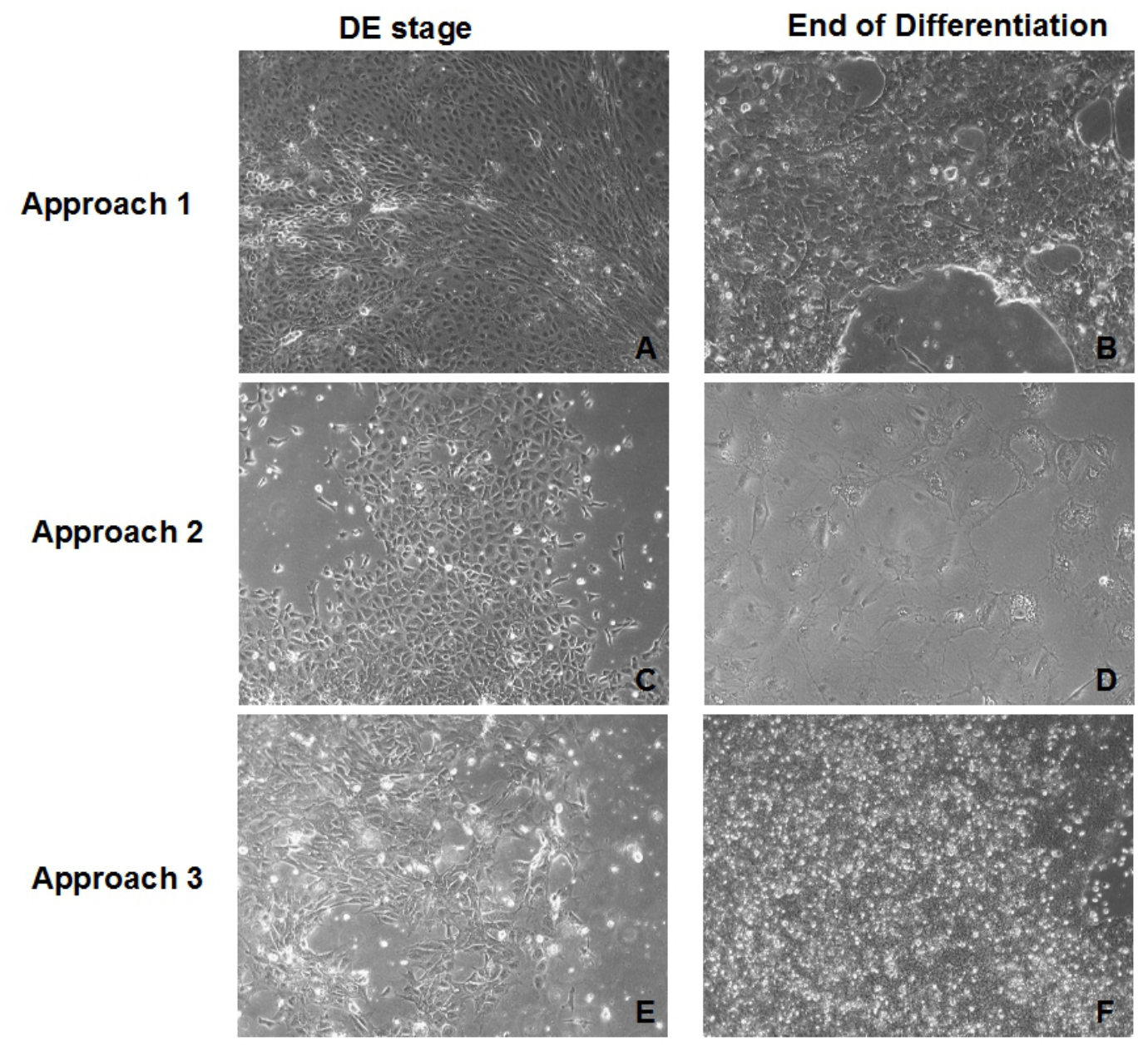

Figure 18: hESC after accomplishment of DE commitment (A, C, E) and after maturation (B, D) in conventional 2D culture; phase contrast microscopy; $(F)$ undifferentiated hESC on d0; 100x total magnification.

The results from real time PCR analysis of the RNA isolated after DE commitment and at the end of differentiation are shown in figure 19.

An induction of GATA II expression after DE commitment was observed in approach 1. At the end of differentiation the expression of GATA II was still strongly induced. In the second approach a strong induction of GATA II was also seen after DE commitment, but in contrast to the first approach the expression of SOX17 was induced as well. At the end of differentiation the cells in the second approach showed a strong induction of AFP, Albumin, SOX17 and Cytochrome P450 2C9 expression. Definitive endodermal cells of the third approach showed already high expression of 
AFP and SOX17.

After the first step a robust expression of markers for undifferentiated stem cells (Oct-4 \& Nanog) could be seen in all approaches. The expression of these markers was significantly reduced after accomplishment of the differentiation.

DE stage

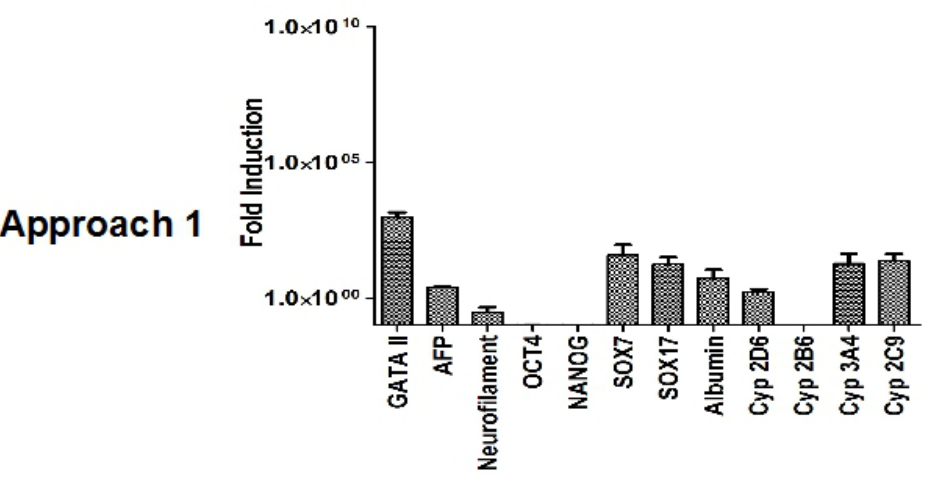

Approach 1
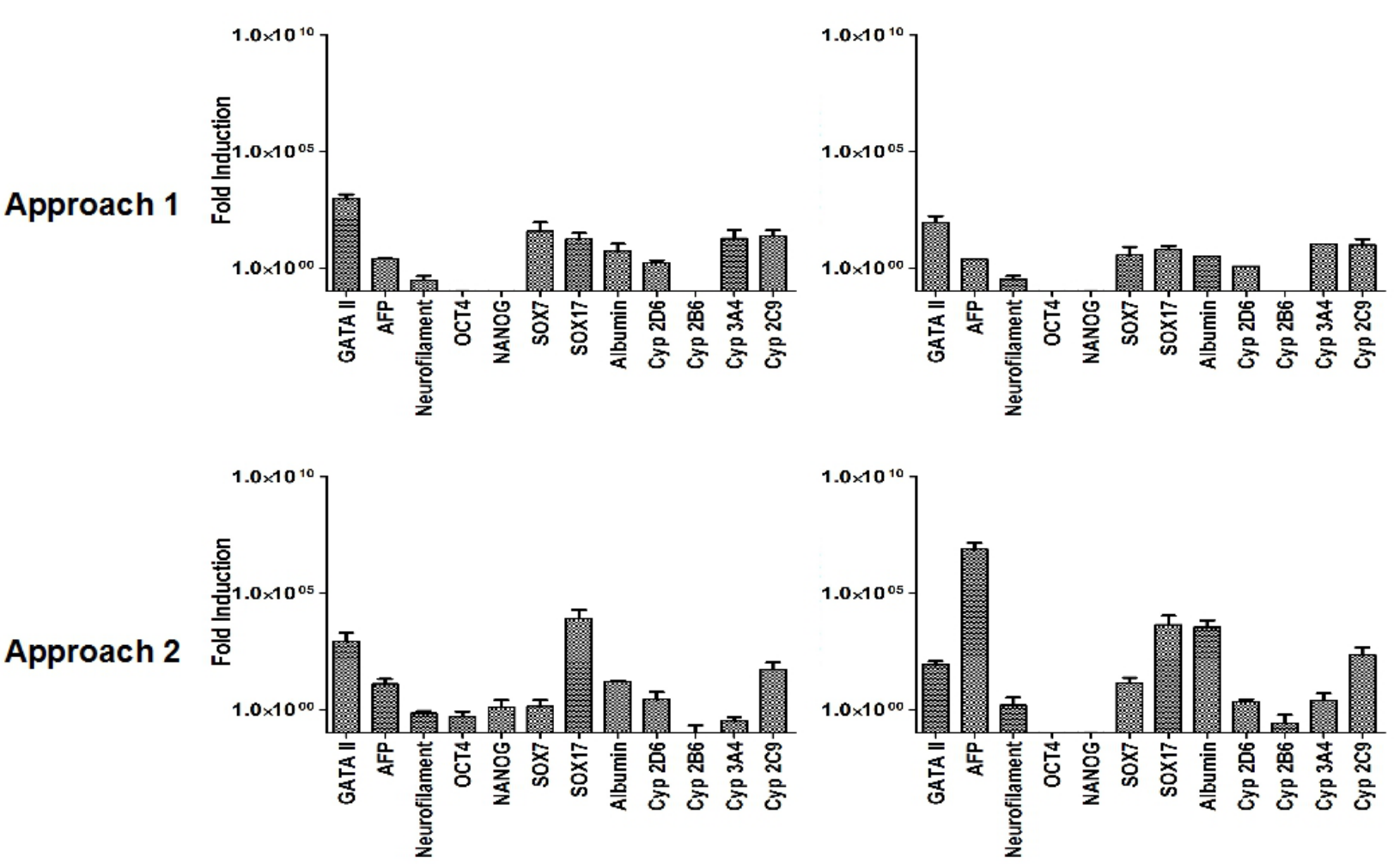

End of differentiation

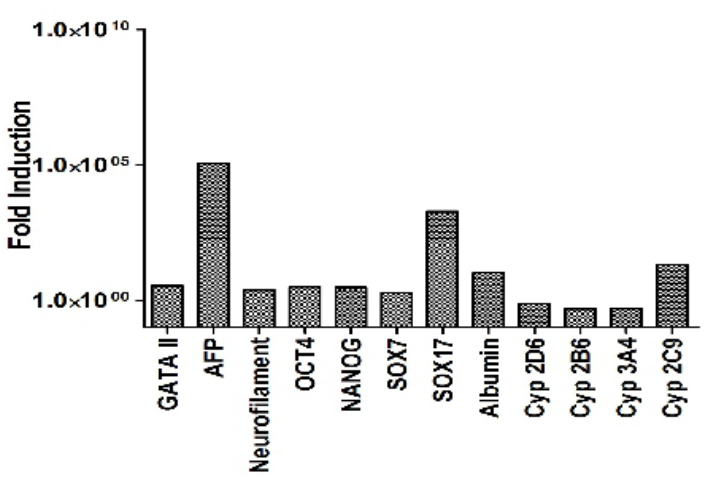

Figure 19: Expression of genes characteristic for undifferentiated cells (Oct-4, Nanog) and for cells differentiated into endodermal (AFP), mesodermal (GATA II), ectodermal (Neurofilament) and hepatic (SOX17, Albumin, Cyp2D6, Cyp2B6, Cyp3A4, Cyp2C9) cells in hESC after DE commitment and at the end of differentiation in conventional 2D culture, normalized to undifferentiated cells $(n=3)$. 
The cells differentiated according to the protocol of the first approach exhibited a CK18/CK19 double positive phenotype. They were not positive for vimentin. Representative pictures are shown in figure 20.
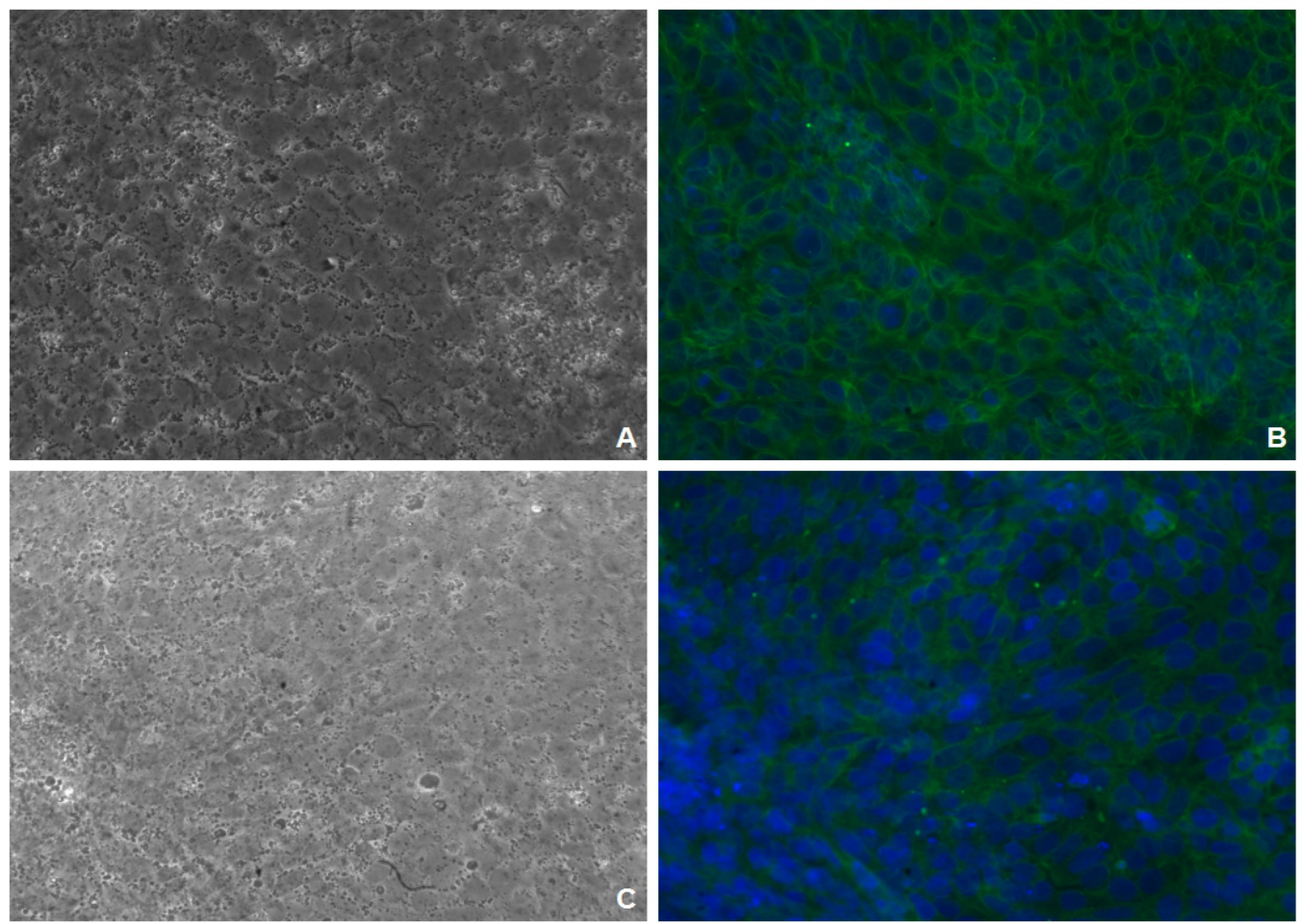

Figure 20: Immune cytochemistry staining of hESC in conventional 2D culture after conducted differentiation according to approach 1; (B) CK18 (green) \& DAPI (blue); (D) CK19 (green) \& DAPI (blue); (A) \& (C) phase contrast microscopy picture; 400x total magnification.

The cells differentiated according to approach 2 were positive for CK18 and CK19 (Figure 21, B and D). In addition a non-uniform positive immunoreaction was seen also for the mesodermal marker vimentin (Figure 21, F). 

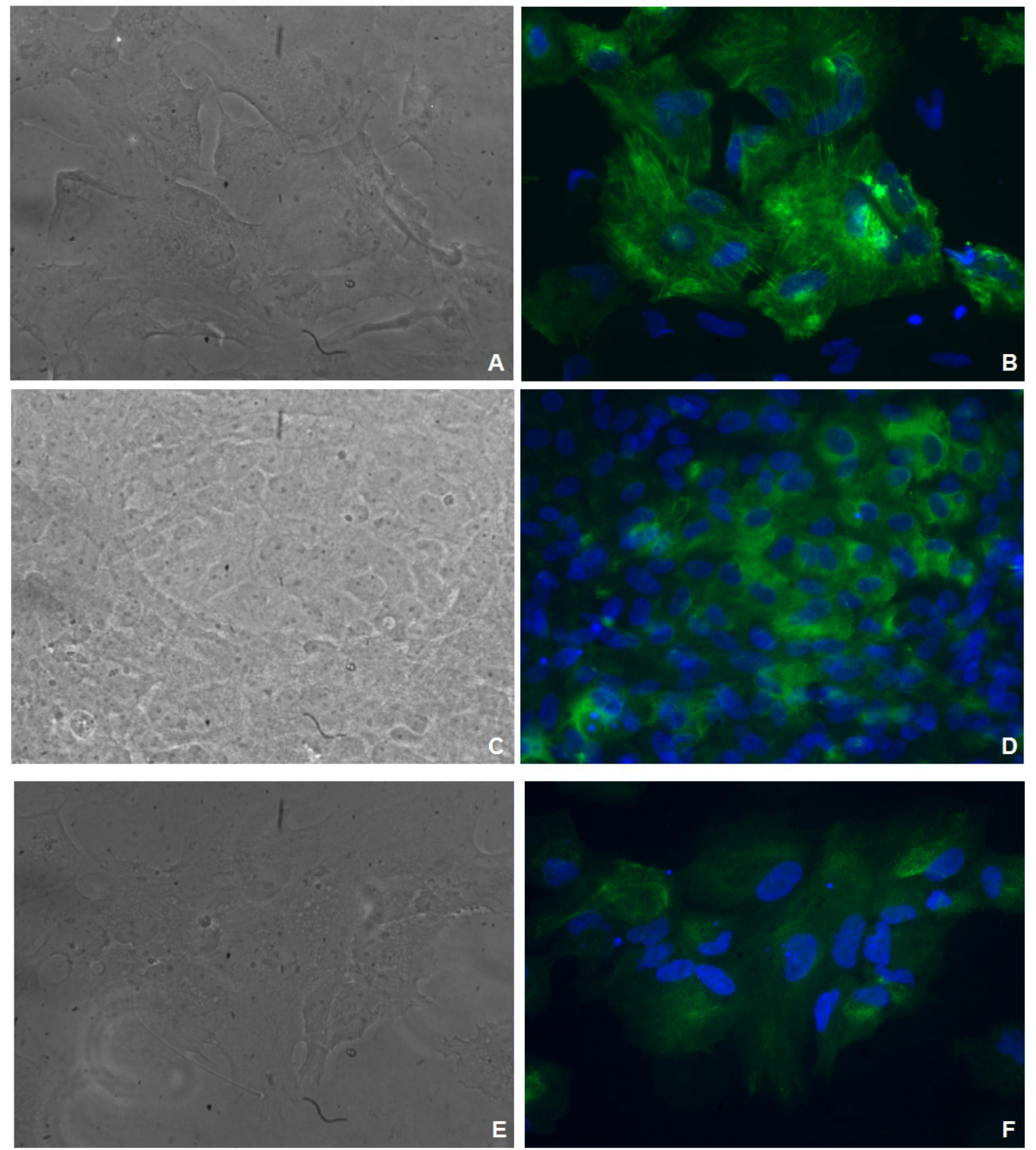

Figure 21: Immune cytochemical staining of hESC after conducted differentiation according to approach 2; (B) CK18 (green) \& DAPI (blue); (D) CK19 (green) \& DAPI (blue); (F) vimentin (green) \& DAPI (blue); 400x total magnification in all pictures. 


\subsubsection{Stability of hepatically differentiated cells}

In order to determine the stability of differentiation hESC were differentiated according to approach 2 and either cultivated in medium that supports hepatic maturation (HCM2.2) or medium that supports spontaneous differentiation (EBMedium) for 14 days. During the experiment duration the concentration of factors that indicate metabolic activity (glucose and lactate), differentiation (AFP and bHCG) and cell integrity (LDH) were measured in the supernatant. RNA samples were collected at the end of differentiation, after 3 days in HCM2.2 or EB medium, and after 14 days.

The metabolic activity of the cells in both culture media was comparable (figure $22 \mathrm{~A}$ and $\mathrm{B}$ ). The higher glucose concentration in EBMedium is a result of the higher concentration in the basal medium $(450 \mathrm{mg} / \mathrm{dl}$ for the EBMedium, $185 \mathrm{mg} / \mathrm{dl}$ for the HCM2.2)

The levels for LDH (figure $22 \mathrm{C}$ ) were also similar in both approaches indicating a comparable cell decline.

AFP levels proceeded comparably until day 26 of culture (figure $22 \mathrm{D}$ ). From that day the levels were higher in the culture that received HCM2.2 medium.

Concentrations for bHCG were elevated in HCM2.2 medium from day 20 to day 24 before they reached levels similar to those in EBMedium again (figure $22 \mathrm{E}$ ). 

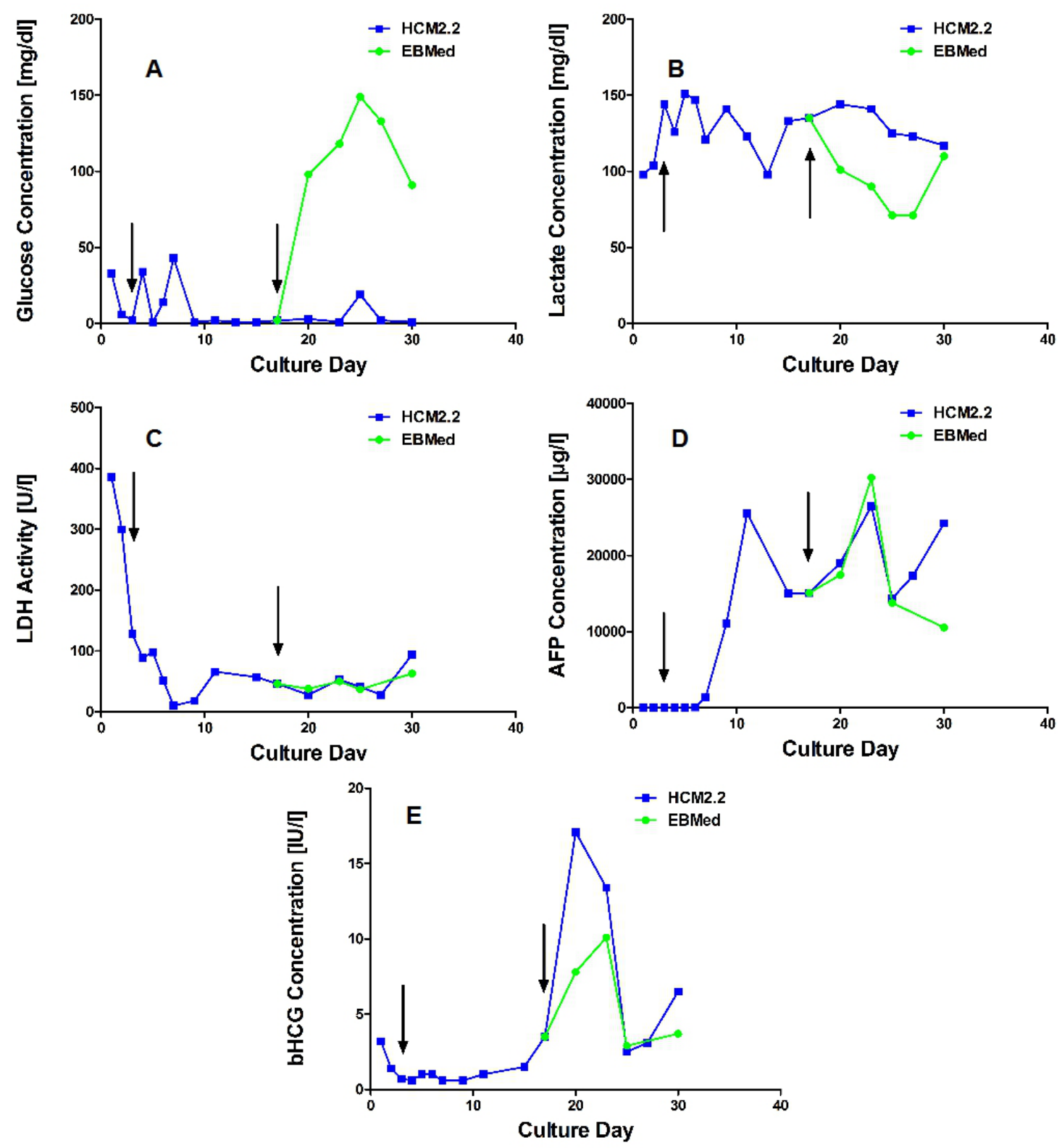

Figure 22: Graphs for glucose (A), lactate (B), LDH activity (C), AFP (D) and bHCG (E) concentration during hepatic differentiation (until d17) and subsequent evaluation of stability of differentiation. The arrows indicate the end of the definitive endodermal commitment (left arrow) and the end of differentiation (right arrow).

The real time PCR analysis of RNA samples collected at day 0 , day 3 and day 14 after the end of hepatic differentiation showed only minor changes in expression of the investigated genes (see figure 23). 

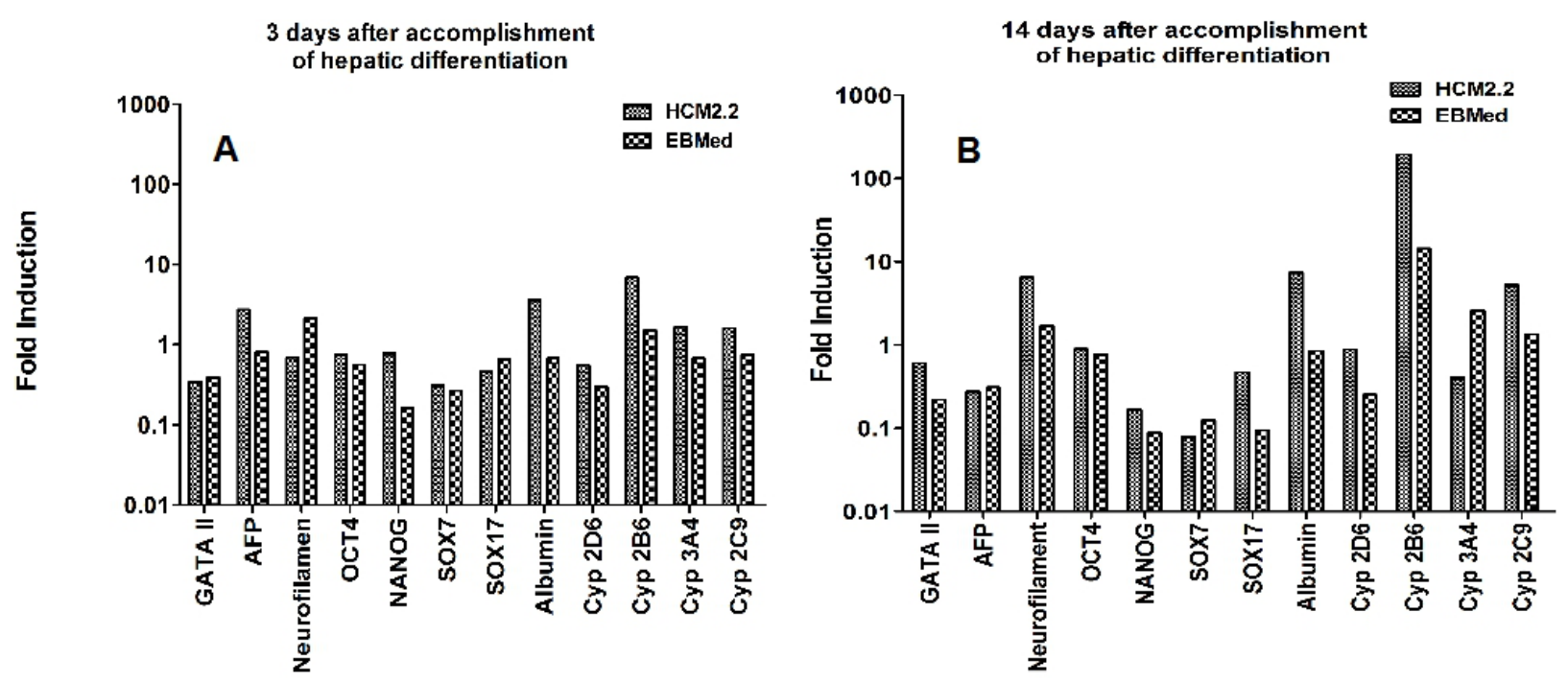

Figure 23: Gene expression profile of differentiated hESC, after 3 days (A) or 14 days (B) in EBMedium or HCM2.2 medium showing markers for undifferentiated cells (Oct-4, Nanog) and for cells differentiated into endodermal (AFP), mesodermal (GATA II), ectodermal (Neurofilament) and hepatic (SOX17, Albumin, Cyp2D6, Cyp2B6, Cyp3A4, Cyp2C9) cells, Expression has been normalized to hepatic differentiated hESC (d0) $(n=1)$.

The expression of markers for non-endodermal germ layers (GATA II and Neurofilament) was not significantly changed in HCM2.2 nor in EB-Medium. The RNA expression of Albumin and Cytochrome P450 2B6 was induced in HCM2.2 medium, a moderate induction of Cytochrome P450 3A4 was found in EBMedium. Genes indicating an undifferentiated state (Oct-4, Nanog) of hESC were expressed at levels similar to those measured at day 0 or below.

The differentiated cells underwent further morphological changes depending on the culture medium (Figure 24). The cells cultured in HCM2.2 medium did not proliferate, they formed colonies with sharp edges. The cells were less homogeneous in total as compared to cells cultured in EBMedium and the cell size was reduced.

The cells that were further cultured in EBMedium appeared more homogeneous, and formed flat colonies consisting of cells with prominent nucleoli. 


\section{End of \\ Hepatic \\ differentiation}

HCM2.2

EBMedium
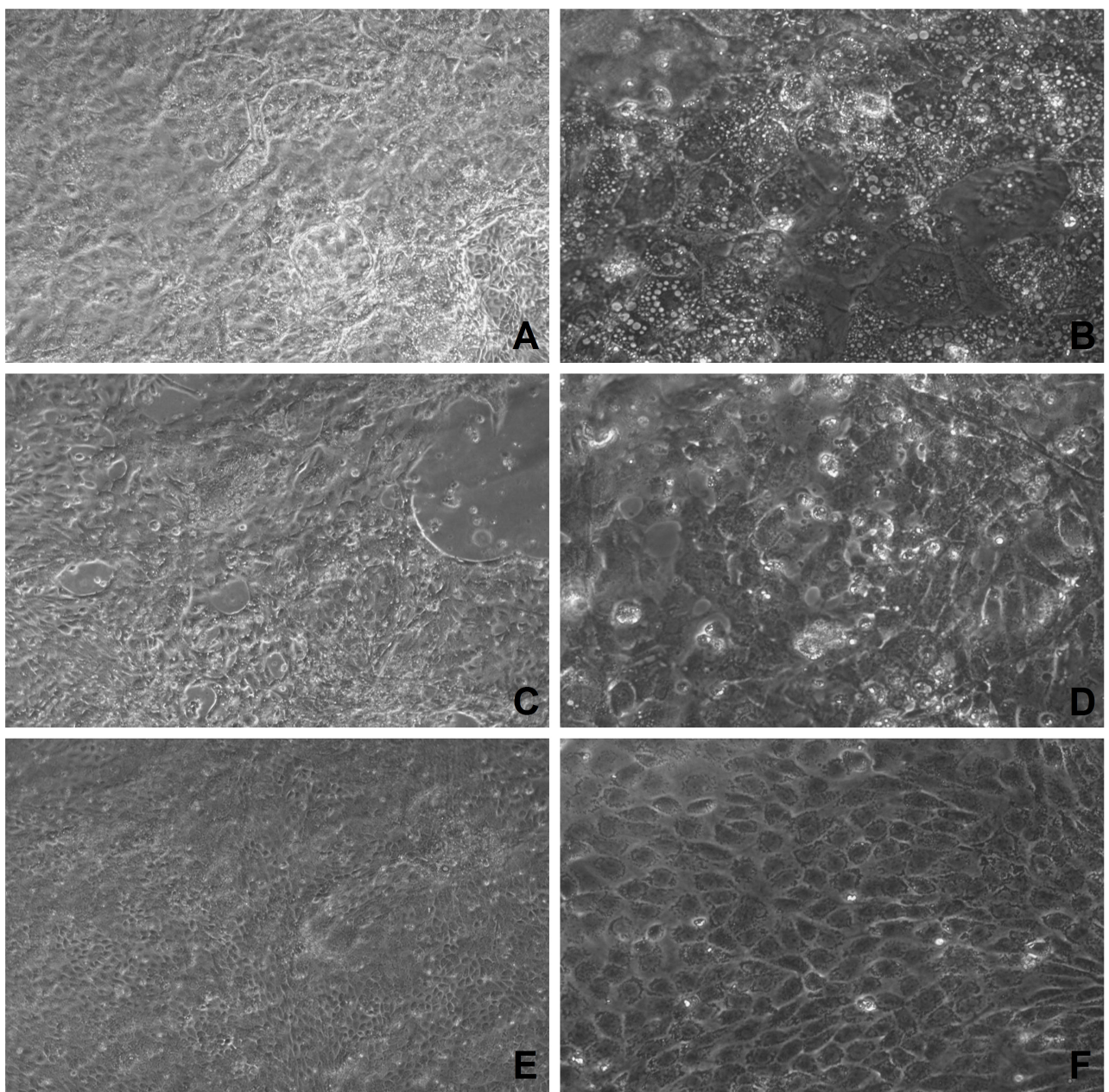

Figure 24: hESC after accomplishment of hepatic differentiation, (A) 100x total magnification, (B) 320x total magnification; hepatic differentiated hESC after 14 days in HCM2.2 (C, D) or EBMedium (E, F) after accomplishment of differentiation; (C, E) $100 \times$ total magnification, (D, F) $320 \times$ total magnification. 


\subsubsection{Culture of hESC in 3D bioreactor systems}

The culture of hESC was carried out in various bioreactor models. Before starting the differentiation experiments a 48 to 72 hour recovery period in mTEsR medium was granted. In order to determine the level of differentiation that hESC acquire during that period, a miniaturized bioreactor was inoculated with 60 million undifferentiated cells followed by a culture period of 48 hours. Daily metabolic parameters (glucose, lactate), parameters that indicate cell integrity (LDH) and differentiation (AFP and bHCG) were measured. A decrease in glucose concentration and corresponding to that an increase in lactate was seen after inoculation of the cells (figure $25 \mathrm{~A}$ ). The LDH activity increased continuously over the time of the experiment (figure $25 \mathrm{~B}$ ). An increase of bHCG or AFP concentrations above the detection limit was not detectable in the samples drawn from the bioreactor recirculation (data not shown). At bioreactor shutdown RNA samples were taken and further processed for real time PCR analysis.
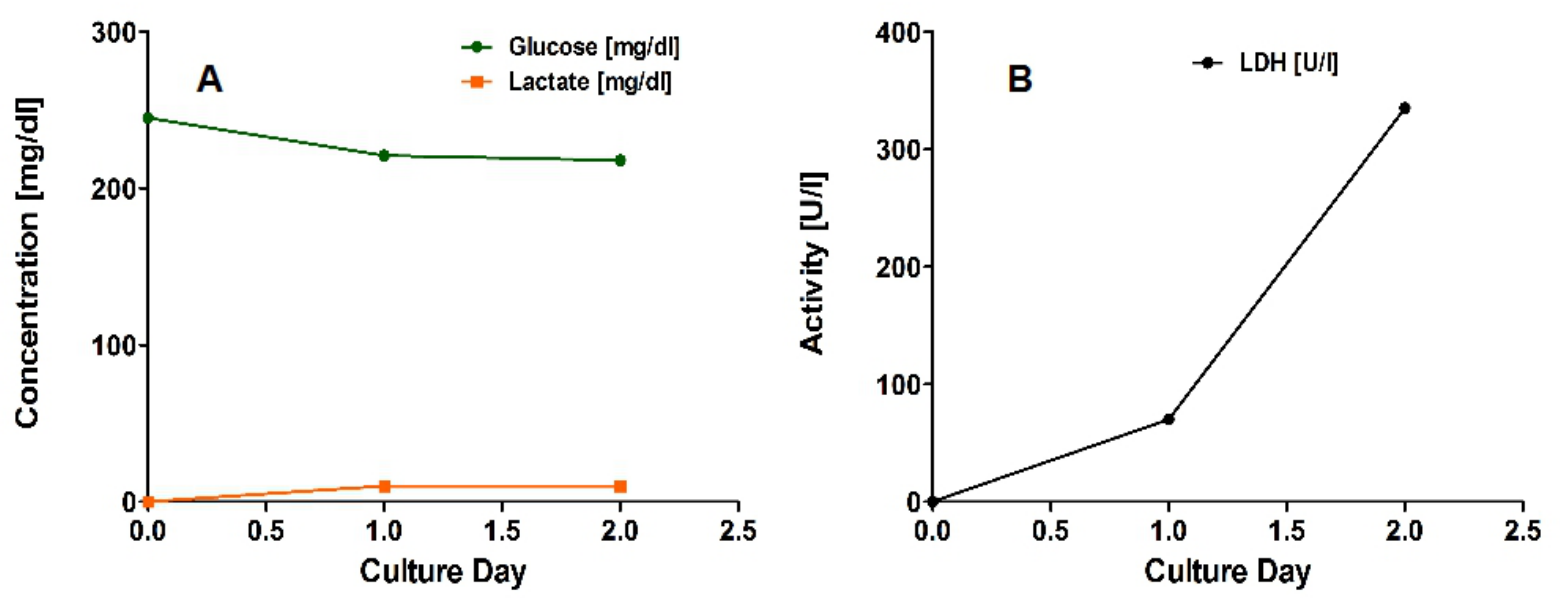

Figure 25: Glucose, lactate concentration (A) and LDH activity (B) during 48 hours culture of undifferentiated hESC under conditions that support the proliferation of undifferentiated cells $(n=1)$

The expression of the majority of investigated genes did not change dramatically, a stable expression of genes indicating the undifferentiated state (Oct-4 and Nanog) was found in the cells after 48 hours of bioreactor culture. A strong induction of 
expression was found for SOX17 (Figure 26). hESC cultured in a miniaturized bioreactor model under conditions that
supports undifferentiated proliferation

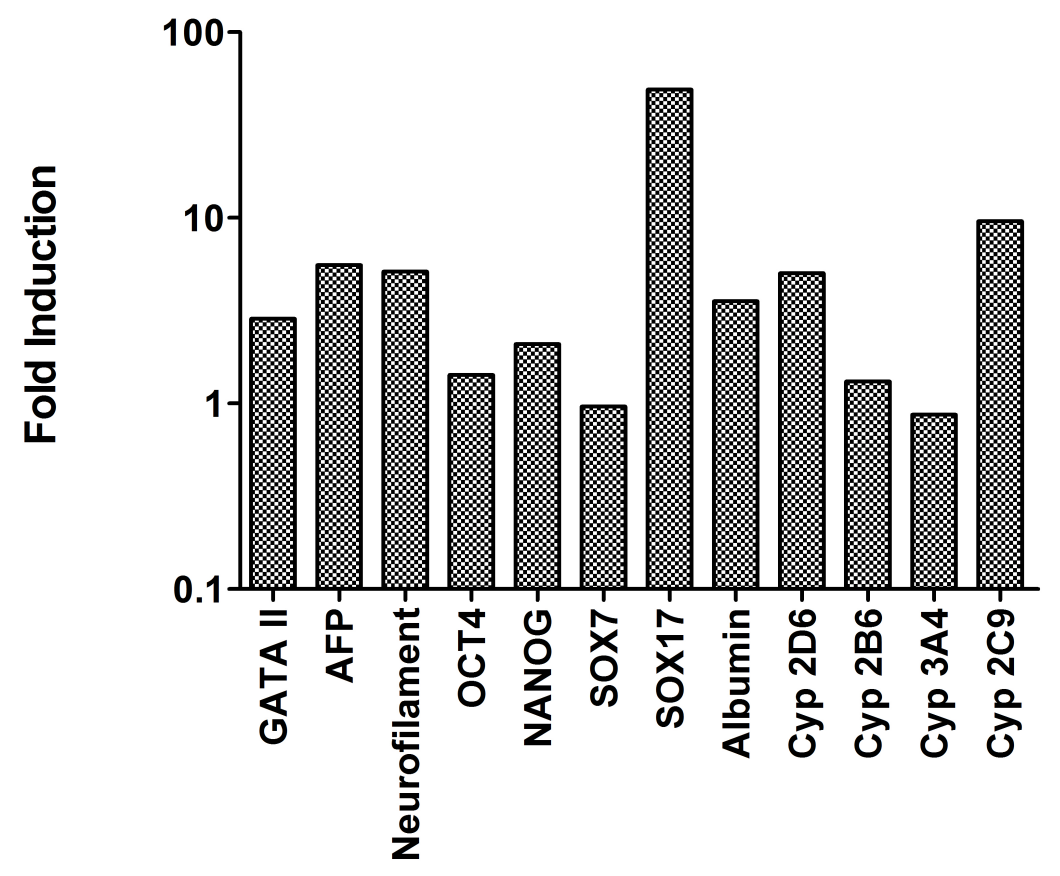

Figure 26: Fold induction of genes characteristic for undifferentiated cells (Oct-4, Nanog) and for cells differentiated into endodermal (AFP), mesodermal (GATA II), ectodermal (Neurofilament) and hepatic (SOX17, Albumin, Cyp2D6, Cyp2B6, Cyp3A4, Cyp2C9) cells $\mathrm{hESC}$ after 48 hour bioreactor culture in $\mathrm{mTesr} 1^{\mathrm{TM}}$ medium. The expression of genes was normalized to undifferentiated hESC before inoculation.

\subsubsection{Hepatic differentiation in 3D bioreactor systems}

\subsubsection{Hepatic differentiation of feeder independent hESC in 3D bioreactor systems or conventional 2D culture according to approach 1}

In this approach 2.5E7 feeder independent hESC (hESC cell line H1) were inoculated into a miniaturized bioreactor ( $0.4 \mathrm{ml}$ cell compartment volume). The cells were differentiated according to the protocol published by Hay et al. $(2007){ }^{22}$ 
adapted for 3D bioreactor cultures. After inoculation into the bioreactors, a 48 hour period in $\mathrm{mTeSR} 1^{\mathrm{TM}}$ medium for adaptation and recovery of the cells from enzymatic passaging was applied. In parallel conventional 2D cultures were performed. For the hepatic differentiation in conventional 2D cultures hESC cultures with about $70 \%$ to $80 \%$ confluence (about $2 * 10 \mathrm{E} 6$ cells per well of a 6 -well plate) were differentiated according to approach 1.
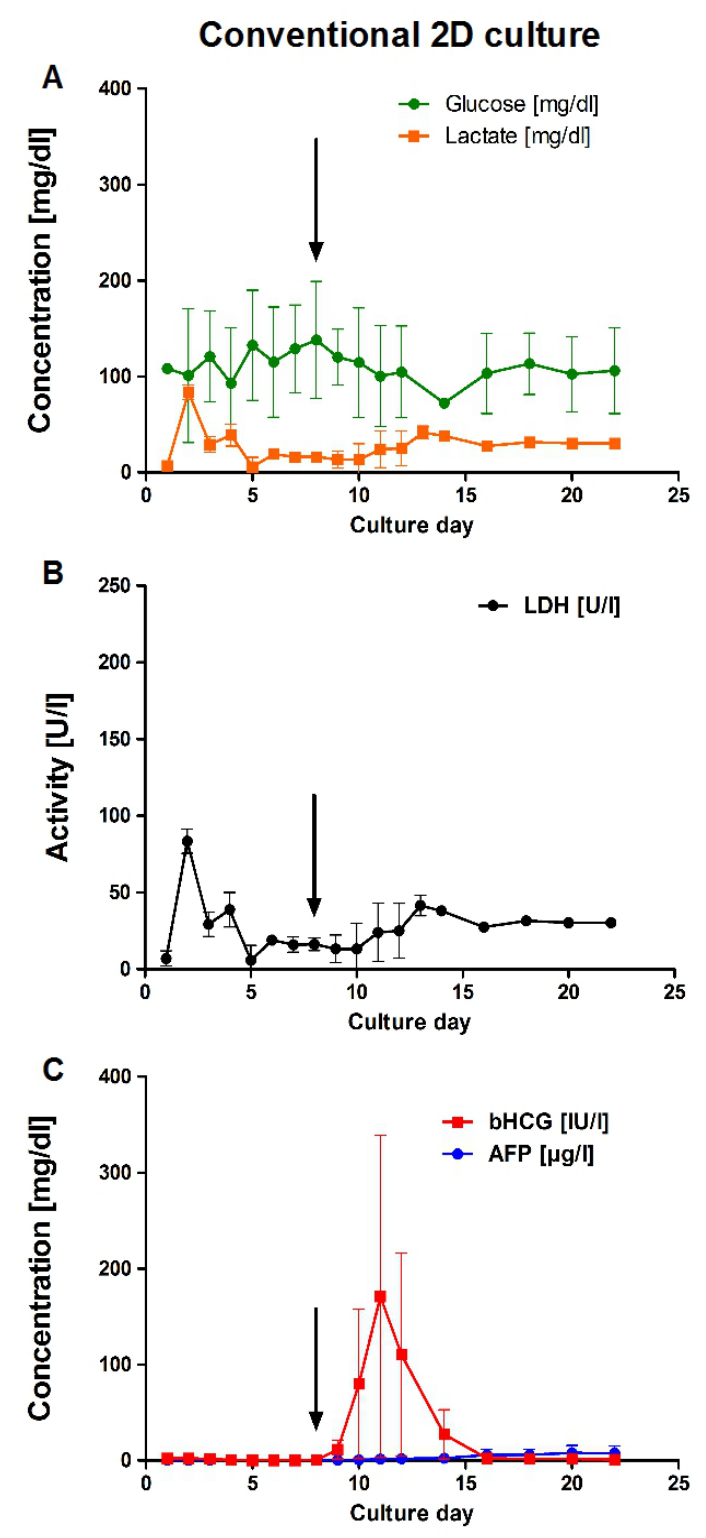

3D bioreactor culture



E
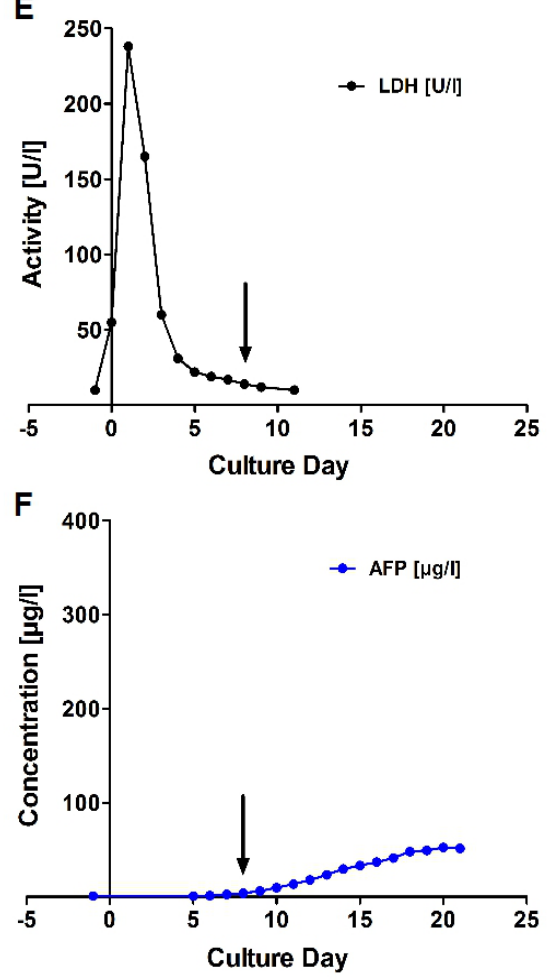

Figure 27: Time course of glucose and lactate (A), LDH activity (B), AFP and bHCG (C) concentrations in a bioreactor culture (right hand side, $n=1$ ) or conventional 2D culture (left hand side, $n=4$ ) differentiated according to approach 1; arrows indicate the end of endodermal commitment of the cells. 
The glucose metabolism in 2D cultures was robust and higher than the activity seen in the 3D bioreactor culture (Figure 27). LDH activities indicating cell stress and apoptosis were found to be higher in bioreactor cultures compared to 2D cultures. This is likely to be more a result of bioreactor inoculation induced cell stress than LDH release due to apoptosis during DE commitment. HCG was only detectable in 2D cultures and not in 3D cultures. It was found to have the highest concentration around day 11. AFP was detected at only low levels in $2 \mathrm{D}$ cultures compared to bioreactor culture. A constant increase in AFP concentration was seen from day 5 on. At bioreactor shutdown cell were harvested and RNA was isolated. After reverse transcription the expression was normalized to undifferentiated hESC after 48 hours bioreactor culture. At the end of hepatic differentiation in conventional 2D cultures RNA was isolated and processed in a similar fashion. The expression of hepatic differentiated cells under 2D culture was normalized to undifferentiated hESC at d0. Results of gene expression analysis are shown in figure 28. A robust induction of AFP and Albumin expression in the 3D bioreactor culture higher than the induction found in 2D cultures was detected. An induction of the mesodermal marker GATA II could be found in 2D cultures and at a minor level in the 3D bioreactor culture as well. The expression of markers indicating the pluripotent state of hESC (Oct-4, Nanog) was down regulated in both 2D and 3D cultures, but could still be found at relevant levels in 3D bioreactor cultures. 
Conventional 2D culture

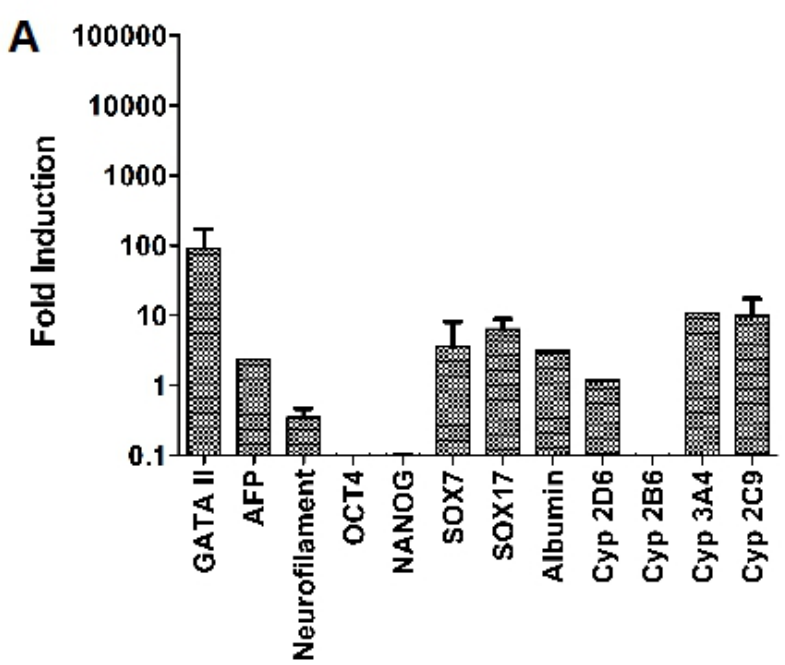

3D bioreactor culture

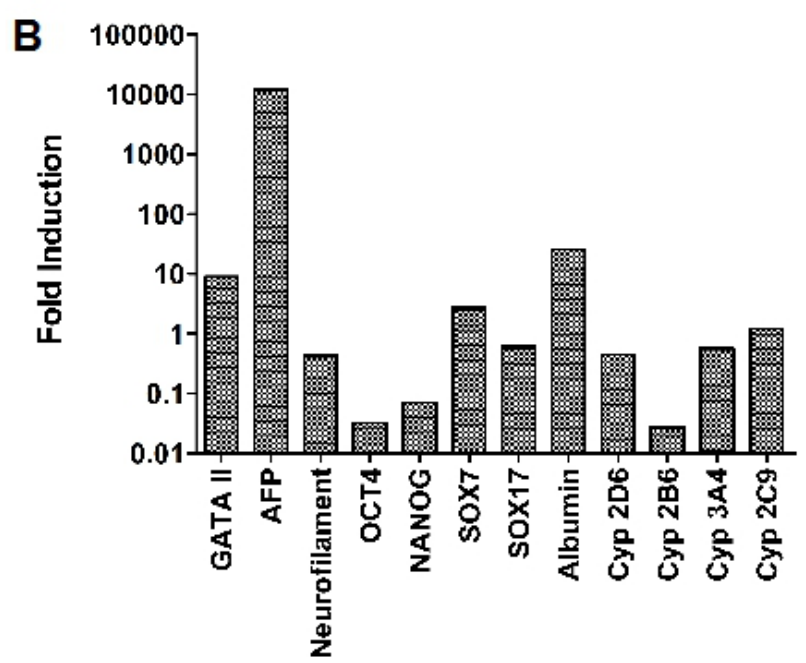

Figure 28: (A) Fold induction of genes characteristic for undifferentiated cells (Oct-4, Nanog) and for cells differentiated into endodermal (AFP), mesodermal (GATA II), ectodermal (Neurofilament) and hepatic (SOX17, Albumin, Cyp2D6, Cyp2B6, Cyp3A4, Cyp2C9) cells in hESC after 21 days differentiation according to approach 1 in conventional $2 D$ culture $(A)$ or in $3 \mathrm{D}$ bioreactor (B). The expression was normalized to undifferentiated $\mathrm{hESC}(\mathrm{A})$ respectively undifferentiated hESC after 48 hours of $3 D$ bioreactor culture $(B)(n=2)$.

\subsubsection{Hepatic differentiation of feeder independent hESC in 3D bioreactor systems and conventional 2D cultures according to approach 2}

In this approach $2.5 \times 10^{7}$ feeder independent hESC (cell line $\mathrm{H} 1$ ) were inoculated into miniaturized bioreactors $(n=2)(0.4 \mathrm{ml}$ cell compartment volume). The cells were differentiated according to the protocol published by Hay et al. (2008) ${ }^{68}$ adapted for bioreactor cultures. The cells were prepared and seeded as described for approach one. 
Conventional 2D culture
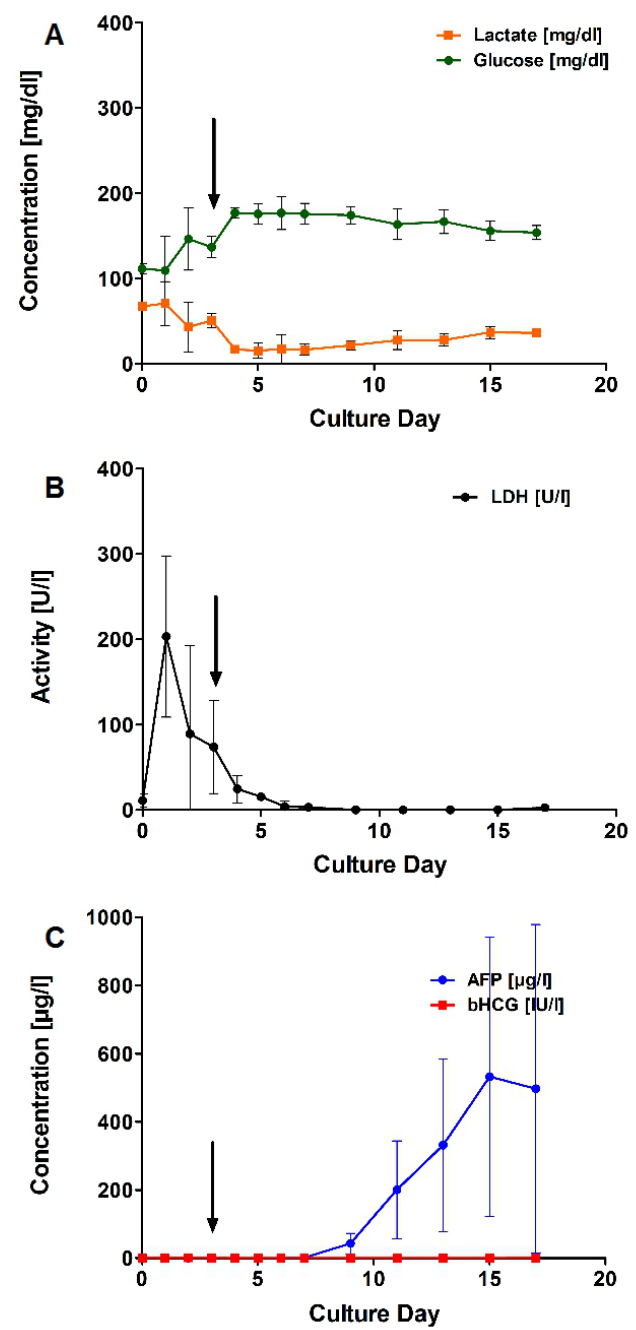

3D bioreactor culture
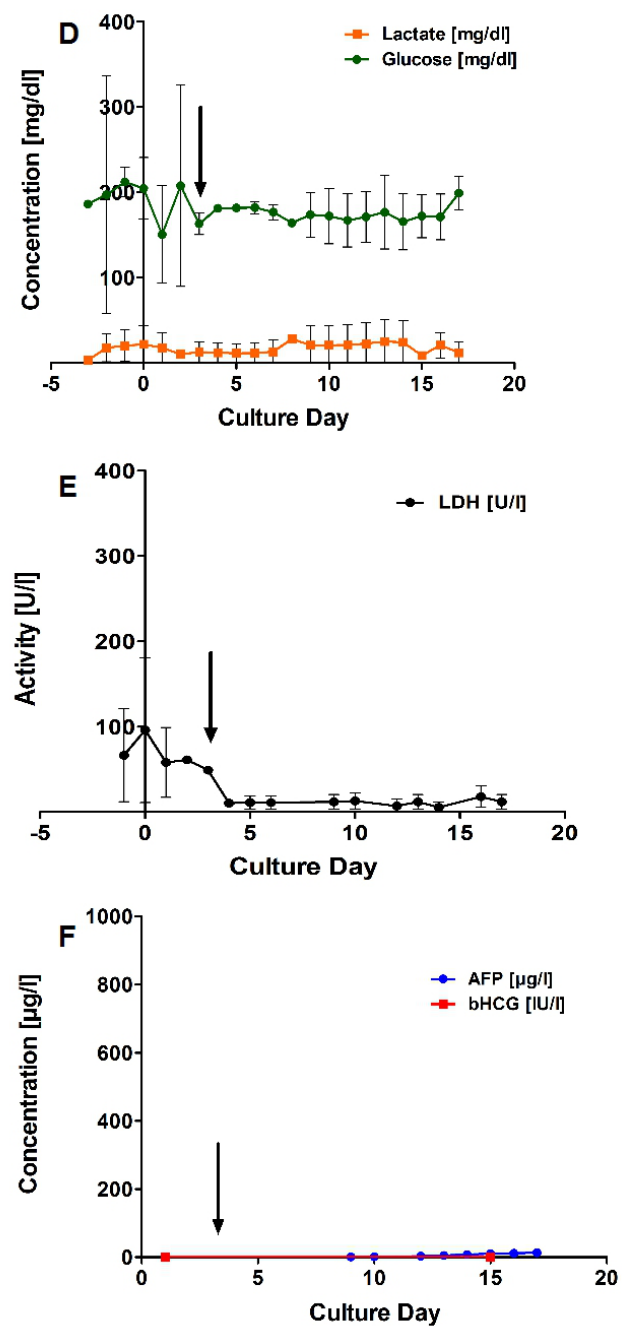

Figure 29: Time course of glucose \& lactate (A), LDH activity (B), AFP \& bHCG (C) concentration of a bioreactor culture (right hand side) $(n=2)$ or conventional 2D culture (left hand side) ( $n=4)$ differentiated according to approach 2; the arrows indicate the end of definitive endodermal commitment of the cells.

The cells inoculated in 3D bioreactor systems had a robust metabolic activity (figure 29 D). The LDH release after cell inoculation was moderate, and the LDH release under definitive endodermal differentiation was surprisingly low (figure $29 \mathrm{E}$ ). Factors marking differentiation (AFP, bHCG) of hESC were barely detectable (figure $29 \mathrm{~F}$ ). The metabolic activity of cells during hepatic differentiation in conventional 2D culture was stable (figure $29 \mathrm{~A}$ ), but a strong LDH release was measured during the first stage of differentiation (figure $29 \mathrm{~B}$ ). A high concentration of AFP was measured, 
while bHCG concentrations were below the detection limit (figure $29 \mathrm{C}$ ).

At the end of 2D or 3D culture experiments cells were harvested and RNA was isolated. Analysis of marker gene expression was performed as described for approach 1.

A strong induction of AFP was found in both culture systems (figure $30 \mathrm{~A}$ and $\mathrm{B}$ ), the expression of the ectodermal marker neurofilament was significantly stronger induced in 3D bioreactors. SOX17 and Albumin were stronger induced in conventional 2D cultures compared to 3D bioreactor systems.

Conventional 2D culture

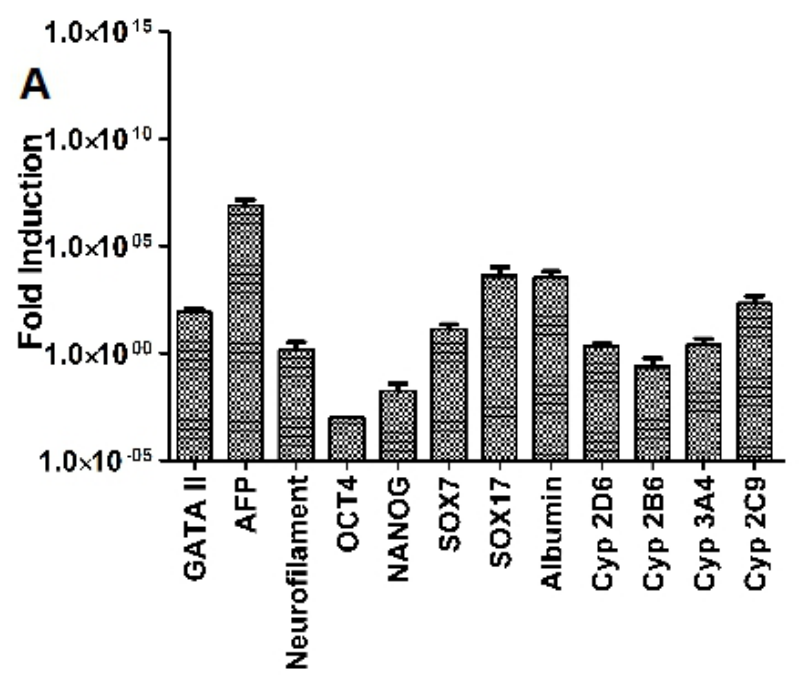

3D bioreactor culture

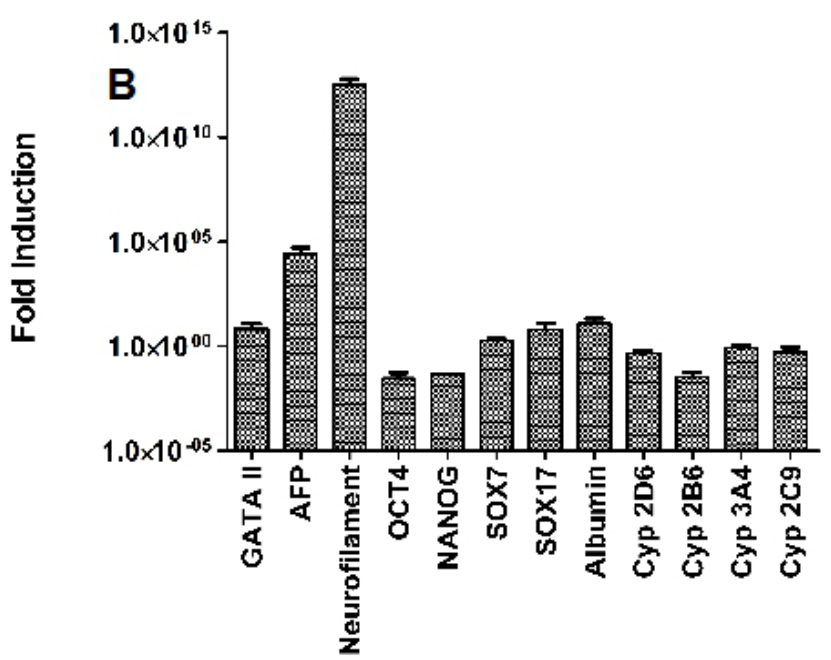

Figure 30: Fold induction of genes characteristic for undifferentiated cells (Oct-4, Nanog) and for cells differentiated into endodermal (AFP), mesodermal (GATA II), ectodermal (Neurofilament) and hepatic (SOX17, Albumin, Cyp2D6, Cyp2B6, Cyp3A4, Cyp2C9) cells in hESCs harvested at bioreactor shutdown after differentiation according to approach $2(n=2)$ or after differentiation in conventional 2D culture $(n=4)$. 


\subsubsection{Hepatic differentiation of partial feeder dependent hESC in 3D} bioreactor systems according to Cellartis approach 1

In order to investigate the hypothesis that cell injury occurring during the DE commitment might influence the differentiation and maturation of cells in 3D bioreactors, feeder independent hESC (cell line: SA121) were initially cultured and differentiated in conventional 2D cultures (1E6 per bioreactor). After accomplishment of the definitive endodermal commitment (d8) the cells were enzymatically detached and inoculated into miniaturized bioreactors ( $0.2 \mathrm{ml}$ cell compartment volume). The cells were further proliferated, differentiated and maturated for 25 days. The time course of glucose consumption, lactate production, LDH, AFP and bHCG release is shown in figure 31 .

The metabolic activity of the cells strongly decreased after the cells were inoculated into the bioreactors (on day 8). A high LDH release was seen during definitive endodermal commitment but not after bioreactor inoculation. Beta-HCG was measured at low levels until about day 19, AFP was measured at low levels from day 15 on. 

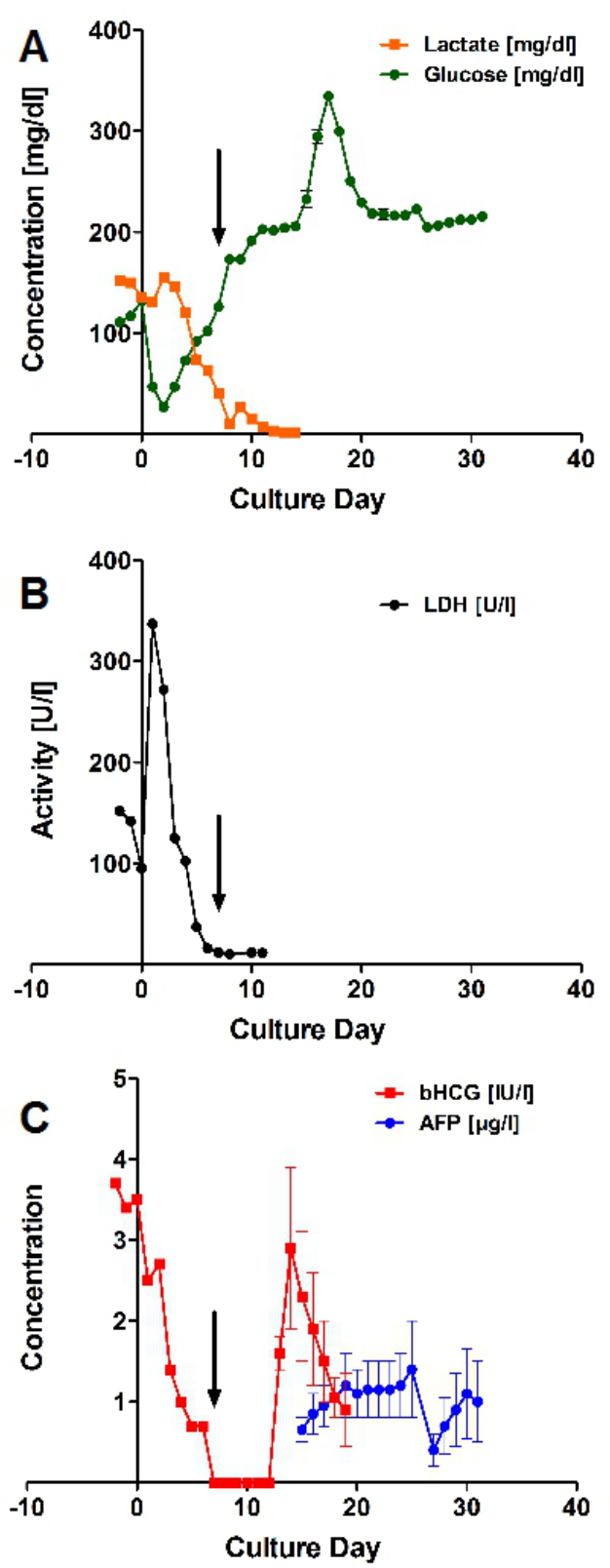

Figure 31: Time course of glucose \& lactate (A), LDH activity (B), AFP \& bHCG (C) concentration taken from 3D bioreactor cultures differentiated according to Cellartis approach 1. Arrows indicate the end of DE commitment and the transfer of cells into the 3D bioreactor systems $(n=2)$. 


\subsubsection{Hepatic differentiation of partial feeder dependent hESC in 3D} bioreactor systems according to Cellartis approach 2

In this approach feeder independent hESC (cell line: SA121) were inoculated into an Analytical scale bioreactor. In total 5E7 viable hESC were differentiated for 30 days after a 3 days adaptation period. The time course of glucose consumption, lactate production, LDH, AFP and bHCG release is shown in figure 32.


Figure 32: Time course of glucose \& lactate (A), LDH activity (B), AFP \& bHCG (c) concentration of a bioreactor culture differentiated according to approach Cellartis 2. 
The metabolic activity of the inoculated cells was stable over the duration of the experiment. Two peaks in the time course of LDH concentration were obvious. The first increase occurred subsequent to cell inoculation and the second during endodermal commitment. After endodermal commitment the LDH activity levels decreased and stabilized.

The concentration of beta-hCG increased from day 13 to day 16 , stayed at this high concentration until day 21 , and afterwards declined. The AFP concentration increased from day 13 on and reached its maximum around day 28. 

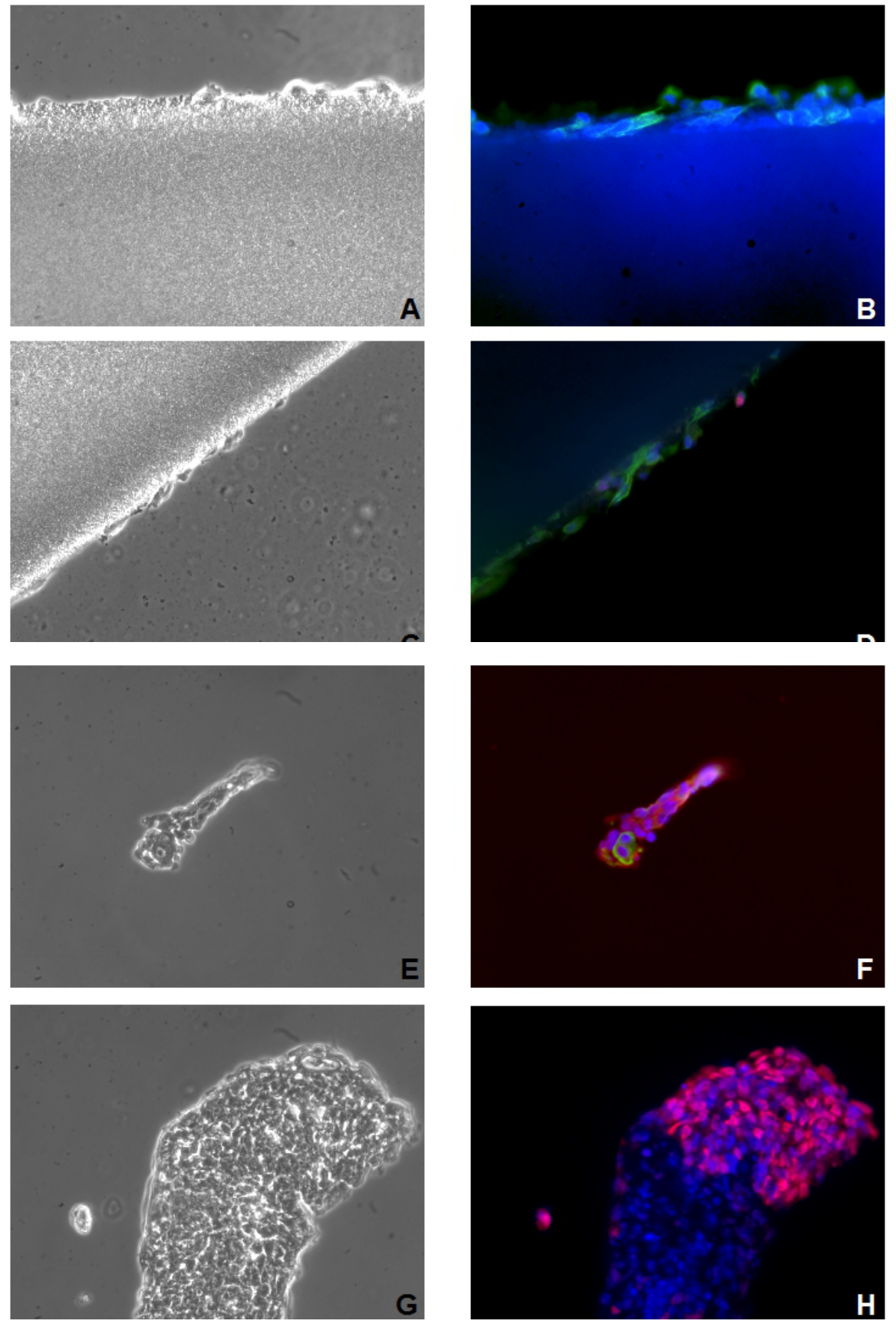

Figure 33: Immune histochemistry of cells harvested after bioreactor culture following differentiation according to approach Cellartis 2 (B) CK19 (green) \& DAPI (blue); (D) CK18 (green), Ki67 (red) and DAPI (blue); (F) CK19 (green), AFP (red), DAPI (blue); (H) Oct-4 (red), DAPI (blue); (A), (C), (E), (G) phase contrast microscopy picture; 400x total magnification in all pictures. 
The samples taken after bioreactor shutdown were stained for various hepatic and non-hepatic markers (figure 33). Interestingly the cells showed a CK18 / CK19 positive phenotype. A relatively high number of these stained positive for Ki67, indicating mitotic activity. The majority of the CK18/CK19 positive cells also stained positive for AFP. The co-expression of vimentin was seen as well in these cells. Interestingly cells expressing the pluripotency marker Oct-4 could also be identified. They were mostly found in larger aggregates.

\subsubsection{Hepatic differentiation of partial feeder dependent hESC in 3D bioreactor systems according to Cellartis approach 3}

In this approach feeder dependent hESC (cell line SA002) were inoculated in lab scale bioreactors after SCED culture propagation. The cells were differentiated for 46 days after a three-day recovery period after cell inoculation. In total two bioreactor runs were conducted following that protocol. In the first run $8.5 \mathrm{E} 7$ viable hESC were inoculated. The second bioreactor was inoculated with the same amount of hESC and additionally with 5E7 MEF. The time course of glucose consumption, lactate production, LDH activity, AFP and bHCG release is shown in figure 34. 



Figure 34: Time course of glucose (A), lactate (B), LDH activity (C), AFP (D) and bHCG (E) concentrations of two bioreactor cultures differentiated according to approach Cellartis 3 $(n=2)$. The arrows indicate the end of the endodermal commitment of the cells.

The metabolic activity of the two bioreactors was stable over the duration of the experiment, with some differences between the bioreactors (Figure 34). The consumption of glucose of cells inoculated with MEF was higher compared to the activity seen in the bioreactor without additional feeders.

In both bioreactors a high concentration of LDH can be seen right after cell inoculation. This is probably a result of cell stress during inoculation/adaptation to 3D conditions.

The curves for AFP and bHCG look similar in both bioreactor runs, although concentrations are about 7 times higher in the bioreactor culture with additional MEF. After bioreactor shutdown samples for immune histochemistry were taken. The 
sample collection for RNA and immune histochemistry analysis in the bioreactor without additional feeder cells failed probably due to the low number of viable cells after accomplishment of the differentiation.

In the microscopic evaluation of the samples two different cell types imposed. The first cells type stained positive for CK18 without (in the majority of cells) a positive coexpression of AFP. HNF4a and Albumin were expressed as well in those cells. The second cell type was not found to express this set of markers, but vimentin and in some cases Ki67 (Figure 35). 

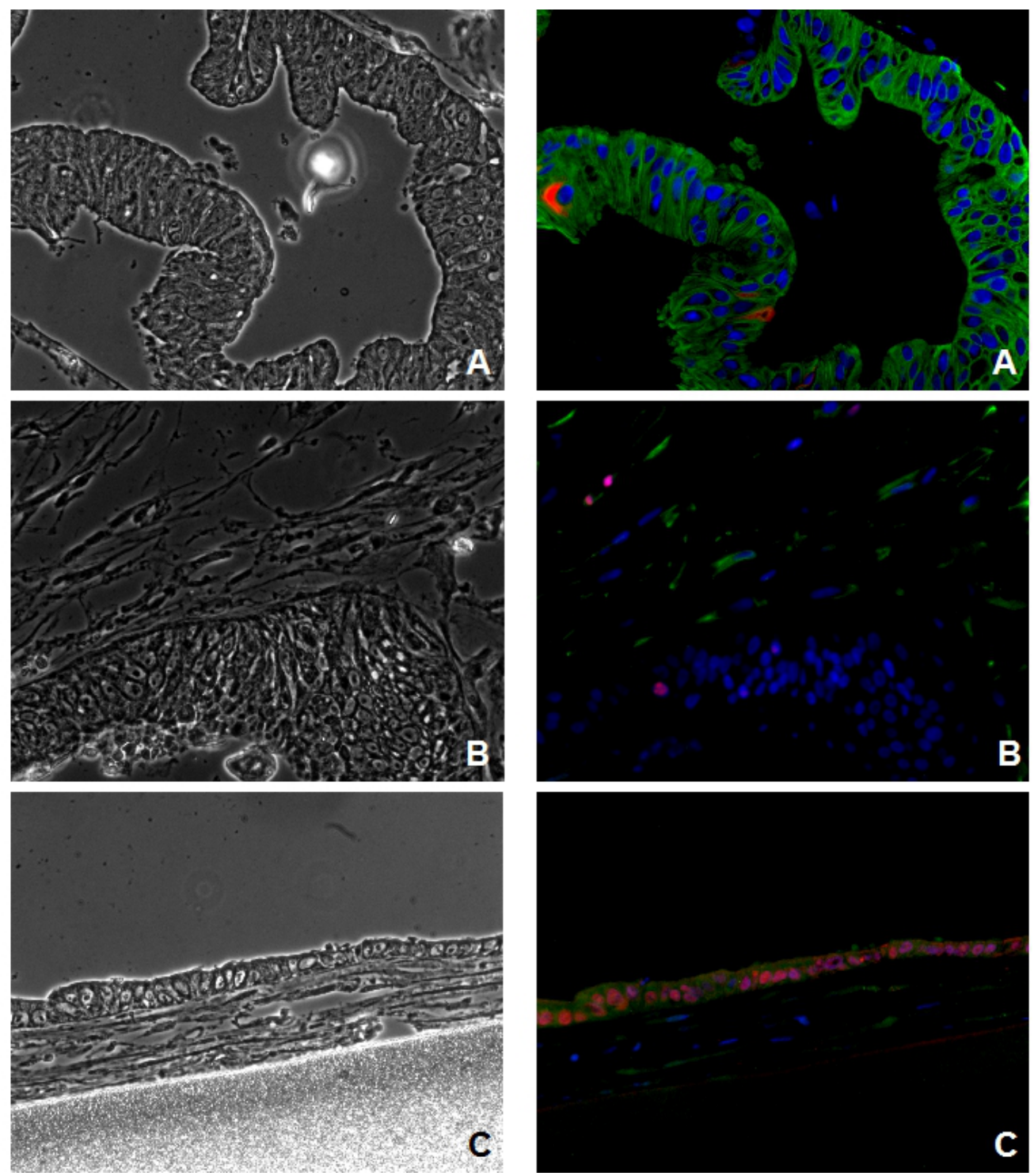

Figure 35: Immune histochemistry of cells harvested after bioreactor culture following differentiation according to approach Cellartis 3, CK18 (green) and AFP (red) (A); Vimentin (green) and Ki67 (red) (B); HNF4a (red) and Albumin (green) (C); 400x total magnification. 


\section{Discussion}

In this study two different strategies for hepatic differentiation of hESC were followed in parallel: The first strategy focused on differentiation of hESC in a 3D bioreactor environment using a minimum of xenobiotic material. First the hESC were adapted to feeder independent conditions. After evaluation of this culture method in terms of maintaining the undifferentiated state of the cells, the hESC were differentiated according to various protocols. Two of these protocols were successfully established and employed in a 3D differentiation approach.

The second differentiation strategy performed in cooperation with Cellartis laid a stronger focus on experiments in 3D bioreactor systems. Initial point was a protocol for the hepatic differentiation in conventional 2D culture (Brolén et al., 2010) ${ }^{67}$. This method was modified and adapted to 3D bioreactor culture conditions.

\subsection{The establishment and improvement of culture conditions of hESC}

The first experimental data of this study were collected using the feeder dependent hESC line SA002. The standard maintenance culture utilized mouse embryonic fibroblasts (CF-1) and included the manual dissection of colonies every 5 to 7 days into small pieces. The fragments were then transferred into prepared culture dishes. Besides the fact that this method is very labor intensive and requires highly trained personal, the dependence on feeder cells of animal origin holds a risk for pathogenic agent transfer over species barriers, and a high feeder batch variation ${ }^{74}$. However, this method also holds a number of advantages compared to other protocols including the enzymatic dissociation of cultures during passage. It has been shown that the enzymatic treatment might induce genomic alterations ${ }^{75}$ and it is possible to pre-select colonies that show hallmarks of differentiation during manual passage. Thus, manual passaging provides the chance of gaining a culture richer in undifferentiated cells after passage.

In order to prepare larger cell numbers for 3D bioreactor experiments the cells were 
cultured in single cell enzymatic dissociation (SCED) culture conditions ${ }^{76}$. Here the concentration of bFGF was increased and inactivated human foreskin fibroblasts (HFF) served as feeder cells instead of MEF. Interestingly the grow pattern changed completely under these conditions. The hESC showed an integrative grow pattern. Microscopic evaluation of the cell morphology was practically impossible in contrast to standard culture conditions in co-culture with MEF.

In order to further standardize and simplify the long-term maintenance of hESC, culture conditions for feeder independent hESC were established. The cultures only sparely differentiated under conditions promoting the undifferentiated proliferation. The expression of markers indicating the pluripotent state of hESC, such as Oct-4 and Nanog ${ }^{77}$ were routinely evaluated via PCR, Real-Time PCR and immune histochemistry. The hESC were adapted to feeder independent culture in mTeSR1 ${ }^{\mathrm{TM}}$ medium. It is known that this medium contains human TGF beta and bFGF. Several reports have shown the necessity of TGF beta superfamily member Activin / Nodal, FGF and Wnt signaling to sustain the undifferentiated state and pluripotency 78,79 of $\mathrm{hESC}$ by the activation of a core network that involves the transcription factors Oct-4, SOX2 and Nanog ${ }^{80}$.

Oct-4 is a POU-family homeobox transcription factor that is exclusively expressed in pluripotent cells of the inner cell mass of a blastocyst ${ }^{81}$ and early germ cells. It has been shown that the expression of Oct-4 is essential for the pluripotency of the cells from the inner cell mass of a blastocyst and in Oct- 4 deficient embryos the ICM cells are restricted to the extraembryonal trophoblast lineage ${ }^{82}$. Interestingly alterations in Oct-4 expression levels result either in endodermal differentiation (in case of up regulation of expression) or mesodermal and endodermal differentiation (in case of down-regulation of expression) ${ }^{83}$.

The SOX (SYR-related HMG box) family member SOX2 is not exclusively expressed in embryonic stem cells, but also in several differentiated cells ${ }^{84}$. It has been reported that the over-expression of SOX2 leads to trophectoderm differentiation whereas the reduction of SOX2 expression leads to trophectodermal and partial endodermal differentiation ${ }^{85}$. The necessity of SOX2 in the maintenance of the undifferentiated state of hESC has been questioned since in some cell lines it has been shown to be absent ${ }^{86}$ and its absence is possibly compensated by other SOX 
family members.

The homeobox transcription factor Nanog is in humans exclusively expressed in the cells of the ICM, early germ cells and hESC ${ }^{87}$. The down-regulation of Nanog has been shown to induce the differentiation of human embryonic stem cells to extraembryonal lineages ${ }^{88}$. The over-expression of Nanog in hESC has been demonstrated to contribute to the maintenance of the undifferentiated state in the absence of feeders or conditioned media for a period of time ${ }^{89}$. Interestingly the expression of Nanog has also been found in several neoplasia ${ }^{90,91}$ and was reported to improve proliferation and life span together with Oct-4 in human mesenchymal stem cells over-expressing these two transcription factors ${ }^{92}$.

It has been reported that Nanog, Oct-4 and SOX2 play an essential role in the regulation of a global transcriptional network responsible for the maintenance of the undifferentiated state of stem cells ${ }^{93}$. Interestingly Oct-4 and SOX2 seem to regulate the expression of genes like Nanog and Utf1 and others, but also their own expression ${ }^{94}$. It was also reported that the expression of Nanog seems to be independent from that of Oct-4 and SOX2. In order to determine the undifferentiated state of cultured hESC the expression of Oct- 4 and Nanog was determined routinely.

In order to determine the in vitro pluripotent potential hESC were cultured under conditions that support the spontaneous differentiation ${ }^{95}$ for 17 days in conventional 2D culture. The data suggest a stable metabolic activity, the LDH activity was constantly high, suggesting apoptotic and / or necrotic processes during culture. During the last third of the experimental duration considerable amounts of beta-hCG were measured in the supernatant. This hormone is physiologically expressed during pregnancy by the syncytiotrophoblast and has recently been found to act promitotically and support neuroectodermal development ${ }^{96}$. RNA was isolated after 5, 9 and 17 days and analyzed via real time PCR. Already after 5 days the expression of markers indicating the pluripotent state of hESC dropped dramatically. Surprisingly no further reduction was seen after 9 or 17 days, indicating a possible remain of pluripotent cells. The expression of the endodermal marker AFP increased over time and the mesodermal marker GATA II was expressed strongly and constantly in all three time points measured. A weak expression of neurofilament was found at day 5 
and day 9, but it was increased at day 17 indicating a progressive commitment to the ectodermal lineage. Comparative kinetics for the expression of lineage specific genes have been described recently ${ }^{97}$. In summary the capability of cultured hESC to differentiate in conventional 2D culture into all germ layers was demonstrated.

In order to investigate the effects of 3D bioreactor culture on the potential of hESC to spontaneously differentiate and to form cells of the three germ layers, hESC were cultured for 17 days under conditions that support embryoid body formation. The metabolic activity was at a low level and stable, LDH concentrations in daily samples increased until day 4, and dropped afterwards constantly. The concentration of AFP increased from day 10 on, indicating a strong commitment to the endodermal lineage. At bioreactor shutdown RNA was isolated, the subsequent real-time analysis revealed a decreased expression of the pluripotency markers Oct- 4 and Nanog to levels comparable to levels seen after 17 days of spontaneous differentiation in 2D. Surprisingly the expression of markers for the mesodermal (GATA II) and ectodermal (neurofilament) lineage were only slightly induced under the given conditions, whereas the expression of AFP was strongly induced. This can be interpreted as a result of the given culture conditions that either support the proliferation or survival of cells that underwent endodermal lineage commitment or aggrieves cells on nonendodermal lineages. Although the induction of markers for the three germ layers was seen during this experiment and in previous studies ${ }^{58}$ the proportions and kinetics seem to vary depending on the culture system chosen. In summary the capability of the 3D bioreactor system to support spontaneous differentiation into the three germ layers was demonstrated.

In addition to the in vitro experiments performed for the demonstration of the pluripotent state of hESC adapted to feeder free conditions, in vivo experiments were conducted as well. In total 97 mice were treated with different amounts of undifferentiated cells (table 37). In three of these animals the formation of a solid tumor was seen after 120 days. In two of the three animals dissected a teratoma composed of derivatives of all three germ layers was identified by HE staining and histopathological interpretation. Only in one animal no ectodermal structures could be identified properly. In general the tumorigenic potential of feeder free cultured 
hESC seems to be rather low. Further investigation is needed to understand the reduced tumorigenic potential of the hESC under feeder free culture conditions.

\subsection{Hepatic differentiation in conventional 2D culture}

In order to establish a protocol for the hepatic differentiation in 2D culture five different approaches were tested. In four of the five approaches Activin A was used for the definitive endodermal commitment (Table 32). After the definitive endodermal commitment of the cells, the cell number was determined and RNA was isolated. During the DE differentiation a combination of one or more of the signal molecules Activin a, Wnt3a, BMP4, bFGF, Ly294002, sodium butyrate and DMSO were used.

The Nodal/Activin A pathway does not only play a central role in the maintenance of the undifferentiated state in $\mathrm{hESC}$, it also induces the formation of mesendoderm and subsequently definitive endoderm and mesoderm in a concentration dependent manner ${ }^{21}$. Interestingly the extent of DE differentiation has been reported to be modulated by FGF and Wnt pathway signaling, but in the absence of Activin/Nodal signaling they can neither maintain hESC pluripotency nor commit cells to the mesendodermal lineage in chemically defined medium ${ }^{98,79}$. In conclusion, Activin A seems to act upstream of the FGF and Wnt pathway, and it has been shown that the inhibition of Activin/Nodal signaling results in the promotion of neuroectodermal differentiation ${ }^{99}$.

The bone morphogenic protein member BMP4 is known to play a crucial role in the development of various tissues like lung, bone and tooth ${ }^{100-102}$. The stimulation with BMP4 together with FGF2 has been shown to induce mesendodermal differentiation ${ }^{103}$. Further it has been reported that the combination of BMP4 and Activin A generates endodermal cells expressing FOXA2 and SOX17 ${ }^{104}$. In addition it has been reported that the combined successive stimulation of hESC with Activin $A$, BMP4, FGF2 and VEGF (vascular endothelial growth factor) promotes the generation of a multipotent mesoderm progenitor population that can give rise to various mesodermal cells ${ }^{105}$. In conclusion BMP4 signaling seems to modulate 
mesendodermal and mesodermal specification.

The transcription of Wnt3a has been reported to experience activation during the induction of primitive streak PS and mesendoderm formation by Activin $A^{78}$. In consistence with these findings, Wnt signaling has been shown to induce brachyury (BRU)-positive PS / posterior mesodermal formation in serum free conditions, and when combined with an antagonist of BMP a differentiation into PS / definitive endodermal and anterior mesodermal cells can be induced ${ }^{106}$. These findings led to the development of protocols using Activin A and Wnt3a for efficient differentiation of hESC to definitive endodermal cells. Despite minor differences between these protocols, in each of these approaches a short-term (24-48 hours) stimulation with Activin A and Wnt3a is followed by a 48 hour long stimulation with Activin A in presence of low serum concentrations.

The fibroblast growth factor pathway has been shown to play a crucial role in embryonic development and the maintenance of the pluripotent state in hESC ${ }^{107}$. Interestingly, when the downstream effector of FGF signaling MAPK is blocked, hESC lose pluripotency markers and differentiate towards the primitive endoderm and trophoectoderm lineage ${ }^{108}$. FGF has been shown to act in a synergistic way in combination with Activin $A$ in the commitment of hESC to the definitive endodermal lineage ${ }^{98}$. In addition it has recently been shown that sodium butyrate can influence the cell fate of definitive endodermal cells in a dose dependent manner ${ }^{109}$.

Sodium butyrate is a small molecule that has various effects on cell cultures including the inhibition of proliferation, induction of differentiation, induction or repression of gene expression and histone hyperacetylation by the inhibition of histone deacetylase ${ }^{110}$. It has been reported to support the definitive endodermal commitment in human ESC ${ }^{111}$ as well as the hepatic differentiation of DE committed cells in mice ${ }^{112}$.

Another small molecule used for the hepatic differentiation is dimethylsulfoxide (DMSO). It was reported to have a dose dependent effect on the expression of a large number of genes ${ }^{113}$. In the past DMSO has been widely used for the cryopreservation of cells, but has recently been found to also affect the undifferentiated state of hESC ${ }^{114}$. In protocols for hepatic differentiation of hESC it 
has been used for the endodermal commitment ${ }^{22}$ and in later stages of differentiation ${ }^{115}$.

The phosphoinositide 3-kinase (PI3K) and mTOR pathway inhibitor LY294002 is a pharmaceutical drug that is currently under clinical evaluation in the treatment for various cancer types ${ }^{116}$. Further on this drug was reported to inhibit insulin signaling during definitive endodermal commitment of human IPSC ${ }^{117}$ and hESC ${ }^{118}$.

After the endodermal commitment of the hESC, cells were found to be viable in differentiation approaches one, two and three. The cells of the fourth and fifth approach perished shortly after the beginning of the differentiation. The determination of cell numbers after endodermal differentiation showed that the highest cell number was achieved in approach one, followed by approach three and two. In general, the DE commitment of the cells is a process that is associated with a large scale decline of cells. This is clearly illustrated by a dramatic reduction in cell number compared to the amount of cells before differentiation and the high LDH activity.

Real time PCR analysis revealed a successful commitment to the endodermal lineage in approach 2 and 3 by the strong expression of SOX17 ${ }^{119}$. Interestingly the expression of the mesodermal marker GATA2 was significantly higher in approach 1 and 2 compared to the third approach. Together with the highest expression of the endodermal marker AFP in the third approach the definitive endodermal commitment seemed to be more robust in the cells differentiated according to that protocol compared to the other two approaches. But despite the superior endodermal lineage commitment in the third approach, the cells vanished after the transfer into a new culture dish. Due to the fact that the LDH activity measured in the supernatant of the third approach was not elevated in the first medium exchange after the passage of the cells it is likely that the cells already declined during passage. Considering the fact that the DE commitment alone has already been demonstrated to induce apoptosis it seems to add an additional challenge to passage cells directly after this sensible step.

In the most promising approaches (one and two) the differentiation was continued to attain fully differentiated hepatic cells. 
After definitive endodermal commitment of the hESC the cells were stimulated by a cocktail composed of insulin, hydrocortisone, EGF, HGF, ascorbic acid, transferrin and oncostatin $\mathrm{M}^{68}$.

The effect of glucocorticoids like hydrocortisone on fetal liver cells has been studied intensively during the last decades. It has been shown that hydrocortisone administration prolongs the expression of AFP and delays the expression of Albumin in fetal mouse liver hepatocytes ${ }^{120}$. In adult liver cell lines it has been demonstrated that the administration of glucocorticoids prolongs the expression of Albumin and transferrin ${ }^{121}$ and keeps primary cells ex vivo longer in their differentiated and functional state. It addition it has been demonstrated that dexamethasone induces the expression of HNF4 and C/EBP-alpha ${ }^{122 .}$

The addition of the TGF-superfamily members HGF and EGF has been demonstrated to induce the expression of AFP, HNF4 as well as genes of the biliary lineage ${ }^{122}$. Further reports showed a positive effect of HGF on the proliferation and differentiation of DE committed hESC towards the hepatic lineage ${ }^{123}$. This is consistent with reports showing the necessity of HFG and EGF signaling for biliary cell formation ${ }^{124}$.

The fibroblast growth factor pathway has been found to be activated during embryoid liver development ${ }^{125}$. Interestingly in an in vitro culture approach with endodermal differentiated human embryonic stem cells an inhibition of hepatocyte differentiation under increased FGF concentrations was shown ${ }^{126}$.

The Interleukin 6 related cytokine Oncostatin M (OSM) has been investigated intensively and has been reported to induce the up-regulation of hepatocyte specific functions, including lipid synthesis, glycogen synthesis, detoxification and ammonia clearance ${ }^{127}$ as well as morphological changes and enhanced inter-cell adhesion ${ }^{128}$. Interestingly, the lack of OSM signaling in high-density cultures does not lead to abolished liver differentiation, indicating an unknown and OSM independent differentiation / maturation pathway. Further on it has been shown that not only a proper cytokine stimulation by Oncostatin $\mathrm{M}$ and high cell density seems to be necessary for the final maturation of hepatocytes but also a certain composition of the extra cellular matrix ${ }^{129}$.

The number of cells in the cultures was determined after accomplishment of hepatic differentiation. A further reduction in total number was found in both approaches, but 
not in an extent seen after DE commitment. The cultures were treated with the same cytokine cocktails as shown in table 32. Interestingly considerable bHCG concentrations were only measured in approach one, whereas AFP was only detected in approach two. It was first measured at detectable concentrations around day six and increased constantly from there on. This finding is consistent with the real time RNA analysis of the cultures. The extent of hepatic differentiation was very limited in approach one indicated by a weak expression of SOX17 and Albumin. In the second approach all these markers were significantly stronger expressed, although the RNA expression of several cytochrome P450 isoforms was low compared to primary hepatocytes (data not shown). This finding is consistent with the fact that the expression of AFP was still quite strong at the end of differentiation, indicating an immature state of the cells ${ }^{130}$, since AFP has been reported to be expressed during fetal development in the liver, and in adult livers only during excessive tissue regeneration or in association with malignant growth. The immune histochemical analysis of the cells revealed a weak cytokeratin18 and cytokeratin 19 double positive immune reaction in the first approach. This again indicates a rather immature state of differentiation. A comparable combination of cytokeratin expression was described for human fetal liver cells ${ }^{131}$. It was obvious that the cell population was not homogenous and areas with cells that showed more and less intense immune reaction altered.

The immune histochemical analysis of the cells of the second approach revealed a double positive reaction for cytokeratin 18 and cytokeratin 19 as well. But in comparison with approach one the cells were larger in size and the reaction was more intense. In addition, the cell population also stained positive for vimentin in some areas. Interestingly this combination of markers has been described previously for adult human liver progenitors isolated from ischemic liver tissue ${ }^{132}$.

In order to investigate the stability of the hepatic differentiation performed according to approach two, cell were cultured after accomplishment of differentiation for additional 14 days in medium that either supports further maturation by a stimulation with HGF, EGF, hydrocortisone and oncostatin M (HCM2.2) or in medium that supports spontaneous differentiation (EBMed).

Over the 14 days of additional culture the cells exhibited a stable and comparable 
metabolic activity. The LDH activity in the supernatant was constantly low. The AFP release remained at a constantly high level with a significant drop in cultures maintained in EBMed at the end of the experiment. Surprisingly the bHCG levels increased slightly after accomplishment of differentiation in both media and reached their maximum two days for the HCM2.2 media and respectively four days for the EBMed. Thereafter the levels decreased to basal levels.

The real time RNA analysis revealed a relatively stable expression profile after three days in media supporting either the maturation or the spontaneous differentiation. The expression of Albumin and cytochrome P450 2B6 was slightly increased in the culture maintained in HCM2.2 compared to the culture in EBMed after accomplishment of differentiation. The expression of markers indicating an undifferentiated state in hESC or a commitment to a non-hepatic lineage (GATA II or neurofilament) was stable.

A further induction of Albumin and cytochrome P450 2B6 expression was seen in HCM2.2 media after 14 days. The expression of AFP was found to be only slightly decreased. Markers indicating the undifferentiated state of hESC or the commitment to non-hepatic lineages were still stable after 14 days. In conclusion the state of differentiation gained after accomplishment seemed to be stable. Despite the differences in media composition the expression levels of the investigated markers did not alter dramatically. A further maturation of the cells that would be associated with a decreased expression of AFP and an increased expression of Albumin and cytochrome P450 isoforms was not seen despite constant stimulation with various cytokines. It has been shown that not only the precise cytokine stimulation and a certain extracellular matrix but also cell-cell interactions found at sufficient levels only in high density cultures are required for the maintenance of liver specific functions in human hepatocytes ${ }^{54}$ as well as in hepatic tumor cell lines ${ }^{53}$. Thus, it appears rational to assume that the degree of maturation can be further increased by the modification of the cell density. 


\subsection{The culture of hESC in 3D bioreactor systems}

The dissociation of hESC has been reported to be highly associated with cell decay 133. Although progress has been made on this issue by the introduction of ROCK inhibitors, the cells appear still fragile after passage (own observations, data not shown). To increase cell survival in bioreactor differentiation experiments, an additional adaptation period between 24 and 72 hours was applied after cell inoculation before the start of differentiation. To determine the effect of the adaption period on the undifferentiated state of the inoculated hESC a $48 \mathrm{~h}$ bioreactor run was performed.

The metabolic activity of the inoculated cells was low but stable, and LDH activity was high after $48 \mathrm{~h}$ indicating a certain degree of cell decay but also viable cells and thus a successful inoculation (Figure 25). The concentrations of AFP and bHCG were below detection limit.

The real time RNA analysis revealed no significant drop in the expression of markers indicating the pluripotency of hESC (Oct-4, Nanog). The expression of markers for lineage commitment was only slightly increased (GATAII, AFP, neurofilament).

\subsection{Hepatic differentiation in 3D bioreactor systems}

In order to investigate the effect of a 3D culture system on the hepatic differentiation, hESC were inoculated and differentiated according to approach one or two. One of the main goals of this strategy was the hepatic differentiation under conditions that allow potential clinical application. Both approaches were conducted utilizing feeder independent hESC and protocols with chemically defined media. 


\subsubsection{Feeder independent Approach 1}

In the first approach cells were inoculated in miniaturized bioreactors (cell compartment volume $0.4 \mathrm{ml}$ ) and a $48 \mathrm{~h}$ additional adaptation period after inoculation in medium supporting the undifferentiated growth was applied before the start of differentiation.

The cells showed a stable but lower metabolic activity compared to the same approach in conventional 2D cultures. A high LDH activity was measured during the first days of bioreactor culture with its maximum around day one. This was seen in various bioreactor experiments and can be interpreted as a result of inoculation associated cell decay. Interestingly, cells differentiated according to this approach in conventional 2D cultures tended to release bHCG into the medium with maximum concentrations measured around day 10 to 12 . HCG is known to be released next to various other signal molecules by the syncytiotrophoblast during pregnancy. It has further been reported that trophoblast (a precursor of the syncytiotrophoblast) differentiation of hESC can be achieved by the addition of exogenous BMP4 or by spontaneous differentiation ${ }^{134}$. Under $3 D$ bioreactor conditions though, the levels of bHCG concentrations remained below detection limit and instead considerable amounts of AFP were measured indicating endodermal commitment of the cells. AFP is known to be not only expressed in the developing liver, but also in cells of the yolk sac that develops from extra-embryonic endoderm. It has been reported that extraembryonal cells can be identified by a high expression of SOX7 and SOX17 ${ }^{135}$. Interestingly, the induction of SOX7 expression appears to be robust in 3D bioreactor cultures and exceeds the level of SOX17 induction. However, taking into account that the induction was normalized to gene expression after 48 hours of 3D bioreactor culture (Figure 26) and a strong induction of SOX17 was found already at that timepoint, the induction of SOX17 exceeds SOX7 about 10 times. A strong expression of SOX17 and FOXA2 has been described for cells committed to the definitive endodermal lineage ${ }^{118}$. In addition, an induction of Albumin expression was found, both in cells after 48 hours bioreactor culture and in the cells after hepatic differentiation in a 3D bioreactor system according to approach one. Therefore it appears that the change of the culture system did not only change the general lineage commitment, but also supports the hepatic differentiation under the given 
cytokine stimuli.

Notably, although the expression of markers indicating the undifferentiated state of hESC (Oct-4 and Nanog) seems to be dramatically diminished in conventional 2D culture, a basic expression was still present in the sample taken from the 3D bioreactor culture.

\subsubsection{Feeder independent Approach 2}

In order to investigate the potential of the hepatic differentiation of hESC in 3D bioreactor systems according to approach two, cells were inoculated in miniaturized bioreactors (cell compartment volume $0.4 \mathrm{ml}$ ). An additional adaptation period of 48 hours was conducted compared to conventional 2D cultures. Here again, a basic but reduced metabolic activity compared to the $2 \mathrm{D}$ culture was seen in the bioreactor cultures. A high LDH activity after cell inoculation with a subsequent LDH release due to the endodermal commitment of the cells was seen in the 3D culture. In both culture systems the LDH activity decreased after DE commitment. HCG was measured at moderate concentration in $2 \mathrm{D}$ and $3 \mathrm{D}$ cultures. Interestingly from day nine on, constantly increasing concentrations of AFP were measured in 2D cultures, while in 3D culture these were only barely over detection limit. This might be due to the potentially low survival rate of the inoculated cells, and the unfavorable medium volume to cell number rate, but analysis of the expression revealed only a subordinate commitment to the hepatic fate in the 3D bioreactor system. Instead a strong induction of the ectodermal marker was found. Interestingly, several reports have been published that describe the neural differentiation using a chemical inhibitor of TGF-beta superfamily receptors, including the receptor for Activin and BMP ${ }^{136}$.

A possible explanation for these results might be based on the fact that after cell inoculation in 3D bioreactor systems larger cell aggregates accumulate, and that in central areas of these only decreased cytokine concentrations occur. A further explanation of the obviously decreased Activin A cytokine response might be found in the hydrophobic / hydrophilic character of the membranes used for medium / gas supply in the bioreactor cell compartment. The possible permanent or temporary 
adsorption of signal molecules might have a crucial impact on the lineage commitment of the cells.

The main goal of the following experiments conducted in collaboration with Cellartis was the establishment of a protocol for the hepatic differentiation in 3D bioreactors with a more mature phenotype. The experiments were conducted using feederdependent hESC and inactivated MEF.

\subsubsection{Partial feeder dependent Approach Cellartis 1}

In order to investigate the possibility that cell injury due to cell decay during $\mathrm{DE}$ commitment in 3D bioreactors might negatively influence the hepatic differentiation, hESC were differentiated for 7 days and after accomplishment of DE commitment cells were detached and inoculated into miniaturized 3D bioreactors (cell compartment volume $0.2 \mathrm{ml}$ ).

The metabolic activity measured during the following 25 days was very low, with $\mathrm{LDH}$ concentrations below the detection limit. A high LDH activity was seen during DE commitment, but not after bioreactor inoculation, indicating that cell decay occurred already during detachment, and not after inoculation of the cells into the 3D bioreactor system. Interestingly, despite the very low metabolic activity, detectable concentrations of bHCG and AFP were found, indicating a certain amount of differentiation towards syncytiotrophoblastic and hepatic cell fate. In conclusion the inoculation of cells that have previously been committed to the DE lineage does not result in an improved hepatic differentiation. The cells appeared fragile (as seen before in Approach 3 of the 2D experiments) after DE commitment, and thus cell passaging results in a reduced survival rate. 


\subsubsection{Partial feeder dependent Approach Cellartis 2}

In this complex approach cells were differentiated for a total of 30 days in an analytical scale bioreactor (cell compartment volume $4.0 \mathrm{ml}$ ). The metabolic activity was increased compared to the previous bioreactor experiments utilizing smaller bioreactor variants (Figure 32). After a three day adaption period the cells were committed to the DE lineage. This is consistent with the high LDH activity found during the first five days. Interestingly, bHCG and AFP were again detectable at considerable levels during differentiation. Elevated bHCG levels became detectable at around day 13 and maximum concentrations were measured during day 17 and 21. AFP was also detected at elevated levels at around day 14. The concentration constantly increased until the end of the experiment indicating an ongoing hepatic differentiation.

This is consistent with the immune histological stainings that revealed a CK18, CK19 and AFP triple positive reaction of the cells, as it has been described for immature hepatic progenitor cells ${ }^{132}$. In addition, some of these immature cells stained also positive for Ki-67, indicating ongoing proliferation.

Besides cell aggregates that stained positive for markers of the hepatic cell fate, also areas with cells expressing the pluripotency marker Oct- 4 imposed. The coexpression of Nanog was not investigated, but is likely ${ }^{137}$. Notably, Oct- 4 cells were only found in relatively large aggregates, indicating the formation of niche like structures that might have deprived the cells from exogenous signals promoting the differentiation of the cells. In conclusion cells were identified that had differentiated towards the hepatic cell fate, but still carry characteristics of immature cells. In addition cells were found that express Oct- 4 and thus can be considered to be at a very early state of differentiation. 


\subsubsection{Partial feeder dependent Approach Cellartis 3}

In order to enhance the degree of maturation of hepatic differentiated hESC lab scale bioreactors with a cell compartment volume of $17.2 \mathrm{ml}$ were inoculated either with or without additional inactivated MEF and cultured for an extended period of time (46 days) compared to approach Cellartis 2 (30 days).

The metabolic activity of the bioreactor that was additionally inoculated with MEF was significantly higher than that of the bioreactor without feeder cells (Figure 33). Interestingly, although the total number of cells inoculated was higher in the MEF containing culture the LDH activity after cell inoculation and DE commitment was comparable, indicating an improved cell survival not only after inoculation, but also after DE differentiation. Since inactivated MEF exhibit a limited live span the increased LDH activity measured in hESC co-cultured with MEF can be explained by the continuous decay of the MEF. Notably the concentrations of AFP found in samples drawn from MEF containing cultures were significantly higher compared to feeder-free cultures. But since the concentrations of bHCG measured were nearly identical until about day 30 , this fact can not only be explained by improved cell survival during early stages of development, but possibly also by improved commitment to the hepatic lineage. Due to technical issues at culture day 30 the sample collection of the feeder-free culture was not successful.

The immune histological stainings (Figure 35) of cell material from the bioreactor run with addition of MEF revealed two distinct cell types. The first one showed a positive result for the CK18 staining. A CK19 positive reaction was not found. The coexpression of CK18 and AFP was only sparely found, indicating remaining immature cells. In addition, the CK18 positive cell type also stained positive for HNF4a (a transcription factor responsible for the expression of various cytochrome P450 isoforms) and Albumin, as markers of mature hepatocytes ${ }^{138}$. 


\subsection{Conclusion}

The aim of the first strategy was the reduction of xenobiotic materials in the differentiation of hESC under 3D culture conditions. The culture of hESC was successfully adapted from feeder dependent to feeder independent conditions under maintenance of their pluripotent potential in vivo and in vitro. A protocol was established for the hepatic differentiation of hESC in conventional 2D culture, and the resulting cell population was characterized via real time PCR and immune histological staining. The expression of hepatocyte specific genes in the first approach was significantly lower than in the second approach when conducted in conventional 2D culture. Although the cells showed hallmarks of hepatocytes, the level of enzyme expression found in hESC-derived hepatocytes was not comparable to primary human hepatocytes (data not shown). Instead a robust expression of a gene indicating immature hepatocytes (AFP) was found. The prolonged culture of differentiated hESC was not sufficient to further maturate the cells.

The transfer of the established protocols from 2D to 3D culture conditions revealed unexpected effects regarding the amount and the direction of the differentiation compared to 2D cultures. Possible reasons for the altered differentiation kinetics may lie in the adsorption of signal molecules to the bioreactor capillaries, the formation of large cell aggregates associated with the formation of a concentration gradient of signal molecules and nutrients, and also the interference of cell debris or enhanced endogenous signaling due to higher cell densities. Further investigations are needed to address these questions. Surprisingly the expression of hepatocyte specific genes was higher in the first approach compared to the second approach when conducted in a $3 \mathrm{D}$ bioreactor system.

The main goal of the second strategy was the adaption of a protocol for the differentiation of hESC into hepatic cells published for conventional 2D cultures. The interference of cell injury occurring during DE commitment was investigated and the inoculation of DE committed cells subsequent to endodermal differentiation in 2D cultures was found to be not practicable. It was demonstrated that hESC that underwent definitive endodermal commitment feature a fragile state, and therefore the stress due to cell passaging and inoculation into the bioreactor system can 
probably not be compensated. The complete hepatic differentiation in 3D bioreactors was then investigated and revealed an immature cell type after 30 days of culture with remaining potential pluripotent cells. Finally the hepatic differentiation over an extended period of time was investigated and revealed a more mature phenotype identified by the expression of adult hepatic markers. In addition the absence of cells expressing markers of pluripotency was shown. Further a beneficial effect of coinoculated inactivated MEF on hESC cell survival and commitment to a hepatic lineage was revealed. Despite the expression of the adult liver markers the metabolic capacity of the bioreactor cultures needs to be further evaluated.

In general, the results of the 3D experiments demonstrated the possibility of hepatic differentiation of hESC in this culture system. However, the experiments were only conducted in laboratory-scale bioreactors with a cell compartment volume ranging from 0.2 to $17.2 \mathrm{ml}$. The therapeutic effect of these bioreactor models in extracorporeal liver support therapy would not be sufficient to have significant impact on a patient with acute or chronic liver failure. The capability of a small scale up has already been demonstrated during the experiments. The cultures demonstrated a stable and comparable performance in larger bioreactor models. A larger version of the bioreactor that has already been used in clinical application ${ }^{35}$ would meet the requirement to house sufficient numbers of cells for extracorporeal liver support utilizing differentiated hESC.

\subsection{Outlook}

With a growing understanding of the molecular pathways involved in the endodermal commitment and the further differentiation and maturation of the hESC a further optimization of protocols for the differentiation in 3D bioreactor systems also in regards to cost efficiency should be addressed. For example, it has recently been published that the combination of small molecules like rapamycin in combination with reduced amounts of cytokines results in an enhanced commitment to the definitive endodermal lineage ${ }^{118}$.

The various approaches utilizing the bioreactor system performed during this study 
illustrated the fragile nature of hESC that underwent cell passage. The high LDH activities detected after cell inoculation in combination with a lower metabolic activity compared to $\mathrm{hESC}$ in conventional $2 \mathrm{D}$ culture allows the assumption that a portion of the inoculated cells did not adapt to the 3D culture conditions of a bioreactor and underwent apoptosis. A lot of work has been invested into the identification and characterization of small molecules and their mechanism of action. Thiazovivin, pyrintegrin ${ }^{139}$ and the ROCK inhibitor Y-27632 ${ }^{140}$ are only three of these small molecules that might improve stem cell survival after bioreactor inoculation.

A further possibility to improve stem cell attachment, survival and differentiation after bioreactor inoculation might be achieved by the incorporation of various surface coatings. A study has recently been published that describes the benefits on survival and proliferation of undifferentiated hESC cultured in 3D culture systems coated with laminin and vitronectin ${ }^{141}$. In addition, it has been shown that the expression of hepatocyte specific cytochrome P450 enzymes is dependent also on the extracellular matrix ${ }^{142}$. 


\section{Abstract}

Human embryonic stem cells ( $\mathrm{hESC}$ ) are pluripotent cells capable of unlimited proliferation and of differentiation into cell derivatives of all germ layers. With a growing understanding of mechanisms that control cell differentiation, stem cell based therapies could play an important role in the future treatment of diseases. Further on stem cell derived differentiated cells could also be used in pharmaceutical research for in vitro tests of drug metabolism and toxicity.

The goal of this study was to investigate the hepatic differentiation of hESC in 3D bioreactor systems. Two different approaches were pursued.

The first strategy focuses on the reduction of xenobiotic materials. Two protocols were adapted for hepatic differentiation in a 3D bioreactor system.

In 2D cultures, the commitment to a hepatic lineage in protocol two was found to be superior compared to approach one. The differentiation kinetics was altered when the differentiation was conducted in 3D bioreactor systems. The hepatic commitment was now found to be increased in protocol one compared to protocol two.

The second approach was conducted in cooperation with Cellartis based on a protocol for hepatic differentiation of hESC in conventional 2D culture.

The results showed no improvement of differentiation in case of the inoculation of DE committed cells. The differentiation over a 30 day period resulted in an immature phenotype, while in a 46 day bioreactor experiment cells were found expressing adult liver markers.

In conclusion the results of this study suggest that the 3D bioreactor technology could be useful for the hepatic differentiation of hESC. In addition, the study provides evidence for a possible up-scaling by the use of larger bioreactor models, the use in pharmaceutical research and clinical applications. 


\section{Zusammenfassung}

Humane embryonale Stammzellen (hESC) sind pluripotente Zellen, die zur unbegrenzten Teilung und zur Differenzierung in Zellen aller drei Keimblätter in der Lage sind. Mit einem wachsenden Verständnis der an der Zelldifferenzierung beteiligten Mechanismen könnten stammzellbasierte Therapien eine wichtige Rolle in der zukünftigen Behandlung von Erkrankungen spielen. Darüber hinaus könnten aus pluripotenten Stammzellen hergestellte differenzierte Zellen in der pharmazeutischen Forschung für in vitro Tests zum Metabolismus und zur Toxizität von Arzneimitteln genutzt werden. Ziel dieser Arbeit war die Untersuchung der leberspezifischen Differenzierung von hESC in 3D Bioreaktorsystemen. Es wurden dafür zwei verschiedene Ansätze verfolgt.

Der erste Ansatz zielte auf die Minimierung des Einsatzes von Materialien tierischen Ursprungs ab. Insgesamt wurden hierbei zwei Protokolle für die hepatische Differenzierung in 3D Bioreaktorsystemen adaptiert.

In 2D-Kultur war der Grad der hepatischen Differenzierung im zweiten Protokoll dem im ersten Protokoll überlegen. Im 3D-Kultursystem änderte sich das

Differenzierungsmuster. Der Grad der hepatischen Differenzierung im ersten Protokoll stellte sich nun höher als im zweiten Protokoll dar. Der zweite Ansatz wurde in Kooperation mit Cellartis durchgeführt und basiert auf einem Protokoll für die hepatische Differenzierung in 2D Kultur. Die Ergebnisse des zweiten Ansatzes zeigten keine Verbesserung der Differenzierung bei der Inokulation von bereits endodermal differenzierten Zellen. Die Differenzierung über 30 Tage resultierte hier ebenfalls in einem unreifen Phänotyp. Hingegen konnten in einem Experiment mit einer 46-tägigen Differenzierung Zellen identifiziert werden, die adulte Lebermarker exprimierten.

Die Resultate dieser Arbeit zeigen, dass die verwendete Bioreaktortechnologie für die hepatische Differenzierung geeignet sein könnte. Weiterhin stellen sie den möglichen Nutzen des Systems für pharmazeutische Studien, klinische Anwendungen sowie die Möglichkeit eines „Scale-Up“ durch die Verwendung größerer Bioreaktormodelle dar. 


\subsection{List of own Publications}

\subsection{List of own Publications}

Stachelscheid H, Wulf-Goldenberg A, Eckert K, Jensen J, Edsbagge J, Björnquist P, Rivero M, Strehl R, Jozefczuk J, Prigione A, Adjaye J, Urbaniak T, Bussmann P, Zeilinger K, Gerlach JC. "Teratoma formation of human embryonic stem cells in three-dimensional perfusion culture bioreactors." J Tissue Eng Regen Med. 2013; $7(9): 729-741$

Darnell M, Schreiter T, Zeilinger K, Urbaniak T, Söderdahl T, Rossberg I, Dillner B, Berg AL, Gerlach JC, Anderson TB. "Cytochrome P450-dependent metabolism in HepaRG cells cultured in a dynamic three-dimensional bioreactor." Drug Metab Dispos. 2011; 39(7): 1131-1138

Cochrane SW, Zhao Y, Perry SS, Urbaniak T, Sun XH. "Id1 has a physiological role in regulating early B lymphopoiesis." Cell Mol Immunol. 2011; 8(1): 41-49

Gerlach JC, Lübberstedt M, Edsbagge J, Ring A, Hout M, Baun M, Rossberg I, Knöspel F, Peters G, Eckert K, Wulf-Goldenberg A, Björquist P, Stachelscheid H, Urbaniak T, Schatten G, Miki T, Schmelzer E, Zeilinger K. "Interwoven fourcompartment capillary membrane technology for three-dimensional perfusion with decentralized mass exchange to scale up embryonic stem cell culture." Cell Tissue Organs 2010; 192(1): 39-49

Stachelscheid H, Urbaniak T, Ring A, Spengler B, Gerlach JC, Zeilinger K. "Isolation and characterization of adult human liver progenitors from ischemic liver tissue derived from therapeutic hepatectomies." Tissue Eng Part A. 2009; 15(7): 1633-1643

Dong J, Mandenius CF, Lübberstedt M, Urbaniak T, Nüssler AK, Knobeloch D, Gerlach JC, Zeilinger K. "Evaluation and optimization of hepatocyte culture media 
factors by design of experiments (DoE) methodology." Cytotechnology 2008; 57(3): 251-261 


\subsection{List of Poster Presentations}

Urbaniak T, Freyer N, Knöspel F, Zeilinger K. "Sucessful hepatic differentiation of human embryonic stem cells in 3D bioreactor cultures", $48^{\text {th }}$ Annual Meeting of the European Association for the Study of the Liver (EASL), April 24 - 28, 2013, Amsterdam, The Netherlands

Urbaniak T, Jensen J, Knöspel F, Lübberstedt M, Björquist P, Gerlach JC, Zeilinger K. "Hepatic differentiation of human embryonic stem cells in a 3D bioreactor environment.", $27^{\text {th }}$ Annual Meeting of the German Association for the Study of the Liver (GASL), January 28 - 29, 2011, Regensburg, Germany

Urbaniak T, Stachelscheid H, Knöspel F, Gerlach J, Zeilinger K. "Enhanced Proliferation of human adult liver progenitor cells under culture conditions supporting human embryonic stem cell propagation.", $2^{\text {nd }}$ International Congress on Stem Cells and Tissue Formation, July 6-9, 2008, Dresden, Germany

Urbaniak T, Stachelscheid H, Gerlach JC, Zeilinger K. "Proliferation of hepatic progenitors isolated from adult human liver in coculture with mouse embryonic fibroblasts." $2^{\text {nd }}$ Biennial Leopoldina Conference and Final Meeting of the Stem Cell Priority Program 1109 of the German Research Foundation (DFG), September 24 27, 2006, Dresden, Germany

Stachelscheid H, Urbaniak T, Gerlach JC, Zeilinger K. "Characterization of two distinct proliferating liver epithelial cells isolated from liver tissue after ischemic treatment." 3rd International Meeting of the Stem Cell Network North Rhine Westphalia, May 15 - 16, 2006, Münster, Germany 


\section{References}

1. Gertow K, Wolbank S, Rozell B, et al. „Organized Development from Human Embryonic Stem Cells." Stem Cells and Development. 2004; 435: 421-435.

2. Cooke MJ, Stojkovic M, Przyborski SA. „Growth of Teratomas Derived from Human Pluripotent Stem Cells Is Influenced by the Graft Site." Stem Cells and Development. 2006; 259(15): 254-259.

3. Blum B, Benvenisty N. „Clonal Analysis of Human Embryonic Stem Cell Differentiation into Teratomas." Stem Cells. 2007; (25): 1924 -1930.

4. Fazeli AS, Nasrabadi D, Pouya A, et al. „Proteome analysis of post-transplantation recovery mechanisms of an EAE model of multiple sclerosis treated with embryonic stem cell-derived neural precursors." Journal of Proteomics. 2013, (94), 437-450

5. Ishii T, Yasuchika K, Machimoto T, et al. „Transplantation of Embryonic Stem CellDerived Endodermal Cells into mice with induced liver damage." Stem Cells. 2007; 12: 3252-3260.

6. Shin S, Sun Y, Liu Y, et al. „Whole Genome Analysis of Human Neural Stem Cells Derived from Embryonic Stem Cells and Stem and Progenitor Cells Isolated from Fetal Tissue." Stem Cells. 2007, 25(5): 1298-1306.

7. Skardelly M, Gaber K, Burdack S, et al. „Long-Term Benefit of Human Fetal Neuronal Progenitor Cell Transplantation in a Clinically Adapted Model after Traumatic Brain Injury. " Journal of Neurotrauma. 2011; 414(March): 401-414.

8. Doi D, Morize A, Kikuchi T, et al. „Prolonged Maturation Culture Favors a Reduction in the Tumorigenicity and the Dopaminergic Function of Human ESCDerived Neural Cells in a Primate Model of Parkinson 's Disease." Stem Cells. 2012; v30(5): 935-945.

9. Amariglio N, Hirshberg A, Scheithauer BW, Cohen Y, Loewenthal R, Trakhtenbrot L. „Donor-Derived Brain Tumor Following Neural Stem Cell Transplantation in an Ataxia Telangiectasia Patient." PLoS Medicine. 2009; 6(2): 221-231.

10. Kahan B, Magliocca J, Merriam F, et al. „Elimination of tumorigenic stem cells from differentiated progeny and selection of definitive endoderm reveals a Pdx1 + foregut endoderm stem cell lineage." Stem Cell Research. 2011; 6(2): 143-157.

11. Lebkowski J. „GRNOPC1: the world's first embryonic stem cell-derived therapy.“ Research \& Development. 2011; 6: 11-13.

12. Blenkinsop TA, Corneo B, Temple S, Stern JH. „Ophthalmologic stem cell transplantation therapies." Regen Med. 2012; 7: 32-39.

13. Sauer IM, Zeilinger K, Pless G, et al. „Extracorporeal liver support based on primary human liver cells and albumin dialysis - treatment of a patient with primary graft non-function. “ Journal of Hepatology. 2003; 39: 649-653.

14. Braude P, Bolton V, Moore S. „Human gene expression first occurs between the four and eight cell stages of preimplantation development." Nature. 1988; 332(6163): 459-461.

15. Herrero J, Ph D, Meseguer M. „Selection of high potential embryos using time- 
lapse imaging : the era of morphokinetics." Fertility and Sterility. 2013; 99(4): 10301034.

16. Xu C, Inokuma MS, Denham J, et al. „Feeder-free growth of undifferentiated human embryonic stem cells." Nature biotechnology. 2001; 19(10): 971-974.

17. Correia AS, Anisimov S V, Li J-Y, Brundin P. „Growth factors and feeder cells promote differentiation of human embryonic stem cells into dopaminergic neurons: a novel role for fibroblast growth factor-20." Frontiers in neuroscience. 2008; 2(1): 2634.

18. Xu C, Police S, Hassanipour M, et al. „Efficient generation and cryopreservation of cardiomyocytes derived from human embryonic stem cells." Regen Med. 2011; 6(1): 53-66.

19. Toh WS, Lee EH, Cao T. „Potential of human embryonic stem cells in cartilage tissue engineering and regenerative medicine." Stem cell reviews. 2011; 7(3): 544559.

20. Bose B. „Human Embryonic stem cell differentiation into insulin secreting beta cells for diabetes." Cell Biology International. 2012; 36(11): 1013-1020.

21. D'Amour K a, Agulnick AD, Eliazer S, Kelly OG, Kroon E, Baetge EE. „Efficient differentiation of human embryonic stem cells to definitive endoderm." Nature biotechnology. 2005; 23(12): 1534-1541.

22. Hay DC, Zhao D, Ross A, Mandalam R, Lebkowski J, Cui W. „Direct differentiation of human embryonic stem cells to hepatocyte-like cells exhibiting functional activities." Cloning and stem cells. 2007; 9(1): 51-62.

23. Thomson JA, Itskovitz-Eldor J, Shapiro SS, Waknitz MA, Swiergiel JJ, Marshall VS, Jones JM. „Embryonic Stem Cell Lines Derived from Human Blastocysts.“ Science. 1998; 282(5391): 1145-1147.

24. Richards M, Fong C, Chan W, Wong P, Bongso A. „Human feeders support prolonged undifferentiated growth of human inner cell masses and embryonic stem cells." Nat. Biotechnol. 2002; 20(09): 933-936.

25. Mallon BS, Park K, Chen KG, Hamilton RS, Ronald DG. „Toward xeno-free culture of human embryonic stem cells." Int. J. Biochem. Cell Biol. 2006; 38(7): 10631075.

26. Meng G, Liu S, Rancourt DE. „Synergistic Effect of Medium, Matrix, and Exogenous Factors on the Adhesion and Growth of human pluripotent Stem Cells under Defined, Xeno-Free Conditions." Stem Cells Dev. 2012; 21(11): 2036-2048.

27. Rodaway A, Patient R, Centre TR, Hunt N. „Mesendoderm: An Ancient Germ Layer ?" Cell. 2001; 105: 169-172.

28. Sui L, Bouwens LUC, Mfopou JK. „Signaling pathways during maintenance and definitive endoderm differentiation of embryonic stem cells." The international journal of developmental biology. 2013; 12(02): 1-12.

29. Chamuleau RAFM, Deurholt T, Hoekstra R. „Which Are the Right Cells to be Used in a Bioartificial Liver ?" Metabolic Brain Disease. 2005; 20(4): 327-335.

30. Herzer K, Paul A, Gerken G. „Lebertransplantation - wo stehen wir heute?“ Dtsch Med Wochenschr. 2013; 138(28/29): 1471-1477. 
31. Finkenstedt A, Nachbaur K, Zoller H, Joannidis M, Pratschke J. „Acute on chronic liver failure : Excellent outcome after liver transplantation but high mortality on the wait list" Liver transplantation. 2013; 19(8): 879-886.

32. Duncan AW, Soto-Gutierrez A. „Liver repopulation and regeneration : new approaches to old questions." Current Opinions. 2013; 18(2): 197-202.

33. Tranah TH, Vijay GKM, Ryan JM, Shawcross DL. „Systemic inflammation and ammonia in hepatic encephalopathy." Metabolic Brain Disease. 2013; 28(1): 1-5.

34. Yang L, Inokuchi S, Roh YS, et al. „Transforming Growth Factor-beta Signaling in Hepatocytes Promotes Hpatic Fibrosis and Carcinogenesis in Mice With HepatocyteSpecific Deletion of TAK1." Gastroenterology. 2013; 144(5): 1042-1054.

35. Sauer I, Kardassis D, Zeillinger K, Pascher A, Gruenwald A, Pless G. „Clinical extracorporeal hybrid liver support - phase I study with primary porcine liver cells." Xenotransplantation. 2003; 10: 460-469.

36. Irgang M, Sauer IM, Karlas A, et al. „Porcine endogenous retroviruses : no infection in patients treated with a bioreactor based on porcine liver cells." Journal of clinical virology. 2003; 28: 141-154.

37. Phua J, Hoe K. „Liver support devices.“ Current Opinion in Critical care. 2008; 14: 208-215.

38. Adham M. „Extracorporeal Liver Support : Waiting for the Deciding Vote.“ $\underline{A S A I D}$ Journal. 2003; 49(6): 621-632.

39. Brophy CM, Nyberg SL. „Extracorporeal treatment of acute liver failure.“ Hepatology Research. 2008; 38: 34-40.

40. Ghosh Z, Huang M, Hu S, Wilson KD, Dey D, Wu JC. „Dissecting the Oncogenic Potential of Human Embryonic and INduces Pluripotent Stem Cell Derivates." Cancer Res. 2012; 71(14): 5030-5039.

41. Webster R, Edgington A, Phipps J, Walker D. „Pharmacokinetics and clearance processes of UK-279, 276 ( rNIF ) in rat and dog : Comparison with human data." Xenobiotica. 2006; 36(April): 341-349.

42. Mogi M, Toda A, Iwasaki K, Kusumoto S, Takehara H. „Simultaneous pharmacokinetics assessment of caffeine, warfarin, omeprazole, metoprolol, and midazolam intravenously or orally administered to Microminipigs." The Journal of Toxicological Sciences. 2012; 37(6): 1157-1164.

43. Corchero J, Granvil CP, Akiyama TE, et al. „The CYP2D6 Humanized Mouse: Effect of the Human CYP2D6 Transgene and HNF4alpha on the Disposition of Debrisoquine in the Mouse." Molecular Pharmacology. 2001; 60(6): 1260-1267.

44. Lübberstedt M, Müller-vieira U, Biemel KM, et al. „Serum-free culture of primary human hepatocytes in a miniaturized hollow-fibre membrane bioreactor for pharmacological in vitro studies." Journal of Tissue Engineering and Regenerative Medizine. 2012 Nov 20.

45. Gerlach JC, Mutig K, Sauer I, et al. „Use of primary human liver cells originating from discarded grafts in a bioreactor for liver support therapy and the prospects of culturing adult liver stem cells in bioreactors: a morphologic study." Transplantation. 2003; 76(5): 781-786. 
46. Gerlach JC, Zeilinger K, Patzer JF. „Bioartificial liver systems: why, what, whither?" Regen Med. 2008; 3(4): 575-595.

47. Leite B, Zaldivar JM, Airola E, Reis-fernandes MA, Mennecozzi M, Alves PM. „Three-Dimensional HepaRG Model As An Attractive Tool for Toxicity Testing." Toxicological Sciences. 2012; 130(1): 106-116.

48. Lübberstedt M, Müller-vieira U, Mayer M, et al. „HepaRG human hepatic cell line utility as a surrogate for primary human hepatocytes in drug metabolism assessment in vitro." Journal of Pharmacological and Toxicological Methods. 2011; 63(1): 59-68.

49. Darnell M, Ulvestad M, Ellis E, Weidolf L, Andersson TB. „In Vitro Evaluation of Major In Vivo Drug Metabolic Pathways Using Primary Human Hepatocytes and HepaRG Cells in Suspension and a Dynamic Three-Dimensional Bioreactor." The Journal of Pharmacology and Experimental Therapeutics. 2012; 450: 134-144.

50. Zeilinger K, Schreiter T, Darnell M, et al. „Scaling Down of a Clinical ThreeDimensional Perfusion Multicompartment Hollow Fiber Liver Bioreactor Developed for Extracorporeal Liver Support to an Analytical Scale Device Useful for Hepatic Pharmalogical In Vitro Studies." Tissue Engineering: Part C. 2011; 17(5): 549-556.

51. Ohtsuki S, Schaefer O, Kawakami H, et al. „Simultaneous Absolute Protein Quantification of Transporters, Cytochromes P450, and UDP-

Glucuronosyltransferases as a Novel Approach for the Characterization of Individual Human Liver: Comparison with mRNA Levels and Activities." Drug metabolism and Disposition. 2012; 40(1): 83-92.

52. Ulvestad M, Darnell M, Molden E, Ellis E, Åsberg A, Andersson TB. „Evaluation of Organic Anion-Transporting Polypeptide 1B1 and CYP3A4 Activities in Primary Human Hepatocytes and HepaRG Cells Cultured in a Dynamic Three-Dimensional Bioreactor System." The Journal of Pharmacology and Experimental Therapeutics. 2012; 343(1): 145-156.

53. Nibourg G, Hoekstra R, Hoeven T Van Der, et al. „Increased hepatic functionality of the human hepatoma cell line HepaRG cultured in the AMC bioreactor." International Journal of Biochemistry and Cell Biology. 2013, 45(8): 1860-1868.

54. Hoffmann SA, Müller-Vieira U, Biemel K, et al. „Analysis of Drug Metabolism Activities in a Miniaturized Liver Cell Bioreactor for Use in Pharmacological Studies." Biotechnology and bioengineering. 2012; 109(12): 3172-3181.

55. Kowalski MP, Yoder A, Liu L, Pajak L. „Controlling Embryonic Stem Cell Growth and Differentiation by Automation: Enhanced and More Reliable Differentiation for Drug Discovery.“ Journal of Biomolecular Screening. 2012; 17(9): 1171-1179.

56. Serra M, Brito C, Sousa MFQ, et al. „Improving expansion of pluripotent human embryonic stem cells in perfused bioreactors through oxygen control." Journal of Biotechnology. 2010; 148(4): 208-215.

57. Gerecht-Nir S, Cohen S, Ziskind A, Itskovitz-eldor J. „Three-Dimensional Porous Alginate Scaffolds Provide a Conducive Environment for Generation of WellVascularized Embryoid Bodies From Human Embryonic Stem Cells." Biotechnology and Bioengineering. 2004; 88(5): 313-320.

58. Stachelscheid H, Eckert K, Jensen J, Edsbagge J, Björquist P, Rivero M. „Teratoma formation of human embryonic stem cells in three-dimensional perfusion 
culture bioreactors." Journal of Tissue Engineering and Regenerative Medicine. 2013; 7(9): 729-741.

59. Miki T, Ph D, Ring A. „Hepatic Differentiation of Human Embryonic Stem Cells Is Promoted by Three-Dimensional Dynamic Perfusion Culture Conditions." Gene Expression. 2011; 17(5): 557-568.

60. Ulvestad M, Nordell P, Asplund A, et al. „Drug metabolizing enzyme and transporter protein profiles of hepatocytes derived from human embryonic and induced pluripotent stem cells." Biochemical Pharmacology. 2013; 86(5): 691-702.

61. Cai J, Zhao Y, Liu Y, et al. „Directed Differentiation of Human Embryonic Stem Cells into Functional Hepatic Cells." Hepatology. 2007; 45(5): 1229-1239.

62. Kim S, An SY, Woo D, et al. „Engraftment Potential of Spheroid-Forming Hepatic Endoderm Derived from Human Embryonic Stem Cells." Stem Cells and Development. 2013; 22(12): 1818-1829.

63. Lacaille F. „Liver transplantation and liver cell transplantation.“ Clinics and Research in Hepatology and Gastroenterology. 2012; 36(3): 304-307.

64. Lanzoni G, Oikawa T, Wang Y, et al. „Clinical Programs of Stem Cell Therapies for Liver and Pancreas." Stem Cells. 2013; 31(10). 2047-2060.

65. Khan AA, Parveen N, Mahaboob VS, et al. „Treatment of Crigler-Najjar Syndrome Type 1 by Hepatic Progenitor Cell Transplantation : A Simple Procedure for Management of Hyperbilirubinemia." Transplant. Proc. 2008; 40(4): 1148-1150.

66. Haridass D, Narain N, Ott M. „Hepatocyte transplantation: waiting for stem cells.“ Current Opinion in Organ Transplantation. 2008; 13(6): 627-632.

67. Brolén G, Sivertsson L, Björquist $P$, et al. „Hepatocyte-like cells derived from human embryonic stem cells specifically via definitive endoderm and a progenitor stage." Journal of biotechnology. 2010; 145(3): 284-294.

68. Hay DC, Fletcher J, Payne C, et al. „Highly efficient differentiation of hESCs to functional hepatic endoderm requires Activin A and Wnt3a signaling." Proceedings of the National Academy of Sciences of the United States of America. 2008; 105(34) : 12301-12306.

69. Agarwal S, Holton KL, Lanza R. „Efficient differentiation of functional hepatocytes from human embryonic stem cells." Stem cells. 2008; 26(5): 1117-1127.

70. Si-tayeb K, Noto FK, Nagaoka M, et al. „High Efficient Generation of Human Hepatocyte-Like Cells from Induced Pluripotent Stem Cells." Hepatology. 2011; 51(1): 297-305.

71. Touboul T, Hannan NRF, Corbineau S, et al. „Generation of functional hepatocytes from human embryonic stem cells under chemically defined conditions that recapitulate liver development." Hepatology. 2010; 51(5): 1754-1765.

72. Gerlach JC, Lübberstedt M, Edsbagge J, et al. „Interwoven four-compartment capillary membrane technology for three-dimensional perfusion with decentralized mass exchange to scale up embryonic stem cell culture." Cells, tissues, organs. 2010; 192(1): 39-49.

73. Zeilinger K, Schreiter T, Darnell M, et al. „Scaling Down of a Clinical ThreeDimensional Perfusion Multicompartment Hollow Fiber Liver Bioreactor Developed 
for Extracorporeal Liver Support to an Analytical Scale Device Useful for Hepatic Pharmacological in vitro studies." Tissue Engineering: Part C. 2011; 17(5): 549-556.

74. Meng GL, Nieden NIZUR, Liu SY, Cormier JT, Kallos MS, Rancourt DE. „Properties of Murine Embryonic Stem Cells Maintained on Human Foreskin Fibroblasts Without LIF.“ Mol. Reprod. Dev. 2008; 75(4): 614-622.

75. Mitalipova M. „Preserving the genetic integrity of human embryonic stem cells.“ Nat. Biotechnol. 2005; 23(1): 19-20.

76. Eiselleova L, Peterkova I, Neradil J, Slaninova IVA, Hampl A, Dvorak P. „Comparative study of mouse and human feeder cells for human embryonic stem cells.“ Int. J. Dev. Biol. 2008; 363(January): 353-363.

77. Li SS, Liu Y, Tseng C, Chung T, Lee T, Singh S. „Charakterization and Gene Expression Profiling of Five New Human Embryonic Stem Cell Lines Derived in Taiwan." Stem cells and development. 2006; 15(4): 532-555.

78. Xiao L, Xuan Y, Sharkies SJ. „Activin A Maintains Self-Renewal and Regulates Fibroblast Growth Factor, Wnt, and Bone Morphogenic Protein Pathways in Human Embryonic Stem Cells." Stem cells. 2006; 24(6): 1476-1486.

79. Vallier L, Touboul T, Brown S, et al. „Signaling pathways controlling pluripotency and early cell fate decisions of human induced pluripotent stem cells." Stem cells. 2009; 27(11): 2655-2666.

80. Schnerch A, Cerdan C, Bhatia M. „Distinguishing Between Mouse and Human Pluripotent Stem Cell Regulation: The Best Laid Plans of Mice and Men." Stem Cells. 2010; 28(3): 419-430.

81. Niakan KK, Eggan K. „Analysis of human embryos from zygote to blastocyst reveals distinct gene expression patterns relative to the mouse." Developmental Biology. 2013; 375(1): 54-64.

82. Nichols J, Zevnik B, Anastassiadis K, et al. „Formation of Pluripotent Stem Cells in the Mammalian Embryo Depends on the POU Transcription Factor Oct4. " $\underline{\text { Cell. }}$ 1998; 95: 379-391.

83. Rodriguez RT, Velkey JM, Lutzko C, et al. „Manipulation of Oct4 Levels in Human Embryonic Stem Cells Results in Induction of Differential Cell Types." Experimental Biology and Medicine. 2007; 232(10): 1368-1380.

84. Cimadamore F, Fishwick K, Giusto E, et al. „Human ESC-Derived Neural Crest Model Reveals a Key Role for SOX2 in Sensory Neurogenesis." Stem Cell. 2011; 8(5): 538-551.

85. Adachi K, Suemori H, Yasuda S, Nakatsuji N. „Role of SOX2 in maintaining pluripotency of human embryonic stem cells.“ Genes to Cell. 2010; 15(5): 455-470.

86. Bhattacharya B, Miura T, Brandenberger R, et al. „Gene expression in human embryonic stem cell lines: unique molecular signature." Blood. 2004; 103(8): 29562964.

87. Chambers I, Colby D, Robertson M, et al. „Functional Expression Cloning of Nanog , a Pluripotency Sustaining Factor in Embryonic Stem Cells." Cell. 2003; 113: 643-655.

88. Hyslop L, Stojkovic M, Armstrong L, et al. „Downregulation of NANOG Induces 
Differentiation of Human Embryonic Stem Cells to Extraembryonic Lineages." Stem Cells. 2005; 23(8): 1035-1043.

89. Darr H, Mayshar Y, Benvenisty N. „Overexpression of NANOG in human ES cells enables feeder-free growth while inducing primitive ectoderm features."

Development and Disease. 2006; 133(6): 1193-1201.

90. Zhou X, Zhou Y-P, Huang G-R, et al. „Expression of the stem cell marker Nanog in human endometrial adenocarcinoma." Int J Gynecol Path. 2012; 30(3): 262-270.

91. Zhang J, Espinoza LA, Kinders RJ, et al. „NANOG modulates stemness in human colorectal cancer." Oncogene. 2013; 32(37): 4397-4405.

92. Liu TM, Wu YN, Guo XM, Hui JHP, Lee EH, Lim B. „Effects of Ectopic Nanog and Oct4 Overexpression on Mesenchymal Stem Cells." Stem Cells and Development. 2009; 18(7): 1013-1022.

93. Boyer LA, Lee TI, Cole MF, et al. „Core Transcriptional Regulatory Circuitry in Human Embryonic Stem Cells." Cell. 2005; 122(6): 947-956.

94. Chew J, Loh Y, Zhang W, et al. „Reciprocal Transcriptional Regulation of Pou5f1 and Sox2 via the Oct4 / Sox2 Complex in Embryonic Stem Cells." Molecular and cellular biology. 2005; 25(14): 6031-6046.

95. Itskovitz-Eldor J, Schuldiner M, Karsenti D, et al. „Differentiation of Human Embryonic Stem Cells into Embryoid Bodies Comprising the Three Embryonic Germ Layers." Mol. Med. 2000; 6(2): 88-95.

96. Gallego MJ, Porayette P, Kaltcheva MM, Bowen RL, Meethal SV, Atwood CS. "The pregnancy hormones human chorionic gonadotropin and progesterone induce human embryonic stem cell proliferation and differentiation into neuroectodermal rosettes." Stem Cell Res. Ther. 2010; 1(4).

97. Pekkanen-Mattila M, Pelto-Huikko M, Ville K, et al. „Spatial and temporal expression pattern of germ layer markers during human embryonic stem cell differentiation in embryoid bodies." Histochem. Cell Biol. 2010; 133(5): 595-606.

98. Sui L, Mfopou JK, Geens M, Sermon K, Bouwens L. „FGF signaling via MAPK is required early and improves Activin A-induced definitive endoderm formation from human embryonic stem cells." Biochemical and Biophysical Research

Communications. 2012; 426(3): 380-385.

99. Smith JR, Vallier L, Lupo G, Alexander M, Harris WA, Pedersen RA. „Inhibition of Activin / Nodal signaling promotes specification of human embryonic stem cells into neuroectoderm." Developmental Biology. 2008; 313: 107-117.

100. Saadi I, Das $P$, Zhao M, et al. „Msx1 and Tbx2 antagonistically regulate Bmp4 expression during the bud-to-cap stage transition in tooth development."

Development. 2013; 140(13): 2697-2702.

101. Rankin SA, Gallas AL, Neto A, Gómez-skarmeta JL, Zorn AM. „Suppression of Bmp4 signaling by the zinc-finger repressors Osr1 and Osr2 is required for Wnt / $\beta$ -catenin-mediated lung specification in Xenopus." Development. 2012; 139(16): 3010-3020.

102. Gozo MC, Aspuria P, Cheon D, et al. „Foxc2 induces Wnt4 and Bmp4 expression during muscle regeneration and osteogenesis." Cell Death and 
Differentiation. 2013, 20(8): 1031-1042.

103. Xu X, Browning V, Odorico J. „Activin, BMP and FGF pathways cooperate to promote endoderm and pancreatic lineage cell differentiation from human embryonic stem cells." Mech Dev. 2011; 128(7-10): 412-427.

104. Teo A, Ali Y, Wong KY, et al. „Activin and BMP4 Synergistically Promote Formation of Definitive Endoderm in Human Embryonic Stem Cells." Stem Cells. 2012; 30(4): 631-642.

105. Evseenko D, Zhu Y, Schenke-layland K, et al. „Mapping the first stages of mesoderm commitment during differentiation of human embryonic stem cells." PNAS. 2010; 107(31): 13742-13747.

106. Sumi T, Tsuneyoshi N, Nakatsuji N, Suemori H. „Defining early lineage specification of human embryonic stem cells by the orchestrated balance of canonical Wnt / $\beta$ - catenin , Activin / Nodal and BMP signaling." Development and Disease. 2008; 135(17): 2969-2979.

107. Lanner F, Rossant J. „The role of FGF / Erk signaling in pluripotent cells.“ Development. 2010; 137(20): 3351-3360.

108. Li J, Wang G, Wang C, Hong Z, Zhijia Z, Zhihua T. „MEK / ERK signaling contributes to the maintenance of human embryonic stem cell self-renewal.“ Differentiation. 2007; 75(4): 299-307.

109. Ren M, Yan L, Shang C-Z, et al. „Effects of Sodium Butyrate on the Differentiation of Pancreatic and Hepatic Progenitor Cells from Mouse Embryonic Stem Cells." Journal of Cellular Biochemistry. 2010; 244(June 2009): 236-244.

110. Davie JR. „Inhibition of Histone Deacetylase Activity by Butyrate.“ The Journal of Nutrition. 2003, 133(7 Suppl):2485S-2493S.

111. Norrman K, Strömbeck A, Semb H, Ståhlberg A. „Distinct gene expression signatures in human embryonic stem cells differentiated towards definitive endoderm at single-cell level.“ Methods. 2013; 59(1): 59-70.

112. Zhou M, Li P, Tan L, Qu S, Ying Q-L, Song H. „Differentiation of mouse embryonic stem cells into hepatocytes induced by a combination of cytokines and sodium butyrate." Journal of cellular biochemistry. 2010; 109(3): 606-614.

113. Pal R, Krishna M. „Diverse effects of dimethyl sulfoxide ( DMSO ) on the differentiation potential of human embryonic stem cells." Archives of toxicology. 2012; 86(4): 651-661.

114. Katkov II, Kim MS, Bajpai R, et al. „Cryopreservation by slow cooling with DMSO diminished production of Oct-4 pluripotency marker in human embryonic stem cells." Cryobiology. 2006; 53: 194-205.

115. Hay DC, Zhao D, Fletcher J, et al. „Efficient Differentiation of Hepatocytes from Human Embryonic Stem Cells Exhibiting Markers Recapitulating Liver." Stem Cells. 2008; 26(4): 894-902.

116. Maira S-M, Stauffer F, Schnell C, Garcia-Echeverria C. „PI3K inhibitors for cancer treatment : where do we stand ?" Biochemical Society Transactions. 2009; 37(Pt 1): 265-272.

117. Sekine K, Takebe T, Suzuki Y, Kamiya A, Nakauchi H, Taniguchi H. „Highly 
Efficient Generation of Definitive Endoderm Lineage from Human Induced Pluripotent Stem Cells." Transplantation Proceedings. 2012; 44(4): 1127-1129.

118. Tahamtani Y, Azarnia M, Farrokhi A, Sharifi-zarchi A. „Treatment of Human Embryonic Stem Cells with Different Combinations of Priming and Inducing Factors Toward Definitive Endoderm." Stem Cells and Development. 2013; 22(9): 14191432.

119. Wang P, Rodriguez RT, Wang J, Ghodasara A, Kim SK. „Targeting SOX17 in human embryonic stem cells creates unique strategies for isolating and analyzing developing endoderm." Cell Stem Cell. 2011; 8(3): 335-346.

120. Freeman AE, Engvallt EVA, Hira K, et al. „Differentiation of fetal liver cells in vitro." Cell Biology. 1981; 78(6): 3659-3663.

121. Chou JY. „Temperature-Sensitive Adult Liver Cell Line Dependent on Glucocorticoid for Differentiation." Molecular and cellular biology. 1983; 3(6): 10131020 .

122. Michalopoulos GK, Bowen WC, Karen M, Luo J. „HGF, EGF and Dexamethasone induced gene expression patterns during formation of tissue in hepatic organoid cultures." Gene Expression. 2003; 11(2): 55-75.

123. Ishii T, Fukumitsu K, Yasuchika K, et al. „Effects of extracellular matrixes and growth factors on the hepatic differentiation of human embryonic stem cells." $\underline{A m ~ J}$ Physiol Gastrointest Liver Physiol. 2008, 295(2): 313-321.

124. Michalopoulos GK, Bowen WC. „Histological Organization in Hepatocyte Organoid Cultures." American Journal of Pathology. 2001; 159(5): 1877-1887.

125. Kinoshita T, Miyajima A. „Cytokine regulation of liver development.“ Biochimica et Biophysica acta. 2002; 1592(3): 303-312.

126. Ameri J, Stahlberg A, Pedersen J, et al. „FGF2 Specifies hESC-Derived Definitive Endoderm into Foregut / Midgut Cell Lineages in a ConcentrationDependent Manner." Stem Cells. 2010; 28(1): 45-56.

127. Kojima N, Kinoshita T, Kamiya A, Nakamura K. „Cell Density-Dependent Regulation of Hepatic Development by a gp130-Independent Pathway." Biochemical and Biophysical Research Communications. 2000; 277(1): 152-158.

128. Matsui T, Kinoshita T, Morikawa Y, et al. „K-Ras mediates cytokine-induced formation of E-cadherin-based adherens junctions during liver development." The EMBO Journal. 2002; 21(5): 1021-1030.

129. Kamiya A, Kojima N, Kinoshita T, Sakai Y, Miyaijma A. „Maturation of Fetal Hepatocytes In Vitro by Extracellular Matrices and Oncostatin M: Induction of Tryptophan Oxygenase." Hepatology. 2002; 35(6): 1351-1359.

130. Tomasi TB. „Structure an Function of Alpha-Fetoprotein“ Ann. Rev. Med. 1977; 28: 453-465.

131. Rao M-S, Khan AA, Parveen N, Habeeb A, Habibullah CM, Pande G. "Characterization of hepatic progenitors from human fetal liver during second trimester." World Journal of Gastroenterology. 2008; 14(37): 5730-5737.

132. Stachelscheid H, Urbaniak T, Ring A, Spengler B, Gerlach JC, Zeilinger K. "Isolation and characterization of adult human liver progenitors from ischemic liver 
tissue derived from therapeutic hepatectomies." Tissue engineering. Part A. 2009; 15(7): 1633-1643.

133. Watanabe K, Ueno M, Kamiya D, et al. „A ROCK inhibitor permits survival of dissociated human embryonic stem cells." Nature biotechnology. 2007; 25(6): 681686.

134. Giakoumopoulos M, Golos TG. „Embryonic stem cell-derived trophoblast differentiation: a comparative review of the biology, function, and signaling mechanisms." Journal of Endocrinology. 2013; 216(3): R33-R45.

135. Shirai T, Miyagi S, Okuda-katayanagi T, et al. „Identification of an Enhancer That Controls Up-regulation of Fibronectin during Differentiation of Embryonic Stem Cells into Extraembryonic Endoderm., The Journal of Biological Chemistry. 2005; 8: 7244-7252.

136. Zhou J, Su P, Li D, Tsang S, Duan E, Wang F. „High-Efficiency Induction of Neural Conversion in hESCs and hiPSCs with a Single Chemical Inhibitor of TGFbeta Superfamily Receptors." Stem Cells. 2012; 28(10): 1741-1750.

137. Rodda DJ, Chew J-L, Lim L-H, et al. „Transcriptional regulation of Nanog by OCT4 and SOX2. The Journal of biological chemistry. 2005; 280(26): 24731-24737.

138. Amiyama YK, Atsubara TM, Oshinari KY, Agata KN, Amimura HK, Amazoe YY. „Role of Human Hepatocyte Nuclear Factor 4alpha in the Expression of DrugMetabolizing Enzymes and Transporters in Human Hepatocytes Assessed by Use of Small Interfering RNA.“ Drug Metab. Pharmacokinet. 2007; 22(4): 287-298.

139. Xu Y, Zhu X, Sik H, et al. „Revealing a core signaling regulatory mechanism for

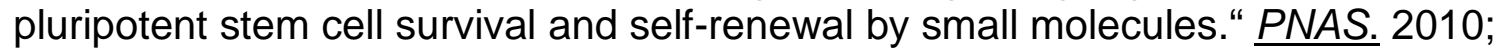
107(18): 8129-8134.

140. Gauthaman K, Fong C, Bongso A. „Effect of ROCK Inhibitor Y-27632 on Normal and Variant Human Embryonic Stem Cells ( hESCs ) In Vitro: Its Benefits in hESC Expansion." Stem Cell Rev and Rep. 2010; 6(1): 86-95.

141. Heng BC, Li J, Chen AK, et al. „Translating Human Embryonic Stem Cells from 2-Dimensional to 3-Dimensional Cultures in a Defined Medium on Laminin- and Vitronectin-Coated Surfaces." Stem Cells and Development. 2012; 21(10): 17011715.

142. Oda H, Yoshida Y, Kawamura A, Kakinuma A. „Cell shape, cell - cell contact, cell - extracellular matrix contact and cell polarity are all required for the maximum induction of CYP2B1 and CYP2B2 gene expression by phenobarbital in adult rat cultured hepatocytes." Biochemical Pharmacology. 2008; 75(5): 1209-1217. 


\section{Danksagung}

An dieser Stelle möchte ich all jenen danken ohne die die Anfertigung dieser Arbeit in dieser Form nicht möglich gewesen wäre.

Ein großes Danke an Frau Dr. Katrin Zeilinger und Herrn Prof. Dr. Jörg Gerlach für die Möglichkeit der Anfertigung dieser Arbeit, für die konstruktive Kritik, die vielfältige Unterstützung und die Freiheit eigene Ideen umzusetzen. Des weiteren möchte ich mich bei allen aktuellen und ehemaligen Mitgliedern der Bioreactor Group (BCRT, Charite) bedanken, ein ganz besonderes Danke an Frau Dr. Ing. Fanny Knöspel, Herrn Marc Lübberstedt und Frau Nora Freyer für die exzellente Zusammenarbeit. Für die Durchführung der Tierexperimente möchte ich ganz besonders Frau Maria Stecklum und Herrn Dr. Klaus Eckert von der EPO (experimental pharmacology and oncology) Berlin Buch danken.

Einen großen Dank auch an Frau PhD Janne Jensen und Herrn PhD Petter Björquist die eine große Unterstützung bei der Planung der ersten Reaktorenexperimente waren. Einen besonderen Dank auch an Herrn Prof. Dr. Roland Lauster, nicht nur für die exzellente Lehre während des Studiums, sondern vor allem auch für die Zeit danach.

Des weiteren möchte ich allen Mitarbeitern von Stem Cell Systems danken. Ohne deren kontinuierliches Bestreben nach Verbesserung in der Fertigung wäre diese Arbeit nicht möglich gewesen. Am Ende möchte ich im Besonderen meiner Familie Danken, für deren Liebe, Geduld und Vertrauen. Für all die, die vor mir waren, die mit mir sind, und die nach mir kommen.

Die Arbeiten zu der Dissertation wurden im Rahmen des von der Investitionsbank Berlin (IBB) aus Mitteln des Europäischen Fonds für regionale Entwicklung (EFRE) geförderten Vorhabens „Glykanbasierte Biomarker für die Qualitätssicherung in der Stammzelltherapie" (FKZ: 10147245) und des von der Europäischen Kommission geförderten Vorhabens „Vitrocellomics“ (LSHB-CT-2006-018940) durchgeführt.
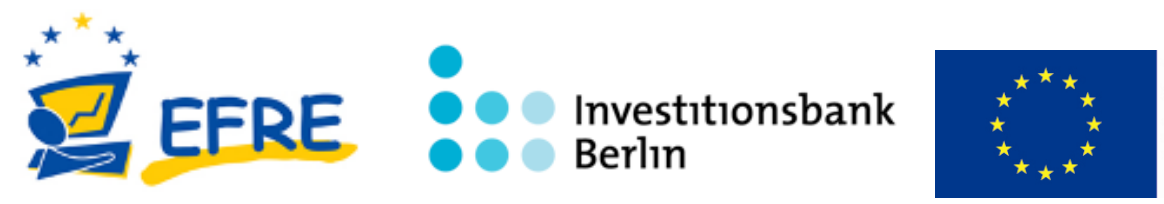


\section{Eigenständigkeitserklärung}

Ich erkläre an Eides Statt, dass ich die vorliegende Dissertation in allen Teilen von mir selbständig angefertigt wurde und die benutzten Hilfsmittel vollständig angegeben worden sind.

Veröffentlichungen von irgendwelchen Teilen der vorliegenden Dissertation sind von mir wie oben angegeben vorgenommen worden.

Weiter erkläre ich, dass ich nicht schon anderweitig einmal die Promotionsabsicht angemeldet oder ein Promotionseröffnungsverfahren beantragt habe.

Weiter erkläre ich, dass mir die geltende Promotionsordnung für die Technische Universität Berlin vom 23. Oktober 2006 bekannt ist. 